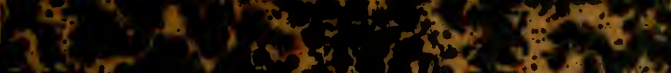

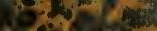

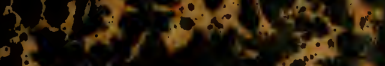

\title{
porst
}

$8+7$ ?

box

$x^{2}+x^{2}$

ar -2

$x^{2}-x^{4}+x^{2}+2$

sy

cose

(2)

30 i)

x brot.

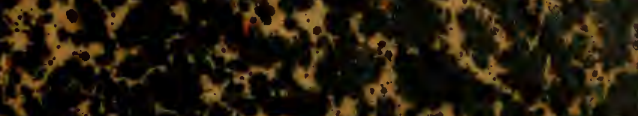

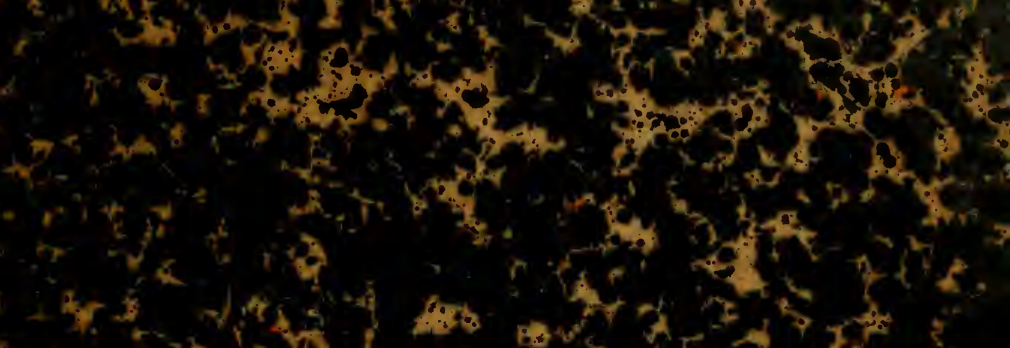

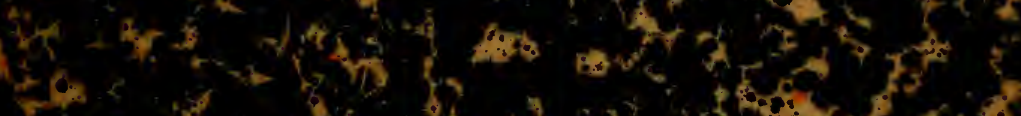

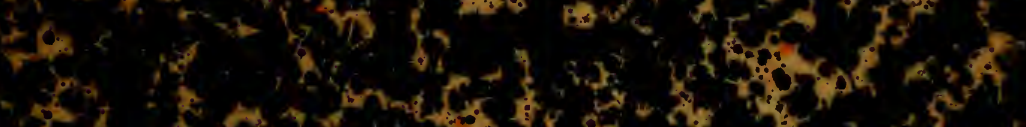

(2)

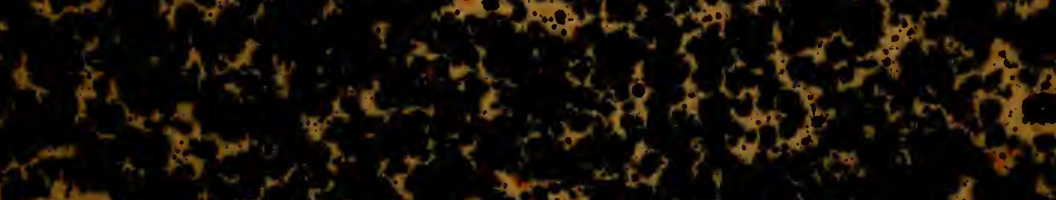

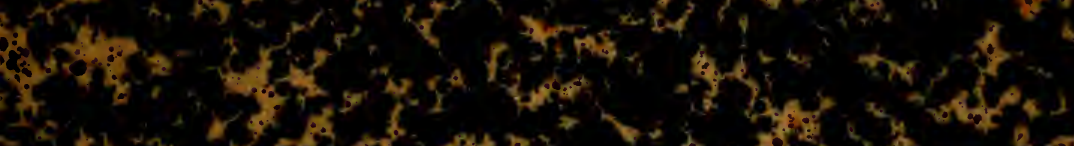

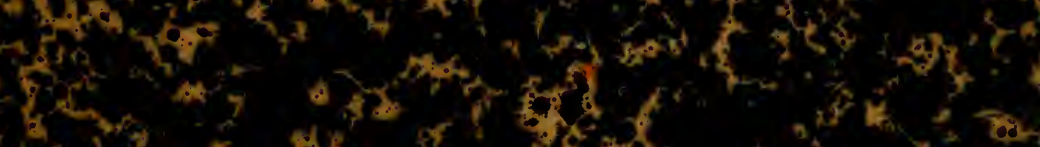
(3)

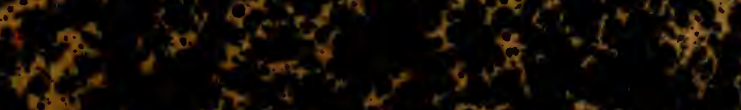

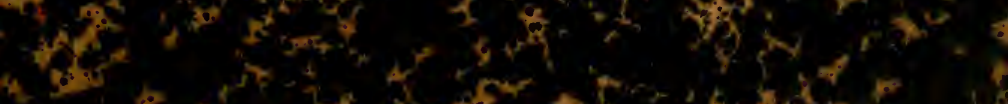

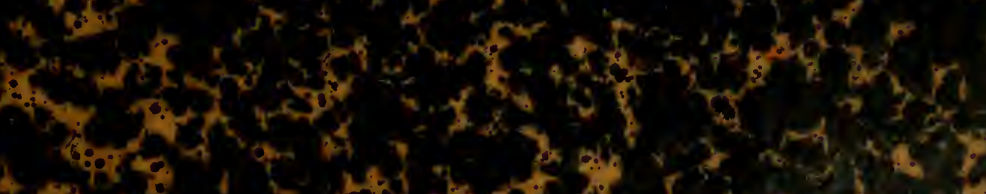

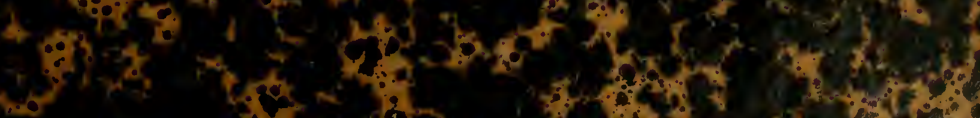

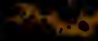
$4.92-13$ 

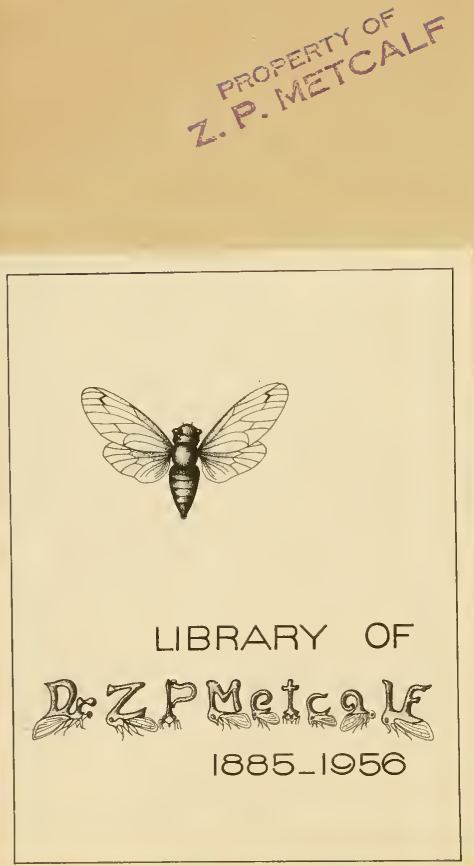
$\geqslant A$ कर 



\title{
NUOVI STUIII
}

\section{SULLA ENTONOLOGIA}

I) E L. L A

\section{CALABRIA ULTERIORE}

MEMORIA

DEL. SOCIO URDINARIO

A G H I L LE C OSTA

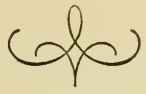

\author{
N A P O L I \\ STAMPERIA DEL FIBRENO \\ Strada Trinità Maggiore $n{ }^{\circ} 26$ \\ 1863
}


Memoria estratta dal $\mathbf{V}^{\prime}$. $I^{\circ}$ degli Atti della $R$. Accademia delle Scienze Fisiche e Matematiche. 


\section{NUOVI STUDII SULLA ENTOHOLOGIA DELLA CALABRIA ULTERIORE}

MEMORIA

DEL socio ordinario A. COSTA

letta nella tornata del di 19 agosto 1862 .

Se volessimo esordir questo lavoro dal discorrere della utilità delle peregrinazioni scientifiche entro la patria, oltre allo spendere inutile il teinpo, potremmo ben meritare la taccia di apportar vasi a Samo e lueciole in Atene. Dappoichè quest'Accademia d'assai buon'ora ha sentita non pure la utilità, ma la necessità di siffatte peregrinazioni tanto, che spedì essa un tempo a proprie spese e per più anni di seguito alcuni dei suoi Socii or in una, or in un' altra delle svariate regioni del regno, col fine di vederle illustrate ne' diversi rami delle naturali produzioni. Di che fan fede non peritura gl'importanti lavori che leggonsi negli Atti Accademici, frutto di quelle ricerche.

Convinti adunque dello interesse che questo Corpo Accademico sa apporre a lavori di simile argomento, veniamo con fiducia ad esporgli il risultamento ottenuto da un viaggio scientifico testè eseguito per le calabre regioni. Le quali se vennero da noi in preferenza scelte a campo di ricerche zoologiche e soprattutto entomologiche, non ostante già innanzi per altri esplorate, lo fu per due ragioni: in prima per la convinzione di essere il suolo calabro troppo esteso e svariato nelle sue condizioni fisico-lopografiche, per potersi dire esplorato abbastanza ; di poi per esser quelle per noi interamente sconosciute. E non potendo tutte 
in una sola stagione percorrerle, ci siam limitati alla estesa eatena delle Sile nella Calabria Citeriore, ed alla estrema parte della Calabria Ulteriore. Però di quello che riguarda la prima di tali contrade ci riserbiamo discorrere altra volta; nel presente lavoro ci limiteremo al risultamento ottenuto dalle ricerche nella Calabria Ulteriore.

Di quanto si appartiene al regno animale sia vivente, sia estinto nulla abbiam trascurato. Alcuni avanzi organici li abbiamo comunicati al nostro genitore, che son ispecialità attende alla illustrazione della Paleontologia patria. Di animali viventi le cose osservate nelle classi superiori e nelle infime sono sì poche, da non meritare che vi ci intrattenessimo. La classe che principalmente fissa l'attenzione del zoologo che percorre l'interno delle Calabrie è quella degl' insetti: e di questa ci siamo particolarmente occupati, ed abbiam formato il soggetto del presente lavoro.

Come è facile comprenderlo, un mese e mezzo, quanto potemmo consacrare nella Calabria Ulteriore, è tempo troppo limitato per potersi non direm già perlustrare, ma rapidamente percorrere dal naturalista tutta intera quella provincia. Per la qual cosa noi limitammo le nostre ricerche alla sua parte estrema e più meridionale, come quella che riunisce le più disparate condizioni che la provincia intera può offrire. Infatti, a cominciare dalle maggiori alture dell' Aspromonte, fino alla spiaggia che da quel lato pon termine alla parte continentale della penisola, tu vi trovi e folti boschi di pini, falsi abeti, faggi, querce; e profonde valli solcate da fiumi e torrenti; e colline ridenti con abbondante vegetazione spontanea; e luoghi padulosi; e spiagge arenose. Nelle quali condizioni tutte l' entomologo trova ben da spaziarsi, avendo località che alla loro volta prestano asilo ad entomati di ogni famiglia. Ad effettuare quindi il nostro proponimento, dopo aver percorse le adiacenze di Reggio, ci recammo direttamente sull'Aspromonte ascendendovi pel suo lato occidentale, percorremmo tutti i punti più culminanti di quella estesa giogaja di monti e le principali vallate interposte, discendendone per quella valle che prende il nome dal Santuario eretto nel basso di essa in onore della Madonna di Popsis. Di là ci recammo a S. Luca, ed indi per Motticella ci estesimo sulla lunga valle di Bruzzano, nella quale riconobbimo uno de'punti più interessanti per l' Entomologo ; battemmo intero il littorale di Brancaleone; girammo le colline interposte tra Brancaleone, Staiti, Pietrapennata e Palizzi, ed in ultimo guadagnato novellamente il littorale presso il Capo Spartivento, ci restituimmo a Reggio. Nel 
ricercare $i$ quali luoghi ben ci accorgevamo che anche avendo così ristretto il campo delle investigazioni, troppo breve era il tempo alle medesime consagrato a fronte della importanza che quelli ci offrivano. In comprova di chè bastercbbe accennare che nella valle di Bruzzano uno spazio palustre non più esteso di tre metri quadrati fu sufficiente per intrattenerei non men di sei ore con immenso vantaggio; e che sulle colline di Brancaleone, in un punto che potrebbe dirsi matemalico, potemmo passarvi due intere matinate, facendovi principalmente raccolta di molte ed interessanti specic di Imenotteri.

Il risultamento di siffatte nostre investigazioni forma il subietto del presente lavoro, che abbiam creduto ripartire in cinque distinti capitoli. Nel primo faremo un cenno de' lavori esistenti sull' entomologia della Calabria Ulteriore, onde si abbia il confronto tra lo stato in cui trovavansi le conosccnze sull' argomento innanzi quest'epoca, e quello cui mercè le nostre ricerche si sono elevate. - Nel secondo daremo un prospet to generale di quanto le contrade da noi ricereate ci hanno offerto di più interessante.-Seguiranno nel capitolo terzo alcune speciali osservazioni su Ia Fauna di Aspromonte. - Il capitolo quarto sarà destinato alla descrizione od illustrazione di parecchie specie. - Nel quinto ed ultimo sarà dato il catalogo sistematico generale delle specie tutte da noi raccolte nella Calabria Ulteriore: nel quale a maggior chiarezza ed intendimento de'due lavori che ci han preceduti, apporremo in due distinte colonne la sinonimia dello Specimen del Petagna, e della Fauna d'Aspromonte del Costa (0. G.)

\section{CAPITOLO PRIMO}

Cenno storico-critico de'tavori esistenti sulla Entomologia della Calabria Utteriore.

Non si è molto imbarazzato a raggranellare gli elementi storici sull'argomento che ci occupa. In fatti, a due soli possonsi ridurre i lavori che con ispecialità trattano degl' Insetti della Calabria Ulteriore. Essi sono lo Specimen Insectorum Ulterioris Calabriae di Vincenzo Petagna, e la Fauna d'Aspromonte e sue adiaceñe di O. G. Costa.

Lo Spccimen dal Petagna pubblicato nel 1786 a tutti voi è ben noto, e dalla prefazione stessa dell'autore rilevasi, essere stato scritto sopra un branco d'insetti nella Ulteriore Calabria raccolti da' due giovani di ottime speranze Giulio Candida e Giuseppe Stefanelli, i quali seguirono 
la commissione che la Real Accademia delle scienze spedì nelle calabre contrade nel 1783 a fine di studiare i guasti cagionativi dal tremuoto, che nel nominato anno fu tra $i$ più forti onde le Calabrie siano state il teatro. Quell'opuscolo era il primo lavoro entomologico che vedeva la luce nell'ex-regno di Napoli. Per lo che con molta anzietà fu ricercato dagli studiosi di questa branca di naturali scienze, ed in Francfort l'anno appresso riprodotto.

Le specie d'insetti delle quali in quel saggio si tiene parola ascendono a dugentotrentanove, dovendosi dall'apparente cifra di dugento quaranta sottrarre una che agl' insetti non si appartiene, l'Aranea nigra. Fra le dette specie l'autore ne descrive dodici come nuove, le quali sottoposte ad accurato esame ci danno il risultamente che segue - Il Paehypus Candidae, il Rhinomaeer coeruleus, la Mutilla brutia, la Mutilla littoralis, la Phalaena calabra sono oramai sancite nella scienza come patrimonio del quale questa si è arricchita mediante il lavoro del nostro Petagna. In fatti la novità delle due cennate Nutille venne riconosciuta immediatamente dallo Gmelin nella tredicesima edizione del Systema Naturae di Linneo: comunque non si fosse fatto altrettanto da scrittori posteriori, i quali anzi rivocandole in dubbio, e confondendole con altre, non ban fatto che imbrogliare maggiormente la sinonimia, la quale è stata da noi ridotta alla sua vera lezione nella monografia de'Mutillidei della Fauna napoletana. Pel Paclyypus Candidae si è per lungo tempo dibattuto fra gli Entomologi. Anche negli Atti della Reale Accademia delle Scienze di Napoli leggesi una discussione su tale argomento. Oggi però non più si dubita essere stato Petagna il primo a descrivere la detta specie. Il Rhiuomacer cocruleus è stato da noi primamente rivendicato al suo seopritore, riportandolo al conveniente genere Stenostoma $(\mathbf{I})$ : e comunque qualche autore che ha scritto dopo di noi non avesse riconosciuta tale anteriorità, pure questa è stata recentemente constatata da Schaum, che nel Catalogus Coleopterorum Europae ritiene il nome dell'Entomologo napoletano, rimandando a' sinonimi l'altro rostratus di Fabricio generalmente adottato innanzi di noi.

Il patrimonio di che il Petagna col suo Specimen avrebbe arricchita la scienza sarebbe stato anche maggiore, se buone collezioni pel confronto od opere più accurate avesse egli tenute a sua disposizione. In fatti tra 
gl'insetli che ebbe per le mani, varii altri ve ne erano che in quell'epoca non erano conosciuti, e da lui erroneamente definiti per specie già note. Erano in tal condizione il Carabus rostratus descritto posteriormente da Bonelli col nome di italicus (Cychrus); il Clerus formicarius denominato varii anni dopo da Charpentier transversalis; il Tenebrio caraboides nel quale ravrisiamo senza esitazione la specie stessa da noi descritta nel 1847 col nome di Pandarus strigosus (I). Intorno alla quale ultima specic è qui acconcio notare che il Mulsant riconoscendo in noi l' anteriorità nel descrivere tale specie, riferendola al genere Colpotus, si è poi creduto autorizzato a mutarne il nome specifico in strigicollis, per la ragione che uno identico trovavasi già impiegato da Faldermann per una specie di Pedinideo della Cina boreale, la quale secondo il suo medesimo sistema spetta all' altro genere Pelinus. Noi rispettiamo il distinto Entomologo di Lione; i cui lavori hanno sempre l' impronta dell' accuratezza. Nella circostanza però di tale specie crediamo che non abbia avuta ragione a mutare il nome specifico. Dappoichè le regole di nomenclatura vietano che lo stesso nome sia impiegato per due specie dello stesso genere, non però per specie che riferisconsi a generi diversi fossero anche affinissimi. In comprova di chè molti esenpii potremmo addurre. Per la qual cosa noi crediamo che il nostro Coleottero debba conservare il nome di Colpotus strigosus, siccome l' abbiam già veduto adottato dal Redtenbacher nella sua Fauna Austriaca, che mette per sinonimo l'altro di strigicollis.

Per opposto a quel che innanzi si è detto, dobbiamo avvertire che varie specie dal Petagna date come nuove, tali non erano. Per esempio la sua Buprestis Stephanelli era stata descritta da Fabricio precedentemente col nome di cyanicornis; la Buprestis brutia in nulla differisce dalIa $c a-$ riosa dello stesso autore; il Rhagium nigrum è evidentemente la Leptura scutellata.

Da ultimo ci resterebbe a dire di molte specie gid note, ma erroneamente determinate; ma la loro giusta nomenclatura potrả rilevarsi dalla sinonimia che apporremo nel catalogo generale che sarà dato in fine di questo lavoro. Però non possiamo dispensarci dal richiamare l'attenzione sopra talune, le quali dovrebbero non poco sorprendere chi ciecamente prestasse fede a quelle determinazioni. Chi vi legge ad esempio fra gli

(1) Memorie Entomologiche. 
Insetti calabri la Cicindela capcrisis, aequisterebbe idea assai erronea della Entomologia di quella regione. Pertanto nella $C$. capensis del Petagna noi non esitiamo a riconoscere l'Omophron limbatum, comune a tutta quasi l'europa. Parimenti nella sua Scolia quadrimaculata, che è specie propria dell'America, noi riconosciamo il maschio, della volgare Scolia hortorum. In fine il Lucanus Capreolus è quello descritto da Thunberg col nome di tetraodon.

La Fauna d'Aspromonte e sue adiaccnze del Prof. 0. G. Costa venne compilata in seguito di un viaggio eseguito nelle Calabrie per missione della R. Accademia delle Scienze in compagnia dell' altro Socio Professore Gussone, che dal suo canto ne illustrava la Flora. Con quel lavoro la conoscenza degli entonati abitatori della estrema calabria prese più ampio sviluppo; chè il numero delle specie si elevò a trecento tredici , non ostante la regione cui si riferiva fosse stata assai più ristretta; e non ostante pure che l'autore non avesse tenuto conto che di alcuniordini soltanto. Infatti, delle trecentotredici specie, dugentoquarantotto si appartengono a Coleotteri, de'quali pare l'autore si fosse principalmente occupato; e le rimanenti sessantacinque van ripartite fra Ortotteri, Emitteri e Lepidotteri. Di Nevrotteri e Ditteri nessuna specie vien riferita, benchè in una delle tavole veggasi rappresentata una Efemera ed altro insetto che dalla sola immagine non può in alcuna guisa ravvisarsi qual sia. Parecchie specie furono illustrate : e talune nuove ancora descritte. Fra queste ultime vuolsi principalmente ricordare il Rhysodcs canaliculatus, il quale per la poca diffussione di quel lavoro è rimasto fino a tempo recentissimo ignorato, e descritto due altre volte come nuovo, l'una da Germar col nome di trisulcatus, e l'altra da Mulsant con quello di sulcipennis; nomi che per la prima volta veggonsi rimandati ai sinonimi nel cennato eatalogo de' Coleotteri d'Europa di Schaum. Nè diversamente è avvenuto del Podisma calabrum, altra interessante specie che nella Fauna d'Aspromonte trovasi descritta ed effigiata, e che molti anni dopo venne descritta da Burmeister col nome di Pamphagus marmoratus (1). Il Serville credette a torto essere il Gryllus elcphas (2), e forse neppure è altra cosa l'Acridium sardeum dell'HerrichSchaeffer (3). Il Fischer nella sua importante opera sopra gli Ortot-

(1) Handbuch der EntomoI. II, p. 617, n. 5 ,

(2) Hist. natur. des Horthopt. p. 6 I5.

(3) Nomencl. It p. 7. 
teri europei, sebbene ritenga il nome specifico del Burmeister chiamandola Porthetis marmorata (1); tuttavolta nella nota avverte che per diritto d'auteriorità dovrebbe il nome del Costa adottarsi: Secundum jus prioritatis huic speciei nomen Porth. calabra a 0. G. Costa tributum restituendum esset; e che se ciò egli non ha eseguito, l' è stato per non aver avuto sotto gli occhi individui napoletani per accertarsi della identità loro con quelli descritti dal Burmeister. Ora noi possiamo dileguare un tal dubbio, essendoci assicurati che gl'individui raccolti in Calabria quadrano perfettamente con la minuta descrizione che il Fischer dà della specie del Burmeister. Resta quindi assodato che ambedue i cennati autori han descritto una specie stessa, la quale portar deve il nome di Porthetis calabra, O. G. Costa, siccome il Fischer proponeva. L'Eumorphus calabrus se non costituisce una specie distinta nell'attuale genere Mycetina, cui si appartiene, certo per la costanza delle sue tinte rappresenta una varietà ben singolare della Myc. cruciata, il cui tipo non mai si rinviene, là dove la cennata varietà è molto abbondante sotto le cortecce degli abeti e dei pini.

Delle specie descritte come nuove, e nondimeno già note innanzi quel lavoro, se ne rileverà la sinonimia nel catalogo finale: solo avvertiremo come l'autore sia caduto nell'errore stesso del Petagna in quanto al nostrale Lucano, ritenendo coi nomi di $L$. cervus e capra la comune specie che è sempre il L. tetraodon.

\section{CAPITOLO SECONDO}

Ragguaglio succinto del risultamento delle nostre ricerche.

Passare a rassegna tulte quante sono le numerosissime famiglie naturali d'Entomati, per dire in cadauna di esse la scarsezza o l'abbondanza, le specie rare o nuove, che le regioni percorse della Calabria Ulteriore offrono, sarebbe cosa assai lunga ed in parte superflua. Dappoichè, consultando il catalogo generale delle specie tutte raccolte, è facile rilevare la prima delle due cennate condizioni. E però ci limiteremo quì a discorrere soltanto di quelle cose che ci sembrano più degne di nota. Innanti però di scendere a tali specialità, diremo che uno degli

(1) Horthopt. europ. p. 383. 
scopi che ci proponevamo nel perlustrare la estrema parte della Calabria, era quello di vedere quali rapporti essa offrisse con la contigua Sicilia. Chè, sebbene convinti strette relazioni dover esistere fra le due regioni; nulladimeno per ben corrispondere alle esigenze della geografia entomologica, era mestieri determinare con dati precisi quali esse si fossero, e fino a qual punto si estendessero. In fatti l'Isola di Sicilia racchiude in sè tali e tante singolarità e produzioni esclusive, da farla giudicare una terra tutto affatto per natura di clima e di suolo diversa dalla vicina parte continentale. Ora sono appunto tali singolarità esclusive che sono andate a diminuire con le accurate ricerche nella estrema $\mathrm{Ca}$ labria, e quelle sulle quali in preferenza ci intratterremo brevemente, costituendo i migliori documenti a dimostrare le relazioni che passano fra le due regioni.

In tal categoria cenneremo dapprima l'Ancylopus mclanocephalus. Questo Coleottero veniva primamente descritto dall' Olivier (I) col nome di Endomychus melanocephalus sopra un individuo femina trovato nel $\mathrm{Mu}$ seo di Parigi senza indicazione di luogo natale, e di poi riportato da Dejan nel catalogo de'Coleotteri con la indicazione della Sicilia per patria. Posteriormente fu da noi illustrato nella monografia degli Endomichidei della Fauna Napoletana ( $\mathcal{(})$ sopra individui parimenti ricevuti dalla Sicilia, fissando ancora i caratteri del genere fino allora non determinati. Avvertivamo innoltre nel citato luogo esser tuttavia ignote le metamorfosi del cennato coleottero, la sua ubicazione, i costumi, e le sostanze di che ne' diversi periodi di sua vita alimentasi. Più recentemente il signor Gerstaecker nel bel lavoro sopra i Coleotteri Endomichidei (3) riprodusse la specie senza riempire alcuna delle lacune da noi additate, e ritenendola ancora come abitatrice della Sicilia. Ora possiamo aflermare che l'Ancylopus melanceephalus non è più esclusivo di quell'isola, ma abitatore eziandio della Ulteriore calabria, ed in qualche contrada di questa non affatto raro. Delle sue metamorfosi nulla abbiam potuto disvelare: però un passo più oltre abbiam dato riconoscendone la sua ubicazione; la eui conoscenza è tanto più interessante, in quanto per essa il cennato coleottero si allontana dalle altre specie della famiglia cui appartiene. In fatli è noto che gli Endomichidei, almeno quelli

(1) Entom. VI p. I073, n. 3, pl. I. fig. 3 .

(2) Pag. 15, tav. VIII fig. 3.

(3) Monogr. der Endomychiden. 
della Fauna europea, vivono sotlo le cotecce degli alberi, principalmente faggi, pini, abeti, e qualeuno entro i funghi. L'Ancilopo per opposto abita i luoghi maremmosi, vivendo presso le radici delle piante, delle quali probabilmente si nutrica ancora ne' diversi periodi di sua vita. In tali condizioni l' abbiamo costantemente trovato in punti svariati dalla stessa Valle di Bruzzano presso le sponde del fiume-torrente dello stesso nome, le cui acque nel basso della valle durante la state ristagnano quà e là rendendo l'aere poco salubre. - Speciale parimenti della Sicilia ritenevasi dagli Entomologi il Bembidium Dahlii. Ora è cessata talo privativa, vivendo la cennata specie ancora nella Calabria, e nelle condizioni stesse di abitazione dell' Ancilopo.-Altro Coleottero che neppur conosceasi abitare la parte continentale delle provincie meridionali d' Italia è la Drypta cylindricollis, la quale rinvienesi più facilmente nella Sicilia e nella Spagna. Essa pertanto trovasi nella estrema Calabria, ne' luoghi e condizioni medesime delle altre di cui abbiamo poco innanzi discorso. - L'Opilus mollis non è certo specie rara in Europa; noi stessi l'abbiamo già incontrata nel territorio napolitano. La ricordiamo nondimeno in questo luogo per avvertire, che tra le diverse varietà che presenta relative al colorito, gl' individui raccolti nella Calabria appartengono alla varietà $E$, dallo Spinola (1) segnata come propria della Sicilia, nella quale il colore oscuro prende sull'elitre tale estensione, che la prima fascia chiara è più angusta e più corta, per modo da non scendere in dietro lungo la sutura per raggiungere la seconda, siccome ba luogo negli individui ordinarii. - Tra gli Emilleri ne abbiamo avuto ancora un esempio nel Pygolampis femoratus, da noi primamente rinvenuto abbondante nelle adiacenze di Palermo, ed ora discoperto nella Calabria.-Tra gl'Imenotteri possiamo ancora citare sotto il punto di vista che ci occupa, l' Anthidium sulphurcum e il Lithurgus haemorrhoidalis, ambedue specie non conosciute altrimenti, che per la descrizione datane da Lepeletier sopra individui della Sicilia. In quanto poi alla seconda ci ha pur da riflettere, che la conoscenza di tale specie limitavasi soltanto alla femina, ed oggi viene completata, avendone ambedue i sessi. Il maschio differisce essenzialmente dalla femmina pel rilievo frontale quasi obliterato, pe'piedi posteriori più grossi, soprattutto i femori e le tibie, pel capo e torace rivestiti di folta peluria cenerino-fulviccia, del qual

(1) Essai sur les Cleriles. 
colore è pure la peluria addominale si dorsale, che ventrale: la frangia marginale degli anelli addominali è di un bianco meno puro, ed il sesto anello ha la peluria rossa più pallida. Potremmo pur aggiungervi il Rhygchium Lefeburei, Lep., se non fossimo convinti non essere questo altra cosa che varietà dell' oculatum, specie alla quale deve restituirsi il nome specifico di variabile impostole dal nostro Cirillo, rimandando a' sinonimi tanto quello or detto di Fabricio, quanto l'altro europaeum impostole dallo Spinola.

Dopo aver esposte queste poche cose relative alla geografia entomologica, passiamo a dare un breve ragğuaglio delle specie più interessanti rinvenute in ciascun ordine.

\section{COLEOTTERI}

In quest'ordine ci pare dapprima degna di esser notata la positiva scarsezza di Carabidei, sia che questi si considerino per numero di specie, sia che si guardino per la copia degl'individui. La qual cosa è principalmente straordinaria per la catena dell'Asp̧romonte, ove l'alternarsi delle alture con le valli, i boschi onde i monti sono rivestiti, i numerosi torrenti dai quali vengono in varie direzioni solcati sembrerebbero ofirire le più favorevoli condizioni per la vita degli entomati della enunciala famiglia, ed analoghe a quelle che s' incontrano nelle più alte montagne degli Abruzzi, precisamente la Najella. E pure se si istituisse un parallelo fra i Carabidei di queste due catene di monti, per nessuna famiglia si troverebbe tanta differenza, quanto per quella in parola. Infatti su'monti della Najella tu trovi abbondanti svariate specie di Carabus, di Pterostichus, di Nebria, di Zabrus, ec.; mentre in quelli dell' $\Lambda$ spromonte il numero totale di Carabidei raccolti si eleva appena ad una quarantina. Nè varrà l'opporre non conoscere noi tutte quante sono le specie di Carabidei che vivono sull'Aspromonte; poichè lo stesso dir si potrebbe ancora della Nejella. Ma quello che debbe riflettersi l'è, che sulle montagne dell'Aspromonte a forza di ricerche dilingenti puossi a stento rinvenire quà e là qualche Carabideo; mentre sulla Najella ricercando anche fugacemente ti trovi quasi ad ogni passo nella posizione di far buona raccolta di interessanti specie di Carabidei. La ragione di tale notevolissima differenza ci pare doversi attribuire meno all' altezza maggiore cui si elevano i monti della Alajella, che alla posizione più settentrio- 
nale di queste montagne. In fatti considerando in generale la distribuzione geografica de'Carabidei di europa, vedesi, che ad eccezione di pochi generi, pe' rimanenti l' abbondanza cresce a misura che si va verso il settentrione.

Gl'insetti che vivono ne'pini debbono certamente richiamare l'attenzione dell' entomologo che perlustra la catena dell' Aspromonte, ove il pino comune nelle Calabric tutte, pinus larieio, ed il falso abete, pinus picea, ne covrono tutta quasi la superficie, benchè oggi vadano continuamente scemando per affetto de' continui lagli. Noi vi abbiamo quasi esclusivamente consagrati varii giorni alla ricerca degl'insetti de'pini, non ostante la dimora su que'monti fosse la più incomoda che avessimo sperimentata, per assoluta mancanza di ricovero. Del frutto raccolto non siamo del tutto scontenti : dobbiamo però anche per queste genie d'insetti osservare che la copia e la importanza delle specie sono state di molto inferiori a quelle che le analoghe condizioni di vegetazione offrono nelle regioni settentrionali di europa. Soprattutto la Fauna della Germania è assai ricea d'insetti abitatori de' pini. Anche nella Francia il solo pino maritimo ha dato al signor Perris una copia non indifferente di specie, non meno che centoventi. Vero è però non potersi fare paragone tra il risultamento di ricerche assidue e di parecchi anni, con quelle di ura fugace perlustrazione di pochi giorni; nondimeno la sproporzione è tale, da non potersi a questa sola cagione altribuire. Egli è principalmente nella famiglia de' Bostrichidei, che è appunto quella che rappresenta la parte maggiore degl'insetti di cui ragioniano, che il difetto si avverte.

Il gruppo de' Malacodermi vi è piuttosto abbondante, ed in esso dobbiamo fra le altre notare l'Omalisus sanguinipennis descritto primamente da Kuster come proprio della Dalmazia, e di poi da noi illustrato sopra individui raccolti sulla montagna di Santangelo a Castellammare. Aggiungi che gl'individui raccolti sopra l'Aspromonte sono notevoli per la statura doppia di quella degl'individui raceolti nell'altra citata località.

Nella famiglia degli Edemeridei, la quale è abbondantemente rappresentata, menzioneremo che la copia d'individui di ambo i sessi della Oedemera il cui maschio venne in prima deseritto da Schmith col nome di melanopyga sopra individui ricevuti dalla Sicilia, ci ha messi nella posizione di completare la conoscenza di tale specie, riconoscendo per femmina di essa quella descritta da noi nella Fauna Napolitana col nome 
di Oed. maculiventris, convertendo in eertezza il sospetto nel citato luogo già manifestato. E siamo indotti a credere esser questa stessa Edemera quella che nella Fauna d'Aspromonte trovasi registrata col nome di Oed. ruficollis, mentre la vera ruficollis, oggi spettante al genere Anoncodes, non l'abbiamo mai vista finora nolle nostre provincie.

La sezione de'Curculionidi è certamente tra le più intrigate, e nel tcmpo stesso tra le meglio studiate. Essa non può dirsi proporzionalmente assai ricca nella estrema Calabria. Solo di minute specie ne abbiam fatta abbondante raccolta. E sebbene non sia molto agevole pronunziare sulla novità di una specie, pure ci pare averne talune che come tali possiamo presentare agli Entomologi. Precisamente del genere Nanophyes ci abbiam raccolto buon numero di speeie, fra le quali ve n'ha che crediamo degne d'illustrazione, e due che giudichiamo nuove, e che verranno descritte coi nomi di ccutromaculatus e quadrivirgatus.

In fatto di Longicorni la Ulteriore Calabria offre un qualche interesse per l' Entomologo, albergandovi molte e non spregevoli specie, principalmente della famiglia de' Lepturidei. Perù l' essere stata questa parte de'Coleotteri studiata d'assai buon' ora e da molti, e l' essere gli animali che vi si riferiscono di statura quasi non mai minutissima, son due condizioni per le quali non è molto facile discoprir novità. La specie che crediamo più singolare fra quelle rinvenute in tale peregrinazione si è una Leptura, la quale avendo stretta affinità con varie già note, come la $b i$ punctata, la bisignata c la unipunctata, nondimeno non può con alcuna di esse dirsi identica. Sicchè verrà deseritta col nome di Leptura excellens.

Da ultimo dobbiam notare tra Colcotteri il genere Lejestes degli Endomichidei, che pure è stata una nuova aggiunta per la Fauna Napolitana, tanto più importante, in quanto non si aveva notizia che fossesi rinvenuta in Italia: almeno il Redtenbacker, il quale nolla sua recentissima opera sopra la famiglia in parola ha riunito quanto su tali Culeotteri innanzi di lui conoseevasi, assegna per patria all' unica specie europea, L. seminigra, la Svezia, la Germania settentrionale, e la Francia; l' Italia non già.

ORTOTTERI

Sebbene ricca piuttosto di Ortotteri dir si debba la estrema Calabria, nulladimeno poco di singolare ci ha offerto. La specie più rara che vi avessimo raccolta è stata la Porthetis calabra, della quale nel precedente 
capitolo abbiamo discorso. Vengono in seconda linea come specie che è meno facile incontrare ovunque il Trigopdium cicindcloides, che vive nei luoghi pantanosi della valle di Bruzzano; la Mantis Spallanzania, non rara nelle adiacenze di Reggio; la Mesonema meridionalis (1) stata descritta pochi mesi dopo di noi dal signor Yersin col nome di brevipennis (2) sopra individui ricevuti dalla Sicilia.

\section{NEVROTTERI}

Chi fosse nel caso di consagrar molto tempo alla ricerca de' Nevrotteri Calabri, perlustrando ripetute volte le vallate dell' Aspromonte solcate dalle acque, precisamente quella di Popsis, quella di Bruzzano ed altre simili, ne farebbe certamente ricca ed interessante raccolta, principalmente della famiglia de'Friganeidei. Noi poche specie abbiam potuto raccogliere, e nondimeno fra queste poche ve ne ha taluna che offre tale organizzazione, da dover costituire a nostro modo di vedere un distinto genere nella famiglia degli Emerobiidei, cui imporremo il nome di Isoscclipteron per alludere alla figura delle ali che l'è quasi di un triangolo isoscele. Ne possediamo un solo individuo raccolto sulle colline di Staiti. Anche del genere Mucropalpus abbiamo una specie dell'Aspromonte, che illustreremo col nome di $M$. hyalinatus.

\section{IMENOTTERI}

È questo l'ordine che in preferenza di ogni altro ci ha presentato specie interessanti per la scienza, ed aggiunte per la Fauna Napoletana. Però è da far distinzione tra le due grandi sezioni nelle quali l' ordine naturalmente dividesi. Di una di esse, vuol dire di quella che racchiude i trivellanti, assai scarsa è stata la raccolta, mentre per l'opposto d'Imenotteri aculeati la raccolta è stata si abbondante, da aver richiamato tutto il nostro siudio. La ragione di tanta discrepanza, che noi trovavamo diametralmente inversa di quella osservata il mese innanzi sulle montagne delle Sile, crediamo doversi attribuire ed alla stagione nella

(1) A Cost. Faun. Napol. Locustid. p. 14 tav. X, fig. 2 e 3; 0ttobre 1860.

(2) Note sur quelques Orthopteres d'Europe. Annal. de la Societ. Entom.de Fran. $3^{\text {a }}$ ser. vol. VIIl, 1860, pag. 519 , pl. 10 , fig. $7-9$. 
quale eseguivamo le nostre ricerche, od alle condizioni di vegetazione molto diverse. Cosi ad esempio per la sottosezione de' trivellanti serricaudi, nella quale, se ne eccettui poche e volgari specie, nulla vi abbiam rinvenuto, nelle basse pianure e nelle mezzane colline la stagione era troppo innoltrata; e nelle montagne poi dell'Aspromonte vi si opponeva la mancanza di quelle piante che in preferenza danno pascolo a simili insetti. Non meno de'Serricaudi furono scarsi i Pupivori : fra quali tuttavia, oltre a qualche specie rara per noi, come l'Ichneumon lugens e l'Ephialtes neanifestator che raccoglievamo su'boschi dell' Aspromonte, abbiamo un Iencumone propriamente detto, e due Trifoni i quali non possono con esattezza riferirsi ad alcuno di quelli descritti dal Gravenorst nella sua classica opera sugl'Ínemonidi europei, la quale non cesserà mai di essere il primo codice importantissimo per tale famiglia d'insetti. E quantunque non fosse fuori probabilità che altri le avessero descritte dopo del Gravenorst; pure le nostre indagini non ce le han disvelate. Verranno quindi descritte coi nomi di Ichneumon calabrarius, Tryphon flavitarsus, o Tryphon nigricarpus. - Nella famiglia dei Braconidei due ne menzioneremo, il Vipio desertor, la cui frequenza ci ha messi nel caso di conoscere i due sessi essere tra loro perfettamente simili, se ne eccettui la trivella della femina; mentre il maschio rimase dubio al distinto Entomologo Nees di Esenbeck; e lo Spathins erythrocepkalus descritto da Wesmael come proprio del Belgio, e di cui non si ha notizia fosse stato rinvenuto in Italia. - In fine tra Calcidei descriveremo una specie col nome di Cheleis obtusedentata.

Passando a dire degli lmenolleri aculeati, non vi ha tra essi famiglia, nella quale non avessemo rinvenuto specie o nuove per la scienza, o per lo meno da aggiungersi alla fauna napolitana, nella quale appunto parecchie di tali famiglie erano state pubblicate poco innanzi di muovere per le ricerche di cui favelliamo. Per questi adunqne non possiamo dispensarci dal passare a rassegna ciascuna delle naturali famiglie per dirne le specialità, non potendo esser tutte in un sol quadro prospettate.

Sfecidei. Di tre specie si è accresciuta la nostra fauna per gli Sfecidei. Una di esse era già nota fin da Fabricio: è il Pelopoeus femoratus, che nella fauna curopea rappresenta qualche cosa di affine alle specie del nuovo mondo. Le altre due sono la Sphex strigulosa e la Enodia lividocincta, ambedue state ога da noi già descritte nel seguito agli Sfecidei della citata fauna Napoletana. 11 rinvenimento poi della femmina 
della Sphex parthenia ci ha dato la opportunità di togliere una lacuna rimasta nella storia di tale specie, e ci lia fatto riconoscere che il rosso delle mandibole si appartiene al maschio soltanto, mentre nella femmina quelle sono interamente nere. Dal che conseguita che uno de'caratteri specifici adottati dal Dahlbom per formolare la differenza tra la Sph. fuscata, cui più la nostra si approssima, e la Sph. sorlida, riposto sul colorito delle mandibole, perde ogni valore. Innoltre non dobbiamo tacere aver incontrato nelle collezioni del doltore Sichel e del Iuseo Britannico individui pressocchè identici a' nostri col nome di Sph.paludosa, Ros., con la quale noi fin dal principio riconoscevamo l'affinità, esprimendo le ragioni per le quali non eravamo indotti a riferirvi la nostra specie.

Pompilidei. Nella fauna napolitana (1) descrivendo il Priocnemis annulatus abbiamo avvertito l'equivoco introdotto dal Dahlbom col considerare il Pomp. luteipennis di Fabrieio come la femina del $P$. unmulatus. E noi deducevamo allora il nostro giudizio soltanto dal tenere ambi i sessi del vero annulatus, e dal vedere che la femina non corrispondeva punto alla diagnosi che il Fabricio ei ha lasciata del luteipennis. Ora non solo possiamo eonfermare quanto ivi abbiam detto, ma soggiungiamo che il Pompilus (ora Priocnemis) luteipennis di Fabricio è specie ben distinta. Noi l'abbiam raccolta nella Valle di Bruzzano; l'individuo che possediamo è femina e conviene esattamente con la frase diagnostica fabriciana. Nel genere Pompilus non è facile pronunziare sulla novità di una specie. Nulladimeno ci pare una polerne indicare come nuova, ehe verrà denominata $P$. vomeriventris pel principal carattere che distingue la femina, unico sesso che possediamo, cioè l'addome sensibilmente compresso verso dietro a guisa d'un vomero.

Nissonidei. Ricca d' Imenotteri di questa famiglia è la estrema Calabria: però la più parte delle specie son quelle stesse che rinvengonsi pure nella Terra d'Otranto. Due sole ci giunsero sconosciute, lo Stisus terminalis Dahlb. che avevasi come proprio della Francia meridionale; ed un novello Hoplisus da noi chiamato crassicornis. Ambedue le quali specie, trovansi già pubblicate nella fauna napoletana, di cui la monografia dei Nissonidei fu compiuta dopo il nostro ritorno dalle Calabrie.

Bembecidei. Abbondanti sono le Bembeci in tutti i luoghi arenosi della

(1) Pompilidei, pag. 6. 
estrema Calabria, e in preferenza nella valle di Bruzzano, ove veggonsi svolazzare a sciami intorno i fiori del Vitex Agnus castus, che insieme al Nerium Oleander, anche in fiore nel mese di luglio, danno a que' letti di torrenti l'aspetto di ridenti giardini. Le specie però sono tutte ben note, e non rare in altre parti di queste provincie napoletane.

Filantidei. Nessun luogo si è tanto prestato per gl'Imenotteri di questa famiglia, quanto le colline di Brancaleone. Precisamente del genere Cerceris in un punto limitatissimo tale ve ne era copia, da avervi potuto raccogliere riunite quante la nostra fauna finora ne conta di specie, fra le quali era per noi la prima volta che raccoglievamo la conigera Dahlb. e la bupresticida, L. Duf. Nè deve passar inosservata l' abbondanza del Philantus Sieboldti lungo il littorale che dal paese stesso di Brancaleone s'intitola.

Di Larridei, Pcmfredonidei e Crabronidei nulla di singolare abbiamo incontrato.

Scoliidei. Da quel che abbiamo già pubblicato nella fauna rilevasi che le nostre ricerche nella estrema calabria ci han fruttato in questa famiglia l' aggiunta della Scolia rubra Spin. (abdominalis, Jur.) che raccogliemmo abbondante sulla collina di Brancaleone ove erano copiose le Cerceridi. Nondimeno dobbiamo notare essere opinione di alcuni Imenotterologi esser quella Scolia la femmina della Elis continua Lep. che che noi abbiamo parimenti raccolta nella Calabria, però in luogo diverso, cioè sulle pendici orientali dell' Aspromonte. Quì non altro che maschi, li non altro che femmine; ma ciò nulla oppone a poter considerare le due Scolie cennate come i due sessi d'una specie stessa, alla quale conservar si dovrebbe il nome impostole dallo Spinola.

Mutillidei. Lorchè pubblicammo la monografia de'Mutillidei della fauna napoletana dicemmo che le Calabrie e la Terra d' Otranto erano le due fra le provincie napoletane che principalmente abbondavano d'Imenotteri di tale famiglia. Questa proposizione trovò nuovi documenti nelle ricerche ultime da noi eseguite. In fatti, tra le molte specie raccolte, quattro ve ne erano ancora che prima non possedevamo, e che quindi accrescevano sensibilmente la serie delle IIutille napoletane. Noi le abbiamo già descritte nelle aggiunte alla cennata monografia. E sebbene fosse possibile che qualcuna di esse non sia che la femmina d'altra conosciuta pel maschio solo; pure non polendosi un tal ravvicinamento istituire per semplice ipotesi, è necessità ritenerle con nome distinto fino a che 
novelle osservazioni non verranno a convertire in realità gli attuali sospetti.

Andrenidei. Uno de' generi più singolari di questa famiglia c̀ certamente il g. Nomia, del quale una sola specie erasi incontrata fra noi, la $N$. humeralis. La estrema Calabria ce ne ha date due specie molto interessanti: l'una delle quali sembra affinissima a quella dell'Egitto descritta da Spinola col nome di ruficornis (1); e l'altra è assai distinta per la conformazione de'piedi posteriori, piu strana che in quante altre specie l'Europa possiede, onde l'abbiam descritta nella fauna col nome di monstruosa, all' altra avendo dato il nome di affinis. Quello inoltre che ci han fatto avvertire le Nomie raccolte in Calabria si è la variabilità delle due spine dello scutello del maschio, le quali in una medesima specie van soggette ad impicciolirsi fino a ridursi a piccoli denti, che rimangono quasi occultati in mezzo alla peluria. Dobbiamo inoltre notare cle visitando la ricca collezione degl' Imenotteri illustrata da Smitth, abbiam trovato un maschio simile perfettamente alla nostra monstruosa sotto il nome di diversipes o humerulis; mentre il maschio di questa specie ha $\mathrm{i}$ piedi posteriori assai diversamente conformati. Tra le molte specie dell'esteso ed intrigato genere Andrena per una sola crediamo poterci pronunziare e darla come nuova, presentando tale abito, da non poterla confondere con alcuna delle note. Essa verrà descritta col nome di A. cala$b r a, c o l$ quale ne abbiam lasciato un individuo al distinto Imenotlerologo francese dottore Sichel.

Megachilidei. Il genere Megachile viene pur esso ben rappresentato nella Entomologia calabra, avendovi tre specie probabilmente nuove, le quali denominiamo pugillatoria, melanopyga e minuta. Ancora è interessante per la nostra fauna la $M$. patellimana descritta da Spinola come propria dell' Egitto.

Apidei. Notiamo in questa famiglia la comune Ape da miele per una varietà incontrata sui piani di Aspromonte. Essa distinguesi pel colorito bruno uniforme di tutti gli anelli addominali dorsali.

\section{EMITTERI}

Gli Emitteri Eterotteri avendo costituito d'assai buon'ora oggetto speciale di nostre investigazioni e studì, avrebbero dovuto poco o nulla di

(1) Annal. de la Soc. Entom. de Franc. 1838. 
nuovo offrirci o di assai raro. Tuttavia il viaggio per le Calabrie ci ha pure confirmata la massima, che le provincie napoletane non possono mai dirsi esplorate abbastanza in fatto d'entomologia. Le pianure delle Sile ci han dato sufficiente materiale da accrescere la serie delle specie della nostra fanna ; ma la Calabria Ulteriore con un numero piì limitato di specie, ce ne ha dato delle tanto importanti, da compensare con usura la scarsezza del numero. Ed in prima ad ogni altro convien dire di un Emesideo, il quale offre tali tratti d'organizzazione, da averei indotto ad elevarlo a tipo di un genere distinto, al quale abbiam imposto il nome di Metapterus per alludere ad una delle note caratteristiche che lo distinğuono, cioè le elitre inserite sul posteriore contorno del mesotorace, il quale nel dorso è sviluppato tanto quanto il protorace, e rimane come quello a scoperto. Come novità per la scienza annunzieremo ancora un grazioso Jingideo del genere Dyctionota da noi chiamata formosella. Ambedue le quali, unitamente ad altre discoperte sulle Sile nella Calabria Citeriore, le abbiamo descritte in un nostro recente lavoro sugli Emitteri Eterotteri napoletani (1).

Non meno degne di nota sono state alcune specie, la cui importanza riguarda principalmente la geografia entomologica. Il genere Pelogonus, che unica specic conta in Europa, il P. marginalus, era conosciuto abitatore della Francia meridionale e della Spagna. In Italia non sappiamo che alcuno innanzi ora ne avesse indicala la esistenza: anzi il distinto Entomologo della Liguria, Spinola, nel suo saggio sugli Emilteri Eterotteri dichiarò non averlo conosciuto in natura. La discoperta quindi di tale Emittero se nulla ha aggiunto alla scienza, ha arricchita di un altro genere la fauna napoletana non solo, ma della intera Italia. Essa trovasi sulle sponde sabbionose di varii fumi-torrenti della Calabria si Citeriore, che Ulteriore: ed in taluni di questi tanto frequente, da averne potuto osservare i diversi stati e i costumi, riconosecndo esattissimo quanto sull' oggetto ne scrisse il Dufour (2). - L'altra specie che sotto questa categoria devesi registrare è il Capsus Yercli che poco innanzi aveva deseritto il Mulsant (3) sopra individui della Francia. Esso vive nella Calabria Ulteriore sopra la Tamarin africana, ed è soprattutto frequente nelle adiacenze di Reggio, senza mancare in altri luoghi della provincia

(1) Additamenta ad Centurias Cimicum Regni Neapolitani.

(2) Recherches anatom. et physiol. sur les Hemiptères.

(3) Opuscul, Entomol. 
ove quella pianta vegeta. Ed è singolare, ehe mentre la parte maggiore delle speeie d'Emitteri e talnna ancora di Coleotteri che con quella eonvivono partecipano del eolor verde della pianta che loro presta alimento, questa pel contrario vi fa un sensibile eontrasto pel suo eolor neroeastagno, interrotto dalla fascia bianco-lattea.

Se in stagione più innoltrata avessimo nuovamente visitate le stesse regioni, molte altre interessanti specie di EmitteriEterotteri vi avremmo certanente raceolte; dappoiehè nel mese di luglio moltissime ne lasciammo ancor larve, precisamente delle famiglie dei Coreidei e degIi Scutelleridei.

Più scarsa di prodotto è stata la sezione degli Emitteri Omotteri; ma pure non mancante di qualche novità. Il genere Caliscelis non contava che una sola specie, il $C$. bicolor. Le rieerche nella Calabria ee ne hanno fatta aggiungere una seconda assai ben distinta per la metà superiore del eorpo tutta uniformemente gialla, nentre la sottoposta è bruno-nerastra, e per la mancanza della vena rilevata sull'elitre. Noi l'abbiam denominata C. dimiadiata (1). Sì pure nel genere Psylla una elegante specie ci hanno offerto le vallate dell'Aspromonte, ove vegeta abbondante la ginestra, la quale verrà denominata $P$ s. lactea.

\section{LEPIDOTTERI}

I Lepidotteri son fra tuttigl'insetti quelli pe'quali vi ha in tutta Eurapa maggior numero di cultori; i quali non solo hanno esaurito le ricerche nel proprio territorio, ma si sono estesi ancora in terre dalle native più o meno remote. Per la qual eosa non farà meraviglia se diciamo che quasi nulla degno di nota abbiamo rinvenuto in tale ordine. Di una sola specie ei oceuperemo a darne la descrizione, parendoci del tutto nuova. Essa appartiene alla famiglia della Grometre e verrà da noi distinta col nome di G. bruszanaria.

\section{DITTERI}

Comunque la Ditterologia italiana da parecehi anni venga assai bene illustrata dal distinto Ditterologo di Parma sig. Camillo Rondani, pure

(1) Fauna Napol. Caliscelidei. 
queste meridionali provincie parecchie novità ci hanno di tratto in tratto offerte, che in diversi lavori sono state da noi descritte (1), talune delle quali spettanti appunto alla estrema Calabria; come la Pogonosoma hyalinipenne, la Laphria aenciventris, il Cheilopogon sicanus, la Oscinis Rondani. Ciò nulla ostante tra $i$ Ditteri riportati dalla ultima peregrinazione non mancano alcune novità. $\mathbf{E}$ tra queste voglion esser fricordate due novelli generi, tali dovendoli considerare a causa della sottigliezza cui gli attuali Ditterologi han portato le note generiche. Uno di questi della famiglia de' Bombilidei è molto affine ai generi Usia e Cyrtosia, dai quali differisce per la disposizione delle vene alari, e per altri caratteri che verranno esposti nella rispettiva descrizione. L' altro si appartiene alla famiglia degli Asilidei, nella quale deve prender posto accanto del genere Laphria, con alcune specie del quale offre strettissima simiglianza. Nella famiglia stessa degli Asilidei ne abbiamo inoltre uno che rientra nel genere Gastricheilus istituito dal Rondani nel suo Prodromo di Ditterologia Italiana, onde verrà descritto col nome di Gast. nubeculipennis. - Nella famiglia degli Antracidei varie specie ci rimangono indeterminate: però non volendo su d'esse azzardare alcun ggiudizio, ci riserbiamo discorrerne dietro più maturo esame.

Dopo d'avere esposto quanto d'interessante e di nuovo ci ha offerto la estrema Calabria, ci piace chiudere il presente capitolo con una breve riflessione. Tutto quanto abbiam riferito non è che il frutto d'un mese solo di ricerche, eseguite direm quasi fuggendo pel desio di percorrere in breve tempo molto spazio, e per luoghi già due volte innanzi di noi con lo stesso scopo perlustrati: e la considerazione del tempo importa non solo per la brevità, ma ancora per la stagione, la quale ha stretto rapporto con la vita degli entomati delle diverse famiglie. Dappoichè se il colmo della state era stagione opportuna per le ricerche sulle montagne dell'Aspromonte, non era parimenti favorevole per le regioni basse di quella provincia per se stessa caldissima. Sicchè intere famiglie avevan già compiuta la loro parabola: mentre per contrario molte specie spettanti a famiglie autunnali, le lasciammo ancor larve quando abbandonammo quelle interessanti regioni. Or se non ostante tutte le indicate circostanze sì copiosa e ricca di novità è stata la raccolta, sembra ra-

(1) Frammenti di Entomologia Napoletana-Contribuzione alla Ditterologia italiana-De quibuslam novis insectorum generibus. 
gionevole il eonehiudere che immensamente maggiore dovrebbe aspettarsi se per tempo più lungo e in stagioni diverse si ricereassero quelle medesime contrade ed altre limitrofe che non potemmo visitare. Nui abbiam sempre opinato, ed ora ne siamo pienamente convinti, ehe se la intera provincia della Calabria Ulteriore prima si perlustrasse accuratamente dalla metà della primatera fino al cominciar dell'autunno, offrirebbe tanto aneora d'interessante e di nuovo, quanto nessun'altra delle provineie napoletane può offrire. E poichè non possiamo noi vagheggiare l'idea d'effettuire un tal progetto, lo additiamo quasi a programma per ehi avesse tempo e genio di consacrarvisi; contenti dal eanto nostro di avere eol presente lavoro spianata la via per opera più seria e più vasta.

\section{CAPITOLO TERZO}

\section{Osserrazioni ed addizioni alla Fauna di Aspromonte}

Le Faune come le Flore parziali, soprattutto se limitate a molto ristrette contrade, van soggette a sensibili variazioni per effetto dell'azione ehe la mano dell'uomo esereita sulle terre e sulle piante. La messa in coltura di terreni ineolti, la bonificazione de' terreni paludosi, il taglio di boschi, son tre eondizioni le quali immensamente influiseono a eangiare il numero di genie di animali e di piante di una contrada. E senza diffonderci a porre innanzi esempii estranei al nostro argomento, de'quali ben molti potremmo addurre, diremo di eiò ehe alla eatena de'monti di cui ragioniamo si riferisee. I piani di Aspromonte, giusta le assicurazioni dell'autore della Fauna di detta regione, non che de'veechi popolani di quelle contrade, fino a trent'anni or sono offrivano per varia estensione un suolo pantanoso riceo di vegetazione copiosa e spontanea, la quale dava asilo a numerose ed importanti specie di entomati. Lo stesso cennato autore, al pari del cav. Gussone, ehe insieme nel 1827 perlustravano quelle regioni, ricordano elie in quell'epoea vegetavano abbondantemente le Angeliche lungo la Valle detta Ferràina; le quali piante ovunque vivono, eostituiseono la sede di molti insetti, prineipalmente lmenotteri. Attualmente non una sola pianta ne vegeta; ed al pari di tutte le alture che dominano quella vallata, non di altro son ricoperte, che di felei, le quali è ben noto quanto poco siano dagl' insetti desiderate. I boschi di 
pini (pinus laricio) e di falsi abeti (pinus picea) si vanno alla giornata listruggendo, non rimanendo che arido e nudo suolo, ove innanzi quegli alberi maestosi facevan grandiosa mostra di loro. Tutte siffatte circostanze han prodotto ehe i monti della catena d'Aspromonte non offrano più quell'abbondanza di specie e di individui che un tempo vi si potevano agevolmente raccogliere. Sol pochi punti vi avvanzano ne'quali l'Entomologo possa far buona messe; fra quali deve principalmente noverarsi la vallata di Popsis.

Scendendo poi alle specialità dobbiam dire che non ostante il mutato aspetto di quelle contrade in rispetto a ciò che erano trent' anni dietro; pure molte specic vi abbiam rinvenute interessanti non segnate nella Fauna d'Aspromonte. Nulla diremo degl' lmenotteri e de'Ditteri; poichè l'autore di quel lavoro non essendosi punto occupato degl'insetti di tali ordini, ci manca l'elemento di comparazione; sì pure degli Ortotterie degli Emitteri, pe'quali alcune specie soltanto vengono menzionate. Dei Lepidotteri, abbiamo già dichiarato aver in generale poco da dire. Ci limiteremo quindi a'Coleotteri soli, i quali costituiscono la parte principale della Fauna d'Aspromonte.

Due specie di Malacodermi dobbiamo in prima menzionare; l'Homalisus sanguinipennis e l'Heros minutus; ambedue rimarchevoli eziandio per la vantaggiosa statura alla quale giungono gl' individui raccolti sull'Aspromonte. 11 primo di essi per esempio misura linee quattro e mezzo di lunghezza, mentre quelli che da noi precedentemente raccolti sopra le montagne di Castellammare non ecedono linee tre e quarto. L'Onitis pugil che avevamo innanzi dalla Terra d'Otranto, è abbondante nelle pendici orientali dell'Aspromonte entro lo sterco bovino. Sono parimenti specie interessauti da aggiungere alla Fauna di questa contrada la Leptura excelsa della quale abbiamo superiormente parlato; l'Asclera coerulea che raccoglievamo abbondante nella prateria che riveste il nudo cacume di IIontalto, là ove un tempo era folto bosco di faggi.

Che se con ispecialità prendiamo a considerare gl'insetti abitatori dei pini e de'falsi abeti, non poche specie vi ha che non prima erano state rinvenute e che accrescono la Fauna di quex monti. Menzioneremo con particolarità la Lejestes seminigra, il Lissemus equestris, il Serropalpus striatus, la Peltis grossa e ferruginea, il Micetophagus fulvicollis, il Brontes planalus, il Peromalus parallelepipedus, le Lejades axillaris e glabra, il Bothrideres contractus, la Bitoma crenata, il Menephilus curvipes, lo Xan- 
tholinus collaris. E molte altre ancora potremmo qui registrarne, le quali senza renderci prolissi, si rileveranno dal eatalogo finale.

\section{CAPITOLO QUARTO}

Descrizione di alcune specie nuove

Abbiamo in varii luoghi cennato che per effetto del lungo intervallo di tempo in cui questo lavoro è rimasto inedito ei siam veduti nella necessità di pubblicare nella Fauna napoletana parecehie delle specie che in quello si trovavano descritte. Tanto abbiam principalmente praticato per gl'Imenotteri Sfecidei, Scoliidei, Mutillidei, e per le Nomie; non che per la Caliscele già menzionata. Degli Emitteri Eterotteri poi, uniti ad altri molti discoperti e nella Calabria Citeriore ed in altre provineic ne abbiam formato il soggetto di un supplemento al precedente nostro lavoro pubblicato negli Atti del R. Istituto d'Incoraggiamento. (Additamenta ad Centurias Cimieum Regni Neapolitani).

Per la qual cosa, non ostante le dette specie, che comparivano nuove nel primo lavoro, si trovassero effigiate nelle quattro tavole, incise fin da quell'epoca; noi ad evitar ripetizioni, riporteremo qui la descrizione di quelle soltanto non ancor pubblicate, e per le altre ci sarà sufficiente additare nella spiegazione delle tavole il luogo nel quale le abbiamo deseritte.

\section{NANOPHYES QUADRIVIRGATUS.}

\section{Tav. I, fig. 4 .}

N. oblongus, convexus, rostro capite pronotoque simul haud longiore, recto; pallidus, paree albido pubescens, pronoti punctis duobus elytrorumque lineolis duabus discoidalibus abbreviatis, interna anterius quam externa posita nigris; peetore einereo-nigricante.

Long. corpor. lin. $1 \%$

Corpo oblungo, couvesso, pallido, con breve e discreta pubescenza bianchiccia, con splendore quasi serico, più stivata su'lati del protorace. liostro quasi diritto, cilindrico, non più lungo del capo e torace insieme. Capo nerastro nella regione occipitale. Protorace in forma di cono 
troncato, con due punti neri, uno per cadaun lato del disco. Elitre striatopuntate come nelle specie affini, con due brevi linee longitudinali nere l' una sul terzo intervallo quasi sul mezzo della lunghezza, l' altra sul quinto intervallo posta più indietro, cominciando al livello, nel quale la prima si termina. Femori anteriori e medii con una delicata spina presso l'estremità, ed altra minore appena avvertibile innanzi di quella.

\section{NANOPHYES CENTRONACULATUS.}

\section{Tav. I, fig. 3.}

11. ovatus, valde convexus, rostro capite pronotoque parum longiore, leviter arcuato;pallidus, albido pubescens, pronoli lateribus densins albido-pubescenti-vittatis; pedibus pallide testaceis; elytris macula communi centrali angulata nigra .

Longiludo corporis lin. $1 \%$

Corpo assai convesso, quasi ovato-emisferico, di color pallido, rivestito di breve e poco stivata pubeseenza bianchiccia, quasi a splendore seri$\mathrm{co}$, la quale su ciascun lato del protorace è assai stivata, formando una striscia bianchiccia. Antenne testaceo-pallide con la clava più oscura. Rostro un poco piủ lungo del capo e torace insieme, perfettamente cilindrico, assai leggermente archeggiato; di color pallido tendente al testaceo. Torace quasi in forma di cono troncato, assai leggermente punteggiato. Petto medio e posteriore e base del ventre nerastricon pubescenza cenerina. Elitre con le strie longitudinali poco profonde; con una macchiacentrale, posteriormente ritondata, inavanti e ne'lati angolosa. Piedi pallidi: i femori assai rigonfiati, più oscuri nel mezzo; i tarsi di color testaceo pallido: i quattro femori posteriori con delicata spina presso l'estremità.

\section{LEPTURA EXCELSA.}

Tav. 1, fig. 5.

L. nigra, cinereo pubescens, pronoto castaneo villoso; elystris, pedibus anoque rubro-testaceis, illis quinto apicali (et in ㅇ macula externa media) nigris. 
Longit. corpor. lin. $5 \mathrm{x} / \mathrm{z}-6$.

Maschio. Antenne lunghe quanto il corpo intero, nere; l'ultimo articolo bruno-rossastro. Capo nero: il labbro superiore piceo; i palpi rossastri. Protorace d'un sesto più lungo che alla base largo, convesso, ritondato ne'lati e ristretto in avanti; punteggiato, a punti più irregolari e più stivati alla base; rivestito di peluria rilevata folta e tutta eguale bruno-rossastra. Elitre punteggiate come il protorace, con pubescenza assai fina cenerino-fulviccia a splendore serico; rosso-testacee col quinto apicale nero, colore che però esternamente non giunge sul margine, il quale rimane rosso. Petto e due o tre primi anelli addominali neri con pubescenza bianchiccia, gli altri anelli rosso-testacei. Piedi rosso-testacei; i trocanteri neri; l'ultimo articolo de'quattro tarsi anteriori ed i tre ultimi de' due posteriori picei.

Femina. Corpo, e soprattutto l'addome con l'elitre, proporzionalmente più largo e più robusto che nel maschio. Antenne un poco men lunghe del corpo, nere con gli ultimi due articoli rossastri. Elitre rosso-testacee, col quinto apicale ed una cospicua macchia più vicina al margine esterno che alla sutura e posta poco innanzi la metà della lunghezza, nere. Tarsi interamente rosso-testacei. Nel resto simile al maschio.

\section{ODONTURA PULGHRIPENNIS.}

\section{Tav. I, fig. 6 ठ 7 ㅇ․}

0 . viridis, pronoto vittaque dorsali abdominis ferrugineis; illo utrinque flavo limbato; antennis, geniculis tarsisque fulvo-ferrugineis; elytris pronotum linea $1^{\mathrm{x}} / \mathrm{z}^{*}$, linea 1 우 superantibus, intus sinuatis, parum incumbentibus, laete viridibus marginc externo flavo, vitta intus adiacente nigra \$: lamina subgenitali subscaphaeformi, medio carinata, carina ad apicem denticulata, marginibus incrassatis, ante carinae apicem in ungniculum liberum terminatis; cercis contortis, haud decussatis: o ovipositore pronoto parun longiore, postice recurvo denticulato.

Longit. corpor. lin. 11-12.

Maschio. Capo giallo-verdiccio, tendente più o meno al ferruginoso dopo la morte; il vertice fosco con delicata linea media gialla, che fa continuazione con la simile del torace; un'altra simile linea un poco obliqua sta da ciascun lato del vertice stesso dietro la superior parte degli oc- 
chi: il tubercolo del vertice quasi conico, ottuso, finamente scanalato nel dorso, raggiunge appena la metà del primo articolo delle antenne. Protorace nel dorso lungo il doppio della propria larghezza, leggermente allargato verso dietro, troncato in avanti, troncato-ritondato in dietro, quasi piano ne'due terzi anteriori, leggermente ascendente nel terzo posteriore, nel mezzo con una impressione quasi triangolare, da' cui angoli spiccano due linee impresse rivolte in fuori ed in avanti; ferruginoso con una linea media delicata ed altra lunga ciascun lato gialle: i lobi laterali quasi perfettamente verticali, formando angolo quasi retto col piano dorsale, inferiormente troncati ad angoli ritondati, posteriormente sinuosi, verdi con delicato orlo giallo-pallido, e con una linea superiore nera che fiancheggia esternamente la striscia laterale gialla del dorso. Elitre oltrepassanti d' una linea e mezzo il margine posteriore del protorace, poco men larghe che lunghe, con gli angoli posteriori interno ed esterno ritondati, la sinistra un poco dilatata nella parte interna anteriore; accavallate per un terzo appena della loro larghezza; distintamente reticolato-venose, e con una vena marginale rilevata a guisa di carena; verdi tendenti al ferruginoso verso lo specchio; il margine esterno fino alla vena marginale giallo, con una striscia nera che fiancheggia la detta vena marginale. Ali nulle. Addome ottusamente e poco sensibilmente carenato lungo il mezzo del dorso, verde con una striscia dorsale ferruginosa con la carena più pallida; il ventre gialloverdiccio, dopo la morte tendente più o meno al ferruginoso. Piedi verdi; la parte apicale de'femori e de' tarsi fulvo-ferruginosa; gli spigoli inferiori de'femori di dietro gialli. Lamina sopraanale profondamente immersa, a contorno posteriore rilevato, un poco intaccato nel mezzo, superiormente con due lobi rivolti in dietro ed in sopra; ne'due lati, superiormente alla inserzione de'cerci, triloba col lobo interno più lungo. Cerci robusti, lunghi tanto da raggiungere l'estremità della lamina sottogenitale, arcuati e contorti, terminati in punta cornea nera siinile ad unghietta. Lamina sottogenitale a forma di scafa, assai larga alla base, flessuosamente ristretta da questa all' estremità; a margini laterali ingrossati, terminati in punta nera, con una carena dorsale che si prolunga in punta; liscia e spianata nella prima melà, compressa ed a punte rilevate nere nella seconda.

Femina. Elitre più corte che nel maschio, sorpassando soltanto d'una linea il margine posteriore del protorace, e quindi men lunghe che lar- 
ghe, troncato-ritondate posteriormente, accavallate per una estensione anche minore che nel maschio, col reticolo meno elevato. Trivella lunga poco più del protorace, assai robusta, quasi diritla e liscia nella prima metà, indi arcuata e rivolta in sopra. Il colore generale verde sudicio quasi uniforme, col margine esterno dell' elitre distintamente giallo. Nel resto simile al maschio.

Affine alla $0 d$. punctatissima.

\section{PTEROLEPIS NEGLECTA.}

\section{Tav. I, fig. 11 đ, 12 ㅇ.}

Pt. griseo-rufescens, pedibus nigro maculatis; femoribus anticis infra bispinulosis, pedum posticorum plantulis liberis articuli primi tarsi longitudine; elytris o pronoti marginem posticum ${ }^{5} \%$ lin. superantibus, incumbentibus, cincreis venis primariis nigris; + remotis pronotum vix superantibus, cinereis : o lamina supraanali utrinque oblique truncato-emarginata, postice triangulariter emarginata et in medio profundius excisa; cercis intus basi mucronatis; lamina subgenitali parum profunde emarginata; 9 ovipositore abdomine longiore, recto, basi subinflato.

Longit. corpor. lin. 7-8.

Maschio. Colore generale del corpo grigio-rossiccio con due striscie bruno-rossicce (una da ciascun lato) le quali cominciando da' lati del vertice continuansi dietro gli occhi sui lati del protorace, e con una striscia più larga dell' addome interrotta da una serie di macchie più pallide: due punti neri sulla fronte: ventre giallo. Prominenza del vertice anteriormente ritondata, a margini laterali acuti, neri. Protorace superiormente piano-convesso, con le consuete linee trasversali impresse: posteriormente ritondato; la carena media annunciata nella metà posteriore: i lobi laterali troncati obbliquamente, con gli angoli ritondati, eil seno posteriore poco profondo. Elitre oltrepassanti di men d'una linea il posterior margine del protorace, poco accavallate; col reticolo ben rilevato: grigio-cenerine con le vene primarie nere. Addome con delicata e poco distinta carena lungo il suo mezzo. Femori anteriori con due piccole spine nere verso il mezzo del margine inferiore, ed un anello incompleto anche nero presso l'estremità; i medì del tutto inermi, con una serie di macchie trasversali lungo la faccia interna e l'anello incom- 
pleto presso l'estremità neri. Le quattro tibie anteriori con una macchia nera alla base di ciascuna spina: ànche anteriori con valida spina arcuata. Piedi posteriori assai lunghi; i femori rigonfiati nella prima metà, assai sottili nell'altra, con tre a sette minutissime spine sullo spigolo inferiore interno della metà basilare: le tibie con due serie di macchioline nere lungo la faccia inferiore corrispondenti alla base delle spine. Lamina sopraanale posteriormente scissa profondamente nel mezzo, la scissura terminata in una fossetta quasi rotonda: $\mathrm{i}$ due lobi risultanti dalla scissura troncati obbliquamente e ad angolo ottuso rientrante dalla parte esterna. Cerci robusti, armati di valido pungolo sul lato interno della base. Lamina sottogenitale più lunga che larga, ristretta d'avanti in dietro, triangolarmente smarginata alla estremitì, coi margini laterali ingrossati, e con delicata carena longitudinale nel mezzo; gli stiletti lunghi quanto l'ampiezza della lamina all' estremità.

Femina. Elitre più corte e più anguste che nel maschio, a forma di squame, oltrepassanti appena il margine posteriore del protorace, e distanti tra loro, col reticolo poco pronunziato : di color cenerino uniforme. Trivella lunga quanto l'addome e metà del protorace, diritta, rigonfiata alla base. Cerci più corti, più robusti, privi di pungolo.

Variazioni. Il colore del corpo è in taluni individui tutto uniformemente grigio-rossiccio coi soli piedi macchiati di nero. I femori posteriori in qualcuno presentano delle spine sopra ambedue gli spigoli inferiori.

\section{THAMNOTRIZON MAGNIFICUM.}

\section{Tav. III, fig. 1.}

T. saturate viride (in sicco hutescens), verticis macula utrinque supra oculos, frontis punctis quatuor, proniti vitta utrinque laterali, striga femorum posticorum abdominisque segnento ultimo dorsali postice inflexo emarginatoque nigris; pronoti vittis nigris late albo limbatis; ventre saturate Mavo; elytris brunneo-succineis tarsis tibiarumque apice rufescentibus; lamina supraanali postice inflexa, in medio profunde impressa, excisa ac mucronibus duobus terminata: lamina subgenitali postice profunde lineari-excisa ; cercis longiusculis conico-cylindraceis, muticis. 8 .

Longit. corpor. lin. 9-10. 
Maschio. Corpo robusto, liscio, d' un bel colore verde pistacchio splendente, che nel secco cangiasi più o meno in giallo sudicio. Capo con una macchia da ciascun lato del vertice superiormente agli occhi; due trattolini verticali nel mezzo della fronte, due punti laterali sulla stessit e due altri nella posteriore parte delle guance di color nero. Prominenza del vertice larga, a margini laterali acuti quasi carenati. Antenne lunghe il doppio del corpo, col primo articolo dilatato angolarmente dal lato interno. Protorace grande, posteriormente prolungato e largamente ritondato, senza vestigio di carena dorsale; i lobi laterali inferiormente angolosi, ad angolo quasi retto; seno omerale poco profondo: superficie liscia, con pochi punti impressi sparsi, ed una impressione poco profonda verso la metà del dorso, ed anteriormente a questa una linea a forma di lira: il colore verde pistacchio uniforme, con una striscia nera da ciascun lato del dorso, la quale nella metà anteriore è divisa in piccole macchie. Elitre superanti di poco più di una linea il margine posteriore del protorace, molto convesse, accavallate, con la porzione dietro lo specchio finamente reticolata; di color d'ambra oscuro. Dorso dell'addome ottusamente carenato, verde: l'ultimo anello nero, solcato nel mezzo, posteriormente inclinato in giù e largamente smarginato. Ventre giallo. Lanina sottogenitale grande, carenata ne' margini laterali, posteriormente troncata, con una rima lineare che si protrae per circa la metà della lunghezza : gialla, coi margini laterali neri. Stiletti lunghi la metà della lamina. Cerci lunghi il doppio degli stiletti, conicocilindracei, pelacciuti. Piedi verdicci; i quattro femori anteriori punteggiati di nero; i posteriori del tutto inermi, con due striscie nere, una esterna, nella metà anteriore interrotta da tratti verticali giallicci; un'altra interna più piccola. Le quattro tibie anteriori fornite delle spine medesime che si osservano nelle altre specie congeneri: le spine delle tibie posteriori nere alla estremità. Tarsi ed estremità delle tibie posteriori rossicci: lobi del primo articolo de'tarsi posteriori lunghi poco più della metà dell' articolo medesimo.

La femmina non ci è ancora nota. 


\title{
DECTICUS (PLATYGLEIS) NIGROSIGNATUS.
}

\author{
Tav. III, fig. $3 \delta^{*}, 4$ ㅇ.
}

D. griseo-testaccus, capitis vitta utrinque supra oculos, alteraque media obsoletiore brunneis, omnibus lineam pallidam includentibus; pronoti lobis pallido marginatis, abdomine in medio et utrinque nigro punctato-vittato; elytris pronoto parum longioribus $\sigma^{A}$, parum brevioribus o, cinereis, maculis duabus atris: ơlamina supraanali postice bicuspidata, cercis intus mucronatis; lamina subgenitali in medio acute, lateribus obtuse carinata, postice triangulariter cmarginata: 9 cercis minutis, ovipositore abdomine exiccato dimidio longiore.

Longit. corpor. lin. 8-9.

Maschio. Colore generale del corpo grigio-testaceo. Vertice con una striscia media formata dapunti foschi stivati, divisa per mezzo da delicata linea pallida: altra striscia bruno-marrone da cadaun lato soprastante agli occhi, esternamente fiancheggiata da linea gialla: dello stesso colore bruno-marrone è lo spazio dietro gli occhi: il margine infero-posteriore dell'orbita pallido: fronte con due striscie verticali che scendono dalla base delle antenne, formate da punti foschi stivati. Protorace nella porzione che precede la prima linea trasversale impressa alquanto convesso con delicata carena media ben rilevata nella metà posteriore, ed appena marcata nell' anteriore: le carene laterali divergenti in dietro; il margine posteriore ritondato; i lobi laterali troncati obbliquamente in sotto, con l'angolo inferiore ritondato, marmorati di fosco col contorno inferiore e posteriore giallo pallido. Elitre nella porzione scoperta lunghe un poco meno del protorace, quindi assai più corte dell'addome, anche disseccato; cenerine, la vena media interna ben marcata gialliccia, e due macchie di un nero intenso, l' una allungata alla base fiancheggiante dal lato interno la vena interno-mediana; l'altra posteriore fiancheggiante il lato esterno della vena medesima, l'una e l'altra interrolte da venette pallide. Addome con due serie di punti neri che fiancheggiano la linea mediana, ed una serie di macchioline anche nere, irregolari, lungo il mezzo di ciascuno de'lati. Lamina sopraanale profondamente impressa nel mezzo; $i$ lati prolungati in dietro in due lobi quasi triangolari ed acuti, carenati nel dorso. I cerci robusti, po- 
steriormente incrociati, internamente presso la base forniti di valido pungolo. Lamina sottogenitale posteriormente smarginata ad angolo ottuso, nella faccia inferiore con delicata ed acuta carena lungo il mezzo e coi lati elevati in un cordone terminato alla inserzione degli stiletti. Piedi del colore del corpo: i femori posteriori inermi con una striscia formata da macchie nere lungo la faccia interna e la esterna della porzione ingrossata. Tibie anteriori con tre spine nella faccia anteriore. Tutte le spine delle tibie pallide alla base, nere alla punta.

Femina. Elitre un poco più piccole che nel maschio e similmente colorite. Trivella lunga i due terzi dell' addome disseccato, diritta alla base, indi bruscamente curvata in sopra e falciforme: liscia, di color nero-marrone. Cerci robusti, privi di pungolo. Lamina sottogenitale posteriormente biloba.

\section{MUCROPALPUS MERIDIONALIS.}

\section{Tav. III, Fig. 6.}

M. fulvus, thorace obscuriore, abdomine fusco, alis anticis fulvo-hyalinis venis pilosis dilutiore saturatioreque variegatis, marginalibus fusco variegatis serie media venularum transversarum quinque haud interrupta, scalari; serie apicali venularum transversalium sex bis interrupta; posticis hutescenti-hyalinis, irideis, venis pallide fulvis, apice fuscis.

Long. corp. lin. $1 \frac{1}{2}$; exp. alar. lin. $5 \frac{1}{2}$.

Antenne filiformi, finamente pelacciute, fulve. Capo fulvo-rossiccio con pochi peli sparsi sul vertice. Palpi del colore del capo. Torace di color fulvo più oscuro cangiante in cenerino, con peli setolosi ineguali e disordinati. 11 dorso del protorace con due impressioni trasversali, le quali su' contorni marginali si terminano in due piccoli intacchi. Ali anteriori fulve, trasparenti, le vene di color fulvo chiaro che alterna con fulvo più carico, le marginali variegate di fosco, tutte ornate di peli rilevati del colore stesso fulvo: di venette trasversali ve ne ha tre serie, quella prossima alla base composta di due sole venette, separate da uno intervallo; la media composta di cinque venette, l' una un poco più fuori dell'altra in guisa da costituire una scala, non rimanendo alcuno intervallo vuoto, a cominciare dalla prima e più esterna vena longitudinale, la quale non è unita alla sottocostale per alcuna venetta trasver- 
sale : la serie apicale è costituita da cinque a sei venette trasversali, tutte in livello diverso, ed interrotte dopo la prima ed innanzi l'ultima: vene dello spazio costale nella prima metà bifide o trifide, nell'altra semplici, il margine posteriore privo di serie di venette trasversali. Le ali posteriori sono più trasparenti, iridate, le vene fulvo-pallide, fosche solo nella porzione apicale dell'ala: una cellola discoidale innanzi l' estremità dell' ala. Addome bruno. Piedi fulvo-pallidi.

Osservazioni. La specie cui più si avvicina questa or descritta è il Mucr. irroratus, dal quale però, indipendentemente dal colorito, distinguesi assai nettamente per una diversa disposizione delle venette trasversali della serie media delle ali anteriori, siccome è facile rilevare dal confronto delle immagini rispettive.

\section{Genere NeVrorthus, nob.}

(Famiglia degli Emerobiidei)

Palpi maxillares articulo ullimo praecedentibus singulis longiore, tereti, apice acuminato subarticulato. Alae anticae oblongo-ovatae, venis longitudinalibus subcostali parallelis.

Sebbene per la struttura de' palpi mascellari questo Emerobiideo simigliasse perfettamente a' Mucropalpi, nulladimeno la fabbrica delle ali e per essa l' abito generale dell' insetto ne è tanto diversa, da annunziare da sè un genere distinto, che nulla ha di comune coi Mucropalpi sotto il rapporto delle ali. Quì nelle ali anteriori, come nelle posteriori, le vene longitudinali in luogo di partire dalla seconda vena sottocostale e scendere obbliquamente nel campo dell' ala, partono dalla base dell' ala al numero di quattro, delle quali la prima successivamente bifurcandosi ne produce altre quattro, la seconda si bifurca una volta, le altre due restano semplici, per ramificarsi come le altre presso il margine; le vene longitudinali scorrono per tal modo quasi parallele alla sottocostale, cui le anteriori sono congiunte da qualche venetta trasversale, siccome altre venette trasversali uniscono le diverse vene longitudinali fra loro. Lc ali posteriori, ehe, come abbiam detto, presentano presso a poco la stessa disposizione di vene che le anteriori, partecipa no più della organizzazione de' Mucropalpi. 


\section{NEVRORTHUS IRIDIPENNIS}

Tav. III, Fig. 7.

N. sordide lutescens, pronoto obscuriore; mesonoto abdomineque fusco maculatis; pedibus pallidis; alis hyalinis irideis, venis fuscis, ciliatis, transversalibus triplice serie, media irregulari interrupta, apicali integra, scalari.

Long. corp. lin. $2 \%$ : exp. alar. lin. $6 \mathrm{x} / 2$.

Capo di color giallo fulviccio sporco, liscio, splendente: fronte convessa con delicato solco verticale, che superiormente diviene più profondo, ed inferiormente si divide in due branche, le quali si terminano sopra un'altra linea trasversale impressa che sta tra il mezzo degli occhi: il fondo di queste impressioni è di color più fosco. Occhi neri. Dorso del protorace trasversale, anteriormente ritondato ricoprendo l'oceipite ed il vertice del eapo, posteriormente troneato per diritto ; liscio sparso di setole elevate, e con due solchi trasversali i quali a' due estremi si arrestano prima de' margini, di color bruno gialliceio sporco, col fondo de' solchi più oscuro. Il dorso del mesotorace à il lobo anteriore con delicato solco medio, i lobi laterali grossi e rilevati; l' uno e gli altri di color gialla-sucido con una grande macchia su ciascuno de' lobi laterali ed un' altra più piccola sul lobo medio anteriore, brune. Addome giallo-fulviccio macchiato di bruno. Ali perfettamente incolori, iridate, le vene in parte fosche ed in parte giallo-sucide: la serie media di venette trasversali, composta di sei venette, è interrotta per un solo spazio dopo la prima: le tre anteriori stanno più esterne, le tre posteriori più interne; la serie apicale, posta poco oltre i tre quarti della lunghezza, ̀̀ composta di sei venette disposte a gradini e senza alcuna interruzione. Le venette del campo costale tutte semplici, nessuna ramificata, meno quelle prossime all' estremità nel luogo corrispondente al carpo, le quali sono più stivate e punteggiate. Le ali posteriori offrono presso a poco la disposizione stessa di vene che le anteriori; solo le venette trasversali della serie media sono meno numerose. Piedi pallidi, finamente pelacciuti.

Osservazioni. Il Rambur (I) nella nota apposta al suo Mucropalpus (1) Suites à Buffon, Nevropt. p. 422. 
fallax annunzia allontanarsi dalle altre per la organizzazione delle ali : però eiò che dice nella descrizione non è sufficiente a farci comprendere se si trattasse di cosa analoga a quella da noi descritta. Ad ogni modo, se così fosse, il $M$. fallax sarcbbe una seconda specie del genere da noi istituito, poichè specificamente è evidente esser la nostra diversa da quella del Rambur.

\section{Genere ISOSCELIPTERON, Nob.}

Caput ocellis destitulum. Palpi maxillares articulo ultimo praccedentibus singulis longiore, tereti, apice acuminato, subarticulato. Pronotum longius quam latum, subcylindraceum. Alae anticae et posticae acqualcs, trianguli isoscelis fere figuram referentes, venis longitudinalibus numerosis, transversis serie unica discoidali. Unguiculi tarsorum simplices.

Osscrvazioni. Anche questo Emerobiideo per la organizzazione de'palpi mascellari somiglia ai Mucropalpus. Però la forma delle ali, la disposizione delle loro vene longitudinali, le trasversali in una sola serie, il prolorace allungato, gli danno tale un abito singolare, da non permettere che resti con i Mucropalpi confuso, ed autorizzano invece ad istituire per esso un genere distinto. Le ali offrono quasi la figura di un triangolo isoscele, di cui la base assai larga sarebbe costituita dal margine anteriore (considerando le ali spiegate), i due lati dal margine posteriore-interno e dal posteriore-esterno, che formano un angolo ottuso ritondato. Le vene longitudinali sono in gran numero; nella parte più ampia dell'ala se ne possono contare oltre a venti; di esse, due prendono origine dalla sottocostale, di cui la seconda con le successive biforcazioni dà origine a buona parte delle vene del campo dell' ala; le altre superiori avendo origine alcune dalla prima delle due indicate, le altre da tre altre vene che partono direttamente dalla base dell'ala. Tutte le vene longitudinali presso l' estremità sono semplici, e solo sul contorno sono bifide : esse sono poi riunite tra loro da venette trasversali, delle quali ve ne ha solo una serie oltre la metà dell' ala, e qualcuna presso la base. 


\title{
ISOSCELIPTERON FULVUM.
}

\author{
Tav. III, fig. 5 .
}

I. pallide fulvum, pronoto transverse bisulcato, vinaceo, vitta media lutea; alarum venis ciliatis, pallidis, rufcscenti articulatis; alis posticis in margine anali nigro punctatis anticis linca vcnularum trasversalium fuscescente; pcdibus pallidis rufo-punctatis.

Long. eorp. lin. $3 \%$, cum alis flex is lin. $6 \%$.

Maschio. Capo corto, giallo-fulvo, eon peli setolosi dello stesso eore a splendore dorato; la fronte superiormente alla inserzione delle antenne con due piccole impressioni che si toccano per la base, e superiormente angolose. Parti boceali del colore del eapo. Occhi bruno-cenerini. Antenne poeo men lunghe del corpo, leggermente assottigliate verso l' estremità, del colore del capo, finamente pelacciute. Protorace di un quinto più lungo che largo, leggermente allargato d'avanti in dietro, con due solchi trasversali, assai delicati e superfieiali sul dorso, più profondi ne'lati, non toccanti i margini: il dorso giallo, i lati di color fegatoso, tutto sparso di peli setolosi simili a quelli del eapo. Il mesotoraee ed il metatorace giallo-fulvieei, parimente setolosi. Addome del colore stesso del mesotorace. La valvola anale dorsale fornita di due lunghe appendiei filiformi e pelacciute. Piedi pallidi, punteggiati di rosso, con peluria morbida e lunga del colore stesso de'piedi. Ali fulvicee, trasparenti : le vene pallide macchiate di rossiccio: le trasversali al numero di otto formanti una serie obbliqua non interfotta a piceoli gradini, e fianeheggiate di colore più oseuro, formano una striscia fulvo-oscura: il margine è macehiato parimente di fulvo più earieo; i eigli son fulvo-dorati, sui margini e sulle venette trasversali alternanti con cigli neri. Lo ali posteriori stando ricoperte dalle anteriori nell'unico individuo non ci perınettono vedere con chiarezza la disposizione delle vene: però possiamo rieonoscere che le venette trasversali del diseo sono meno numerose e non formano serie regolare; e che il margine anale è macchiato di nero. 


\title{
ICHNEUMON LAETEPICTUS.
}

\author{
Tav. II, fig. 10.
}

I. nigcr, antennarum annulo lato, facie oreque (vitta media brunnea), orbitis, pronoti margine omni (postico interrupto), mesonoti lineolis duabus, scutello, postscutello, metathoracis parte postica, suturis vittaque pleurarum, abdominisque segmentis omnibus margine postico flavis; horum secundo et tertio sutura baseos carnea; pedilus fulvis, coxis et trochante. ribus anterioribus flavis, tarsis postieis fuscis; alis hyalinis, vonis carpoque testaceis.

Long. corp. lin. 4.

Femina. Capo nero : faccia e clipeo gialli con una striscia media bruna; il clipeo con un punto impresso da ciascun lato della base, fosco: le orbite interamente gialle. Mandibole gialle con l' estremità picea. Palpi gialli. Antenne più lunghe del corpo, nere con largo anello bianchiccio che comprende gli articoli 10 a 14 inclusivi; il primo articolo inferiormente giallo. Torace nero: il protorace con tutto il contorno giallo, interrotto soltanto nel mezzo del margine posteriore : il dorso del mesotorace con due linee gialle ristrette da dietro in avanti: scutello, dietroscutello e parte posteriore del metatorace gialli, quest' ultimo con una macchia bruna rettangolare nel mezzo della faccia declive : pleure con le suture ed una larga striscia longitudinale sopra te medie, gialle. Addome lungo appena quanlo il capo e torace insieme; il primo anello finamente punteggiato, con un solco mediano, ed un altro assai fino da ciascun lato della parte posteriore, nero con angusto margine posteriore giallo; it secondo ed il terzo col margine basilare di color carnicino, ed il margine posteriore giallo, i rimanenti col solo margine posteriore giallo. Piedi robusti, i femori rigonfiati : fulvi, le ànche e i trocanteri de' quattro anteriori gialli, i tarsi de'due posteriori bruni. Ali trasparenti, iridate, te vene ed il carpo testaceo-pallidi. 


\title{
ICHNEUNION CALABRARIUS.
}

\author{
Tav. II, fig. 9.
}

I. niger, antennarum scapo infra, facie et clypeo (maculam nigram includentibus), ore, orbitis totis, pronoti margine postico, tegulis alarnm, mesonoti lineis quatuor posticis abbreviatis, scutelli margine laterali et postico, lineola transversa postseutelli, lineola infra alas alteraque in mesopleuris, albidis; abdomine rufo-castaneo, segmento primo nigro margine postico albido; pedibus rufo-castaneis, coxis et trochanteribus nigris, illis albido pictis; tarsis posticis fuscis; alis pure hyalinis, venis carpoque nigris. $\delta^{*}$.

Long. corp. lin. $5 \% \frac{2}{2}$.

Maschio. Antenne lunghe più della metà del corpo, mediocremente robuste : nel dorso nere, inferiormente il primo articolo bianchiccio, i rimanenti bruno-ferruginosi. Capo nero; la faccia, il clipeo, le parti boccali, il contorno intero delle orbite bianco-giallicci : la faccia ed il clipeo con una macchia nera nel mezzo. Torace nero; il margine posteriore tutto intero del protorace, quattro linee nella posterior parte del dorso del mesotorace, due medie parallele e due laterali obblique contigue agli angoli dello scutello, i margini laterali e posteriori dello scutello, una linea trasversale sul dietro-scutello, una lineetta sotto le ali, altre due sulle pleure medie, l'una verticale l' altra longitudinale, bianchicce. Addome più lungo del capo e torace insieme; poco più angusto del torace : il primo anello col picciuolo più lungo della parte posteriore, la quale à gli angoli anteriori ritondati; sottilmente rugoso, con due linee elevate parallele su tutta la lunghezza dell' anello: nero col margine posteriore bianco-gialliccio : i rimanenti anelli finissimamente e stivatamente puntinati, tutti di color rosso-castagno uniforme. Piedi di quest' ultimo colore: le ànche de' quattro di avanti biancogiallicce, posteriormente macchiate di nero: quelle de' due piedi di dietro nere, macchiate di bianco-gialliccio: trocanteri neri, inferiormente più o meno tendenti al castagnino; i tarsi posteriori oscuri. Ali incolori, trasparenti: le vene ed il carpo neri : la seconda cellola cubitale (areola) pentagonale.

Osservazioni. Sebbene le maggiori affinità di questo Ioneumone fosse- 
ro con le specie della nona sezione del Gravenorst, pure per la colorazione del primo anello addominale disconviene da tulte; parimente che non quadra con alcuna di esse per la dipintura del torace.

\section{TRYPHON FLAVITARSUS.}

Tav. II, fig. 11 .

T. niger, macula faciali, orbitis supra interruptis, pronoti margine postico toto, punctis duobus callosis ad scutelli angulos baseos, altero transverso postscutelli, tegulis alarum, puncto in mesopleuris, maculis duabus posticis minutis metanoti, pectore medio segmentorumque omnium abdominalium margine postico saturate flavis ; pedibus fulvo-rufescentibus, coxis et trochanteribus nigris, infra pallido flavis, tibiis posticis ad apicem fuscis, tarsis posticis pallide flavis apice fuscis; alis hyalinis venis carpoque pallide testaceis; areola mulla. 8 .

Long. corp. lin. $3{ }^{5}$.

Antenne un poco più corte del corpo, nere con le articolazioni ferruginose. Capo nero: una macchia quasi rotonda nel mezzo della faccia, contigua al clipeo; questo, le orbite (interrotte solo nella parte superiore), le mandibole ed i palpi, gialli. Torace abbastanza convesso, finissimamente coriaceo, poco splendente: il dorso del metatorace punteggiatorugoso, mediocremente splendente: nero, il margine posteriore del protorace, due punti rilevati callosi obbliqui presso gli angoli basilari dello scutello, un altro simile trasversale sul dietroscutello, due piccole macchie nella posterior parte del metatorace, un punto sulle pleure medie, ed il mezzo del pelto, gialli. Addome oblungo, finissimamente punteggiato-coriaceo: il primo anello allungato, coi tubercoli laterali posti nel mezzo della lunghezza: nero, tutti gli anelli con delicato margine posteriore giallo, nel secondo terzo e quarto un poco allargato nei due estremi. Piedi: i quattro anteriori delicati, i due posteriori abbastanza lunghi e gracili anch' essi ; tutti fulvo-rossicci : ne' due d'avanti le ànche nella faccia anteriore e i trocanteri gialli; ne' nedii le ànche nere posteriormente, gialle in avanti, i trocanteri gialli con piccola macchia nera nella faccia posteriore del primo articolo ; ne' due posteriori le ànche ed il primo articolo de' trocanteri neri con una striscia gialla lungo la faccia inferiore, il secondo articolo de' trocanteri giallo, le tibie 
bruno-nerastre, rossicce verso la base, i tarsi bruni, coi due primi articoli giallo-pallidi. Ali trasparenti, perfettamente incolori; le vene ed il carpo testaceo-pallidi.

\title{
TRYPHON NIGRICARPUS.
}

\author{
Tav. II, fig. 12.
}

T. capite thorace latiore, transverse quadrato, abdominis segmento primo dorsali hand canaliculato: niger, antennis ferrugineis basi nigris; facie oreque flavis, illa linea media margineque infero nigris; abdomine rufo-testaceo segmento primo nigro; pedibus rufo-stramineis, coxis (anticis antice flavescentibus), trochanteribus omnibus femoribusque posticis nigris; tibiis posticis postice fusco-rufescentibus; alis hyalinis venis carpoque brunneis, hoc summa basi pallida; radice albida, tegulis piceis. 9 .

Long. corp. lin. $3 \%$.

Femina. Capo più largo del torace, trasversalmente quadrato, nero splendente; la faccia gialla con una linea media verticale e la sutura inferiore nere; il clipeo giallo con un punto nero nel mezzo della base; le mandibole gialle con la punta nera; i palpi bruno-giallicci. Antenne gracili, lunghe poco meno dell' intero corpo, fulvo-ferruginose; i due primi articoli per intero, $i$ tre seguenti nel solo dorso, neri. Torace nero, splendente. Addome poco più lungo del capo e torace insieme; il primo anello leggermente e gradatamente allargato d' avanti in dietro, non solcato nel dorso, coi tubercoli laterali assai piccoli, poco sporgenti, posti innanzi la metà della lunghezza; sparsamente e finamente puntinato e con qualche ruga longitudinale, nero splendente : il resto dell' addome rosso-testaceo. Piedi: i quattro anteriori rossicci, con le ànche $\mathrm{e} i$ trocanteri neri; le ànche anteriori giallicce nella faccia anteriore: i due posteriori bruno-neri, con i tarsi e la faccia anteriore delle tibie bruno-rossicci. Ali incolori, iridate; le vene oscure; il carpo bruno con l'angolo interno pallido; la radice bianco-gialliccia, le tegole picee : la cellola cubitale irregolarmente triangolare.

Osservazioni. Affine al T. cephalotes, dal quale differisce pel colore del capo, per la dipintura della faccia, pel primo anello addominale non scanalato nel dorso e coi tubercoli situati innanzl la metà. 


\title{
CHALCIS OBTUSEDENTATA
}

\author{
Tav. IV , fig. 5 .
}

C. niger, capite thoraceque crasse punctatis, subnitidis; abdomine laevi nitidissimo; scutello convexo, postice subintegro; femoribus posticis oblongo-ovatis, infra dentibus duobus obtusis, altero a basi altero ab apice acquc distantibus, margine interposito integerrimo; tarsis rufescentibus; alis hyalinis, vena subcostali picea.

Long. corp. lin. $2 \%$.

Femina. Corpo uniformemente di color nero intenso, poco splendente nel capo e torace, splendentissimo nell' addome, con scarsa e breve pubescenza cenerina: i piedi parimente neri coi soli tarsi rosso-picei. Capo col vertice brevissimo, trasversale ; la fronte e la faccia con l'epistoma formante un solo piano inclinato d' avanti in dietro e da sopra in sotto, prolungato e gradatamente ristretto in giù, con profonda scanalatura in tutta la sua lunghezza; la superficie di tutto il capo grossamente punteggiata, col solo fondo della scanalatura liscio. Antenne inserite presso il margine basilare dell' epistoma; il primo articolo o scapo lungo tanto da raggiungere il piano del vertice, diritto, ingrossato e quasi fusiforme alla base, delicato nel resto; il flagello lungo poco meno che il doppio dello scapo, quasi filiforme. Torace tutto grossamente punteggiato, a punti staccati, non confluenti. Scutello grande, convesso, a punti più grossi e meno stivati; il contorno posteriore finamente marginato, leggermente intaccato nel mezzo. Il dorso del metatorace con due carene longitudinali medie convergenti in dietro, e due altre laterali; gli spazii interposti finamente striati per traverso. Addome levigatissimo. Piedi robusti : i quattro femori anteriori un poco rigonfiati ; i due posteriori ovali, sparsamente puntinati, nel margine inferiore con due angoli sporgenti in forma di ottusi denti, distanti egualmente l' uno dalla base, l'altro dalla estremità ; il margine interposto compresso, tagliente, intero, e guardato con forte ingrandimento finamente striato per traverso. Tibie posteriori robuste, mediocremente arcuate. Ali incolori, tinte appena di fulvo presso i punti stigmatici: la vena sottocostale picea. 


\title{
ANDRENA CALABRA.
}

\author{
Tav. II, fig. 1 .
}

A. nigra, capite thoraceque cincreo-fulvescenti pilosis, abdominis segmentis dorsalibus postice dense cinereo of-cinereo-fulvescente o piloso-fasciatis; antennis ferrugineis; pedibus piceis, o tibiis tarsisque, 우 tarsis apice fulvoferrugineis; alis hyalinis apice fumatis (in disco fuscescentibus 우), venis piceis: $\sigma^{*}$ genis clypeoque albidis, hoc punctis duobus nigris, ㅇ clypeo ferrugineo.

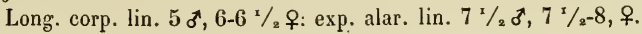

Variat: metathorace - metathorace, scutello et abdominis segmento secundo-genis, occipite medio, thorace toto abdominisque segmentis primo et secundo, rarius etiam tertii et quarti basi, ferrugineis.

Maschio. Antenne ferruginose. Capo nero con peluria cenerina, più folta sulla fronte; le guance ed il clipeo bianco-giallicci, questo con due punti neri; la parte media del margine inferiore picea un poco avanzata, tagliata a traverso per dritto e ad angolo quasi retto ai due estremi. Talvolta vi ha una macchia ferruginosa tra la base delle antenne poco al disotto il livello della loro base, contigua al contorno superiore del clipeo. Torace nero, rivestito di densa peluria cenerino-fulva. Addome nero, leggermente bronzato, con breve peluria cenerina poco folta: il margine posteriore di ciascun anello dorsale scolorito nel fondo, rivestito d'una fascia di peli coricati stivati bianchicci. Ventre piceo-ferruginoso, con scarsa peluria cenerina. Piedi ferruginosi con peluria cenerina: i femori bruno-nerastri; le tibie posteriori macchiate di nero. Ali trasparenti, ombrate all' estremità; le vene piceo-testacee, la costa ed il carpo più oscuri.

Femina. Antenne ferruginose. Capo nero; il clipeo ferruginoso; tutta la faccia ed il clipeo rivestiti di peli folti cenerino-fulvi: le orbite posteriori con peluria corta e folta cenerina; il resto del capo quasi nudo. Torace nero con peluria fulva, più folta sulle spalle, sul contorno del mesotorace, dello scutello e del dietro-scutello; fianchi e petto con peluria meno folta, cenerina. Addome nel dorso nero con brevissimo vello rossastro visibile a certa luce; il primo anello con peli più lunghi e rilevati : i quattro primi anelli con una fascia sul margine posteriore co- 
stituita da folta peluria coricata cenerino-fulva; il quinto con peluria lunga e rilevata ferruginosa. Ventre ferruginoso, nerastro verso l' ano; il margine posteriore degli anelli con peluria cenerino-fulva poco stivata. Piedi neri con peluria cenerina; i tarsi con peli fulvi; i loro ultimi articoli fulvo-ferruginosi.

Variazioni. Il maschio è coslante nel suo colorito, se ne eccettui il nero del dorso dell'addome che talvolta in alcuni degli anelli tende più o meno al piceo. La femina per contrario offre delle singolari varieta, di cui le più lontane dal tipo prendono un aspetto tanto singolare, che si giudicherebbero specie diversa se non si avessero sott' ocehio i passagggi graduali. Il color nero viene sostituito da un bel color fulvo-rossiccio, il quale invade successivamente più parti del corpo con l'ordine che segue: metatorace, scutello, secondo anello addominale, guance, parte media dell'occipite, torace per intero, primo anello dell' addome, base del terzo e quarto anello del medesimo. Quest'ultima varietà, nella quale rimane soltanto di nero una porzione del eapo e gli ultimi anelli addominali è appunto quella che a primo aspetto si prenderebbe per specie distinta.

Osservazioni. La specie già nota cui sembra maggiormente essere affine la presente è l'And. marginata; soprattutto vi si avvicina il maschio a causa delle guance e clipeo giallicei, il secondo con due punti neri. Nulladimeno l' esatta ed immediata comparazione ne fa rilevare le differenze in ciascuno de' due sessi.

\section{ANTHIDIUM MOSAICUNI.}

Tav. II, fig. 6 ๙

A. nigrum, capite, thorace abdominisque lateribus flavo-rufescenti pilosis; facie infra antennas, clypeo, fascia occipitali interrupta, mesonoto antice linea utrinque angulata, scutelli maculis quatuor marginalibus, tegulis alarum, abdominisque singuli segmenti maculis quatuor subquadratis, geniculis, tibiis ex parte tarsisque flavis; alis fumato-hyalinis; valvula anali dorsali postice tridentata, dente medio acnto, lateralibus latis oblique truncatis. 8 .

Long. corp. lin. 5, exp. alar. lin $7 \times / 2$.

Maschio. Antenne nere; il primo articolo con barba di peli giallo-ful- 
vicci dall'uno e l'altro lato. Il capo nero con peluria giallo-fulviccia; la faccia dal livello della inserzione delle antenne in sotlo, il clipeo, ed una fascia occipitale interrotta nel mezzo giallo-ferruginosi. Mlandibole gialle con l' estremità nera. Torace nero, rivestito di peluria simile a quello del capo, scarsa sul dorso, più lunga e folta su'fianchi; il mesotorace nella parte anteriore con una linea giallo-ferruginosa piegata ad angolo poco meno che retto, di cui un lato occupa il margine anteriore, l'altro il margine laterale contiguo alle tegole. Scutello con quattro macchie dello stesso colore sul margine posteriore, le esterne più piccole. Addome nero, superiormente quasi nudo, finamente punteggiato; ciascun anello con quattro macchie gialle quasi quadrate disposte in serie trasversale, le esterne più grandi e toccanti il margine laterali; nel quarto, quinto e sesto anello ciascuna macchia media unita alla esterna del rispettivo lato per un profilo posteriore anche giallo. Il sesto anello ha un dente ben pronunziato in ciascun angolo latero-posteriore. L'uitimo o valvola anale dorsale offre una carena media la quale sul margine posteriore si termina in un dente acuto, lateralmente al quale ne stanno due altri (uno per parte) larghi, spianati, obbliquamente troncati, non superanti il dente medio, gialli. I lati dell'addome ed il ventre guarniti di peluria giallo-fulviccia. Piedi neri con peluria giallofulviccia; l'estremità de'femori, buona parte delle tibie e i tarsi gialli. Ali leggermente ombrate, soprattutto nella metà apicale; le vene nere, la radice o le tegole giallo-ferruginose.

\section{MEGACHILE PUGILLATORIA.}

\section{Tav. II, fig. $4 \delta^{\star}, 5$ ㅇ.}

M. nigra, cinereo pilosa, genis clypeoque pilis longioribus favescentibus; abdominis segmentis secundo tertio et quarto postice pilis stratis albis fimbriatis; alis hyalinis venis piceis, tegulis brunneo-flavescentibus; o valvula anali dorsali dense albo villosa, postice bidentata, marginibus lateralibus subtilissime denticulatis, femoribus anticis infra basim dente valido armatis; \& femoribus anticis muticis, valvula anali dorsali maculis duabus albis, ventre albo piloso.

Long. corp. $0^{7} 3^{x} / 2$, $94 \%$ : exp. alar. lin. $6 \%$.

Maschio. Antenne lunghe tanto da raggiungere il margine anteriore 
dello scutello, filiformi, l'ultimo articolo un poco compresso: brunonerastre. Capo nero rivestito di peluria cenerino-gialliccia: la faccia ed il clipeo coperti di peli più lunghi e più folti coricati bianchicci a splendore serico; la base del clipeo innoltre con una zona di peli rilevati bianco-giallicci, la quale ne' lati si estende fin sopra le guance. Torace rivestito di peli non molto stivati bianco-giallicci sul dorso, cenerini sui fianchi e sul petto. Addome più corto del capo e torace insieme, ristretto d'avanti in dietro; nero, rivestito di peluria simile a quella del dorso del torace, più lunga e più folta sul primo anello: questo ed i tre seguenti con una frangia di peli coricati bianchi nel margine posteriore, il quinto anello rivestito di peli bianchi nella metà anteriore, di vello nero nella posteriore; il sesto, o valvola anale dorsale, posteriormente smarginato, gli angoli della smarginatura prolungati in un dente troncato e quasi bifido all' estremità, i margini laterali finamente dentellati: la superficie ricoperta di denso vello bianco che lascia nuda la sola estremità. I primi quattro anelli ventrali con frangia di peli bianchi simile a quella del dorso. Piedi robusti, bruno-neri, con peluria cenerina; i femori anteriori presso la base dello spigolo infero-posteriore armati d'un forte dente rivolto in dietro. Ali trasparenti, le vene piceo-testacee.

La femina, od almeno quella che crediamo sia femina del maschio descritto, avendola trovata nella stessa località sebbene non accoppiata, oltre alla forma diversa dell'addome e delle antenne differisce dal maschio per la peluria della faccia bianca, per la lamina anale dorsale semicircolare, con due macchie di vello bianco, per la mancanza di dente ne'femori anteriori: il ventre à la peluria bianca che sembra talvolta fulva pel polline della quale è impregnata.

\section{MAGACHILE MIXTA.}

MI. nigra, faeie thoraeisque lateribus densius cinereo pilosis, abdominis segmentis dorsalibus postiee fascia angusta e pilis stratis albo-einereis, in segm. 1-4 in medio attenuanta et late interrupta, in segm. 5 integra aequali; segmentis ventralibus seeundo tertio et quarti basi albido-sericeo, quartiparte postica, quinto et sexto tolis nigro longe pilolis; alis subfumato hyalinis, venis fuscis +.

Long. corp. lin. 4: exp. alar. lin. 7. 
Femina. Corpo interamente di color nero intenso, punteggiato. Capo con peluria bianco-cenerina stivata sopra la faccia, le guance, i lati del clipeo e le orbite posteriori; nel resto quasi nudo. Torace con peluria cenerina alquanto folta sul protorace, sotto la radice delle ali e ne' lati del metatorace; più scarsa nel petto; il dorso del mesotorace e lo scutello quasi nudi. Addome lungo quanto il capo e torace insieme: i primi cinque anelli dorsali impressi strasversalmente presso la metà della lunghezza: i primi quattro con una fascia margine di peli coricati bianchi, ristretta da fuori in dentro e largamente interrotta nel mezzo; il quinto con una fascia simile intera e quasi eguale. Peluria degli anelli ventrali bianco-argentina nel secondo, terzo e marginale anteriore del quarto anello, nera nel rimanente. Piedi con peluria scarsa cenerina su'femori, fulva sulle tibie e su'tarsi. Ali leggermente ombrate; le vene nere.

Ne abbiamo un individuo che probabilmente dovrà considerarsi qual varietà della specie descritta, nel quale la peluria della paletta ventrale è bianco-argentina sotto il secondo e base del terzo anello, nero-rossa. stra nel rimanente.

\section{MEGACHILE MELANOPYGA.}

11. nigra, fulvo-pilosa, abdominis segmentis dorsalibus 1-5 postice fulvo fimbriatis, ultimo nigro, ventre segmentis secundo tertio et quarto fulvo ferrugineo-quinto et sexto nigro longe pilolis; alis fumato-hyalinis, venis nigris. 오.

Long. corp. lin. $5-5 \mathrm{x} / 2$ : exp. alar. lin. 8 .

Femina. Corpo nero. Capo rivestito di folta peluria fulva, più scarsa soltanto sul vertice. Torace rivestito parimente di peluria simile a quella del capo, più folta sui lati. Addome lungo presso a poco quanto il capo e torace insieme, il primo anello con peluria rilevata simile a quella del torace; il medesimo ed i quattro seguenti con frangia sul margine posteriore costituita da peli coricati dello stesso colore: l'ultimo nudo o con breve vello ncro. Paletta ventrale costituita da peli rosso-ferruginosi sul secondo, terzo e quarto anello, neri su'rimanenti. Piedi con peluria simile a quella del torace: la faccia interna del primo articolo de'tarsi con vello ferruginoso. Ali leggermente ombrate; le vene nere. 


\title{
HERIADES BIDENTIGULATA.
}

\author{
Tav. II, fig. 7, 8 .
}

Her. nigra nitida, subtiliter crebre punctata, facie dense, thorace pedibusque minus confertim cinereo pilosis; abdominis segmentis margine postico obsolete albo-ciliatis; segmenti sexti angnlis posticis in dentem brevem. productis, valvula anali dorsali transverse concava, postice rotundata; segm. ventralibus $3^{\circ}$ et $4^{\circ}$ in medio marginis postici fulvo-ciliatis; antennis infra tarsisque anterioribus brunneo-ferrugineis, femoribus tibiisque incrassatis, antennarum articulo ultimo subtus concavo-incurvo; alis hyalinis vix fumatis, venis fuscis. $\sigma^{3}$.

Long. corp. lin. $3 \frac{1}{4}$; exp. alar. lin. 6 .

Maschio. Antenne brune, più chiare dal lato inferiore; i due primi articoli neri; l'ultimo schiacciato, incurvato verso dietro nel mezzo. Corpo di color nero uniforme, cangiante leggermente in bronzino, splendente, tutto egualmente $e$ finamente punteggiato: la faccia rivestita di folta peluria cenerina, il rimanente del capo quasi nudo. Torace poco più lungo che largo, quasi ritondato; la faccia posteriore declive del metatorace con profonda impressione verticale; rivestito di peluria cenerina poco stivata sul dorso e più folta ne' fianchi, bianchiceia sotto il petto. Addome lungo appena quanto il capo e torace, inarcato, leggermente allargato dalla base fino al quarto anello, quasi nudo, con brevissima frangia di cigli bianchi eaduchi sul margine posteriore di ciascun ancllo; il sesto anello fornito di due denti, uno per lato, prolungamento degli angoli latero-posteriori. Valvola anale dorsale incavata nel mezzo a modo di sella, ritondata posteriormente. Ventre piano, nudo; il secondo anello un poco rilevato per traverso nel mezzo del margine posteriore; il terzo e quarto nel mezzo guarniti di frangia di cigli dorati. Ali trasparenti, leggermente ombrate. 


\title{
ANTHOPHORA RECTANGULA.
}

\author{
Tav:II, fig. 8.
}

A. nigra, nigro pilosa, thoracis dorso margine omni rectangulum transversum efficiente flavo fulvescentc; abdominis scymentis secundo, tertio, quarto et quinto dense fulvo-ferrugineo villosis, valvula anali dorsali nuda, alis fumato-hyalinis, tegulis acneo-cupreis. ㅇ.

Long. corp. lin. $6^{x} / 2$ : exp. alar. lin. 13.

Femina. Capo nero, finamente punteggiato, con peluria dello stesso colore: il mezzo del vertice con pochi peli giallo-fulvicei. Il labbro superiore punteggiato-granelloso, quasi nudo, con frangia di cigli sul margine inferiore. Nandibole nere. Antenne nere. Torace nero con peluria dello stesso colore: il dorso con una fascia su tutti i quattro lati formando un rettangolo trasverso costituita da peli stivati giallo-fulvi. Addome nero: il primo anello dorsale rivestito da peluria nera, i due seguenti rivestiti di peluria fulvo-ferruginosa stivata in modo, da occultare perfettamente il color nero del fondo, il quarto rivestito di peluria simile ma meno ferruginosa: il quinto con peluria giallo-cenerina, fulva solo lungo il margine posteriore. Ventre interamente nero. Piedi neri con la peluria dello stesso colore. Ali trasparenti, un poco ombrate, le vene brune, le tegole bronzine.

\section{PSYLLA LACTEA.}

\section{Tav. IV, fig. . .}

Ps. albida, abdomine fusco varicgato, alis lactco-liyalinis, anticis maculis sex marginalibus (quatuor in margine postico) radiatim dispositis, aliaque discoidali pone basin, fuscis, antennis apice nigris.

Longit. corp. lin. 1 ; cum alis lin. $14 / 7$.

Antenne inserite immediatamente innanzi gli occhi, lunghe quanto il corpo, di otto articoli, i due primi assai corti e grossi, i rimanenti delicati e filiformi: di questi, il primo (terzo) il più lungo, gli altri quasi eguali: bianche, il terzo, quarto e quinto all'estremità, gli ultimi tre per intero nerastri. Capo anteriormente bifido, la smarginatura cle di- 
vide $\mathrm{i}$ due lobi protratta fino al livello del contorno anteriore degli ocelli: dorso piano con un solco mediano: interamente di color bianco latteo. Occhi bruno-verdicci. Torace ed addome bianco-lattei, il secondo macchiato di fosco. Ali trasparenti, lattee, le anteriori con sette macchie nerastre: una discoidale posta innanzi la metà della lunghezza; sei marginali, delle quali le due prime più piccole, una per lato verso il mezzo della lunghezza, formanti con la discoidale un triangolo, le altre quattro oblunghe disposte a raggi sul margine posteriore, la esterna isolata, le altre tre convergenti verso la base. Tutte siffatte macchie fiancheggiano altrettante vene che conservano il color latteo. Ali posteriori senza alcuna macchia. Piedi bianchicci.

\section{GEOMETRA BRUZZANARIA.}

Tav. IV, fig. 10.

G. fusca: alis anticis et posticis in medio marginis apicalis angulatis, griseo-purpurascentibus, supra anticis linea arcuata fusca alia extus adiacente carnea, fasciaque fusca extus profunde trisinnata, sinu antico et medio carneis: macula fere triangulari margini antico incumbcnte ultra sinum anticum fusca; posticis linea transvcrsa undulata, fascia extus trisinuosa, anguloque marginali fuscis, illis carneo marginatis; infra alis quatuor linea transversa undulata fusca alia intus adiacente pallida, posticis linea altera punctisque duobus fuscis.

Corpo di color fosco-cenerino. Ali anteriori nella faccia superiore di color cenerino oscuro tendente al porporino. Al terzo interno della lunghezza vi ha una linea arcuata di color bruno intenso, fiancheggiata esternamente da altra carnicina; sul terzo esterno vi ha una fascia dello stesso colore bruno oscuro, più intenso dal lato esterno, sfumato dall' interno, la quale forma esternamente due forti angoli sporgenti, l'anteriore assai più acuto, risultando tre seni, de'quali l'anteriore poco incavato, e il medio più largo, con la concavità riempita da color carnicino, che nel secondo seno forma una macchia meglio terminata semilunare, il seno posteriore occupato da una macchia triangolare fosca, la cui base poggia sul margine posteriore dell'ala, e rimane separato dalla fascia per delicata lineetta carnicina. Presso il margine anteriore in corrispondenza del primo seno vi ha una grande macchia bruna quasi triangolare con la base 
poggiata sul margine, e l'apice, ritondato, verso dietro; il resto dell'ala è di un colore cenerino, un poco rossastro verso il mezzo; il margine estremo carnicino, preceduto da una serie di puntini bianchi; la frangia è alternata di cenerino oscuro e di earnicino. Le ali inferiori hanno nella pagina superiore i primi due terzi cenerino-rossicei, con una striseia ondolata bruna; indi presentano la fascia esternamente trisinuosa simile a quella delle ali anteriori, ma verso la base preceduta da linea oscura, ed esternamente fiancheggiata da una linea carnicina. Lo spazio marginale è colorito come nelle ali anteriori: presso l'angolo vi ha una maechia bruna. La pagina inferiore delle quattro ali è cenerino-rossiccia, traversata da una linea festonata bruna esternamente fiancheggiata da altra simile pallida; le posteriori inoltre àn la linea bruna corrispondente a quella della pagina superiore, e due punti oblunghi più innanzi di questa. Palpi superanti sensibilmente il margine anteriore del eapo, eol terzo articolo molto più corto e più delicato del precedente. Antenne setacee, delicate.

Osservasioni. 11 disegno delle ali di questa Geometra è talmente complicato, che poeo si presta ad una esatta descrizione: sicchè meglio rilevasi dalla ispezione della figura.

Abbiam ritenuta la specie col generico nome di Geometra nel suo più vasto significato: la non conoscenza della larva e delle sue netamorfosi avendoei impedito di assegnarle il convenevole posto tra $\mathrm{i}$ generi numerosi ne' quali trovansi oggi le Geometre distribuite.

\section{Genere ELAOTOMA (I), N.}

(Familia Asilideorum - Subfam. Laphriinorum)

Antennae artieulo tertio inflato obpyriformi, praceedentibus duobus simul parum breviore. Alae venis longitndinalibus tertia et quarta a venula transversa non eonjunetis, quinta et sexta sejunetim marginem alae attingentibus. Abdomen inflatum, basi sensim constrictum.

La specie per la quale instituiamo questo novello genere nella famiglia degli Asilidei, sottofamiglia de'Lafriini, per la disposizione delle vene alari simiglia in tutto alle Laphria propriamente dette; chè anzi per l'abito gene-

(1) Dalle greche voci $\varepsilon \lambda x \cos$ oliva, e $t w \mu x$ articolo. 
rale presenta molta affinità con la L.albilabris. Nondimeno la forma dello addome le dà una fisionomia speciale, la quale ci sembra abbastanza caratteristica per poter autorizzare la sua separazione delle vere Laphria. Esso è lungo poco più del capo e torace insieme presi, assai ristretto alla base, dilatato da questa fino alla metà della lunghezza, e di poi novellamente ristretto fino alla estremità, prendendo la figura ovato-ellittica. La forma poi dell' ultimo articolo delle antenne, benchè non le sia esclusiva, avendosi l'analoga nella cennata Laphria albilabris, nulladimeno è pur singolare, e diversa da quella che trovasi nella maggioranza de'Ditteri : esso è rigonfiato, a forma d'oliva o d' una ghianda, ristretto maggiormente alla base quasi in un piccolo picciuolo.

\section{ELAOTONIA ADUSTIVENTRIS.}

Tav. IV, fig. 11.

E. nigra, nigro hirta albidoque pilosa, genis densius albido pilosis; abdominis disco dorsali postico rufo-fcrrugineo; alis subumbratis venis nigris.

Longit. corp. lin. 6.

Corpo nero rivestito di peli ispidi dello stesso colore, con peli morbidi bianco-cenerini interposti : guance rivestite di peluria bianco-cenerina più stivata. Worso dell'addome nella metà posteriore di colore rossoferruginoso nel mezzo: colore che prende maggiore o minore estensione ne' diversi individui. Ali trasparenti, leggermente ombrate, le vene nere flancheggiate finamente di fosco.

\section{GASTRICHEILUS NUBECULIPENNIS.}

Tav. IV , fig. 12.

G. niger subaeneus, fronte mystaccque aurichalceis, pedibus fulvis, basi nigris, alis hyalinis nubecula discoidali fusco-fumata: ơ abdominis segmento ultimo dorsali postice fulvo-ferrugineo.

Longit. corp. lin. 4.

Maschio. Capo trasversale: il vertice profondamente incavato nel mezzo, con tubercolo che si eleva dal suo centro portante gli ocelli : altro simile tubercolo porta le antenne. Fronte ricoperta di vello coricato 
giallo dorato splendente: dello stesso colore è il mustacchio. Mento od occipite con discreta e morbida peluria nivea. Torace di color nero tendente al bronzino, nel dorso rivestito di cigli coricati poco stivati, che a certa inclinazione di luce gli danno un cangiante fulvo: due macchie di vello cenerino sul contorno anteriore del inesotorace, e due altre simili sulle pleure. Addome del colore del torace, e rivestito di simili cigli: l'ultimo anello col margine posteriore fulvo-ferruginoso. Il secondo, il terzo, il quarto ed il quinto anello con delicato orlo posteriore bianchiccio. Piedi con le ànche, i trocanteri e la prima metà de'femori, neri; nel resto fulvi, coi tarsi più oscuri: tutti con peluria cenerina. Ali trasparenti, incolori, con una macchia fosea sfumata verso il mezzo della meta costale. Bilancieri di color giallo pallido. Organi copulatori forniti di due pezzi a guisa di tanaglia; la lamina sottoanale molto convessa, posteriormente nel mezzo prolungata e ritondata.

Femina. Simile in tutto al maschio, se si eccettui la condizione diversa degli organi genitali, ed il sesto anello addominale dorsale interamente del colore del resto del corpo.

\section{Genere POPSiA, N.}

(Familia Bombylideorum)

Antennae triarticulatae: articulus primus brevis, crassus, secundus longior, oblongus, crassus; tertius secundi longitudine, gracilis, filiformis. Proboscis hori $\approx$ ontalis, capite fere duplo longior, fliformis. Alae venis longitudinalibus decem, ultima anali computata; omnibus sejunctim marginem alae attingentibus; quarta basi tertiae et per venulam transvcrsam quintae, quinta ibidem per venulam transversam sextae conjunctis; area discoidali unica, elongata.

L'abito del Dittero di cui qui diamo la descrizione lo farebbe a prima vista giudicare una Cyrtosia: però la presenza di una cellola discoidale nelle ali lo allontana nettamente e dalle Cirtosie e dagli altri generi a quello affini, come Usia, ec. 


\section{POPSIA RIDIBUNDA.}

Tav. IV, fig. 13.

P. flavo-virescens, abdomine carne-rufescente, segmentis singulis postice anguste flavo-marginatis, capite nigro, peristomate flavo marginato; pedibus pallidis, tarsis apice fuscis; alis irideis, hyalinis, venis fuscis.

Longit. corp. lin. $1 \mathrm{x} / 5$.

Capo ritondato, superiormente quasi piano: nero col margine anteriore del peristoma giallo. Occhi assai grandi, con un piccolo intacco nel mezzo del margine interno, presso il quale stanno inserite le antenne. Antenne nerastre. Dorso del torace interamente di color giallo verdiccio, con minuti cigli coricati neri; i fianchi ed il petto del colore stesso del dorso, ma più' pallidi. Addome di color earnicino-rossiccio, con eigli neri simili a quelli del dorso del torace; il margine posteriore di ciascuno anello giallo. Piedi del colore del petto; l'estremità de'tarsi ne. rastra. Ali trasparenti, incolori, iridate, con le vene oscure. Bilancieri robusti, gialli. 


\section{CAPITOLO QUINTO}

Catalogo generale delle specie raccolte nella Calabria Ulteriore, con la sinonimia dello Specimen Insect. Ult. Calab. $e$ della Fauna d'Aspromonte.

\begin{tabular}{|c|c|c|c|c|}
\hline $\begin{array}{c}\text { NU. } .^{\circ} \\
\text { d' } \\
\text { ORDINE }\end{array}$ & $\begin{array}{l}\text { NOME GENERICO } \\
\text { E SPECIFICO }\end{array}$ & $\begin{array}{l}\text { SINONEMIA } \\
\text { dello } \\
\text { SPEC, INS, ULT. CAL. }\end{array}$ & $\begin{array}{c}\text { SINONIMIA } \\
\text { della } \\
\text { FAuNA DI ASPROsoNTE }\end{array}$ & L OCA I T A \\
\hline $\begin{array}{r}1 \\
2 \\
3 \\
4 \\
5 \\
\\
6 \\
7 \\
8 \\
9 \\
10 \\
11 \\
12 \\
13 \\
14 \\
15 \\
13 \\
17 \\
18 \\
19 \\
20 \\
21 \\
22 \\
23 \\
24 \\
25 \\
26 \\
27 \\
28 \\
29 \\
30 \\
31 \\
33 \\
33 \\
34 \\
35 \\
36 \\
37 \\
38 \\
39 \\
40 \\
41\end{array}$ & 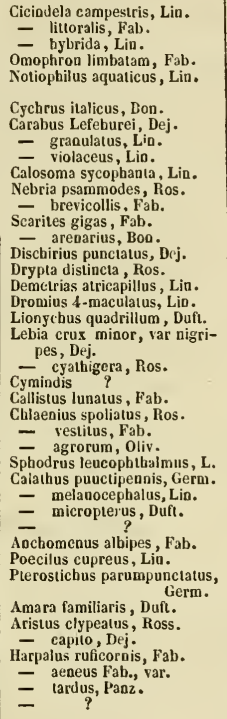 & $\begin{array}{l}\text { Cic. campestris. } \\
\text { Cic. hybrida. } \\
\text { Cic. capensis. } \\
\text { Car. rostratus. } \\
\text { Car. sycophanta. } \\
\text { Scar. areoarius. }\end{array}$ & $\begin{array}{l}\text { Car. cinctus, Oliv. } \\
\text { Car. leucophthalnus. } \\
\text { Car. flavipes, Oliv. } \\
\text { Car. melaoocephalus. } \\
\text { (Car. rufipes, Fab.) } \\
\text { Car. cupreus. } \\
\text { Car. rulgaris, Lin. } \\
\text { Car. bucephalus, Oliv. }\end{array}$ & $\begin{array}{l}\text { (1) } \\
\text { Aspromonte: sulle sponde de' } \\
\text { fiumi-torrenti. } \\
\text { Aspromonte: nelle vallate, solto } \\
\text { Ie pietre. } \\
\text { Ivi, raro } \\
\text { Ivi, raro } \\
\text { Tutto il littorale della provincia } \\
\text { Yalle di Bruzzaoo ne'luogbi ma- } \\
\text { remmosi, alle radici } \\
\text { delle piante. } \\
\text { Aspromonte: sopra i Verbaschi. } \\
\text { Ivi. }\end{array}$ \\
\hline
\end{tabular}

(1) Le specie per le quali non si segaa alcuna località, aè si indica rarità o frequenza, vuol dire che sono state trovate in varii luoghi, e non molto rare. 


\begin{tabular}{|c|c|c|c|c|}
\hline $\begin{array}{c}\text { NUM. } \\
\text { d' } \\
\text { ORDINE }\end{array}$ & $\begin{array}{c}\text { NOME GENERICIO } \\
\text { E SPECIFICO }\end{array}$ & $\begin{array}{l}\text { SINO.NIMIA } \\
\text { dello } \\
\text { SPEC. INS. ULT, CAL. }\end{array}$ & $\begin{array}{c}\text { SINONIMIA } \\
\text { della } \\
\text { FAUNA DI ASPROMONTE }\end{array}$ & L O C A L I T A \\
\hline $\begin{array}{l}42 \\
43 \\
41 \\
45 \\
46 \\
47 \\
48 \\
49 \\
50 \\
51 \\
53 \\
53 \\
54 \\
53 \\
53 \\
56 \\
57 \\
58 \\
59 \\
60 \\
61 \\
62 \\
63 \\
64 \\
65 \\
66 \\
\\
67 \\
68 \\
69 \\
70 \\
71 \\
79 \\
73 \\
74 \\
75 \\
76 \\
77 \\
78 \\
79 \\
80 \\
81 \\
82 \\
83 \\
84 \\
85 \\
86 \\
87 \\
88 \\
89 \\
90 \\
91 \\
92 \\
93 \\
94\end{array}$ & 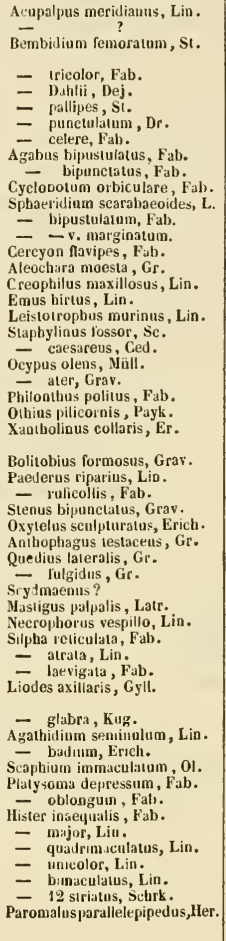 & $\begin{array}{l}\text { Silp, atrata. } \\
\text { " laevigata. }\end{array}$ & $\begin{array}{l}\text { Dityscus bipunctatus. } \\
\text { Sph. scarabueoides. } \\
\text { „ b:pustulatum. } \\
\text { " maryinatum. } \\
\text { Staph. mixillosus. } \\
\text { birtus. } \\
\text { " Inurinus. }\end{array}$ & $\begin{array}{l}\text { Aspromonte: solto le cortecce } \\
\text { de'pini: raro. } \\
\text { Ivi. } \\
\text { Aspromonte: sponde de'torrenti. } \\
\text { Ivi, raro. } \\
\text { Aspromonte: solto le cortecee } \\
\text { de' pini. } \\
\text { Valli d'Aspromonte: alle radici } \\
\text { delle piante. } \\
\\
\text { Aspromonte: sollo le cortece } \\
\text { de' pini. } \\
\text { Ivi. } \\
\text { Ivi. } \\
\text { Jvi. } \\
\text { Ivi, rarissimo. } \\
\text { Ivi. } \\
\text { Jvi. } \\
\text { Valli d' Aspromonte: entro lo } \\
\text { sterco bovino: raro. }\end{array}$ \\
\hline
\end{tabular}




\begin{tabular}{|c|c|c|c|c|}
\hline $\begin{array}{c}\text { NUM. } \\
\text { ORDINE }\end{array}$ & $\begin{array}{c}\text { NOME GENERICO } \\
\text { E SPECIFICO }\end{array}$ & $\begin{array}{c}\text { SINONIMIA } \\
\text { dello } \\
\text { SPEC. INS , ULT . CAL. }\end{array}$ & $\begin{array}{c}\text { SINONIMIA } \\
\text { della } \\
\text { FAUNA DI ASPROMONTE }\end{array}$ & L 0 C A L I T A \\
\hline $\begin{array}{r}95 \\
96 \\
97 \\
98 \\
99 \\
100 \\
101 \\
102 \\
103 \\
104 \\
105 \\
106 \\
107 \\
108 \\
109 \\
110 \\
111 \\
112 \\
113 \\
114 \\
115 \\
116 \\
117 \\
118 \\
119 \\
120 \\
121 \\
122 \\
123 \\
124 \\
125 \\
126 \\
127 \\
128 \\
129 \\
130 \\
131 \\
145 \\
146 \\
147 \\
132 \\
133 \\
134 \\
135 \\
136 \\
143 \\
137 \\
138 \\
143 \\
143 \\
143\end{array}$ & 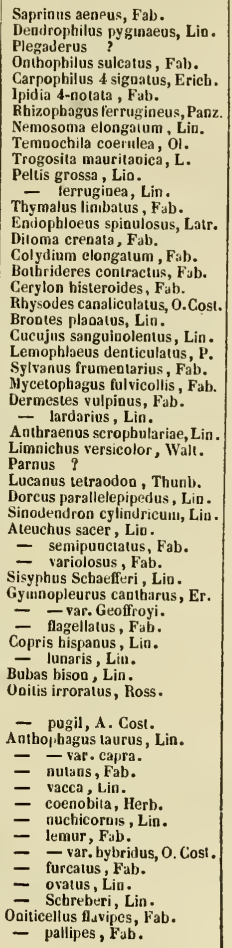 & $\begin{array}{l}\text { Lucanus capreolas. } \\
\text { n parallelepijedus. } \\
\text { Scar. sacer. } \\
\text { Sear. Ialicollis. }\end{array}$ & 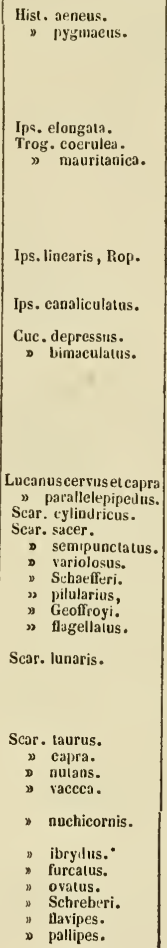 & 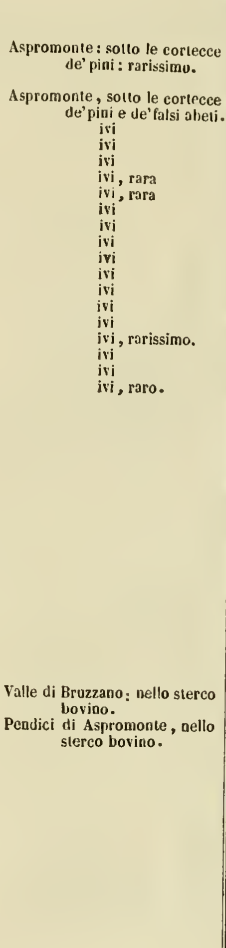 \\
\hline
\end{tabular}




\begin{tabular}{|c|c|c|c|c|}
\hline $\begin{array}{c}\text { NCM. } \\
d^{\prime} \\
\text { ORDINE }\end{array}$ & $\begin{array}{c}\text { NOME GENERICO } \\
\text { E SPECIESCO }\end{array}$ & $\begin{array}{l}\text { SINONIMIA } \\
\text { dello } \\
\text { SPEC. INS. ULT. CAL. }\end{array}$ & $\begin{array}{c}\text { SINONIHIA } \\
\text { della } \\
\text { FAUSA DI ASPRUMONTE }\end{array}$ & L OCA L I T A \\
\hline $\begin{array}{l}119 \\
150 \\
151 \\
152 \\
153 \\
154 \\
153 \\
156 \\
157 \\
158 \\
159 \\
160 \\
161 \\
162 \\
163 \\
164 \\
165 \\
166 \\
167 \\
168 \\
169 \\
170 \\
171 \\
172 \\
173 \\
174 \\
175 \\
176 \\
177 \\
178 \\
179 \\
180 \\
181 \\
189 \\
183 \\
184 \\
183 \\
186 \\
187 \\
188 \\
189 \\
190 \\
191 \\
192 \\
193 \\
194 \\
195 \\
196 \\
197 \\
198 \\
199 \\
200 \\
201 \\
202 \\
203 \\
204 \\
20 \mathrm{j} \\
206\end{array}$ & 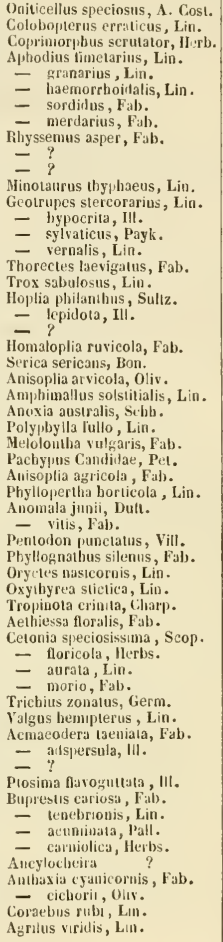 & $\begin{array}{l}\text { Melol. solstitialis. } \\
\text { Melol. fullo. } \\
\text { Melol. vulgaris. } \\
\text { Scar. Candulae: }\end{array}$ & $\begin{array}{l}\text { Scar, erraticus. } \\
\text { „ fimetarius. } \\
\text { granarius. } \\
\text { „ sordidus. } \\
\text { „ bimaculatus. } \\
\text { g guisquilius. } \\
\text { y liyphaeus. } \\
\text { stercurarius. } \\
\text {. } \\
\text { Trox subulosus. } \\
\text { Melol. argeniea. } \\
\text { Melol. coerulea. }\end{array}$ & $\begin{array}{l}\text { Aspromonte, nella valle Fer- } \\
\text { raima. }\end{array}$ \\
\hline
\end{tabular}




\begin{tabular}{|c|c|c|c|c|}
\hline $\mid \begin{array}{c}\text { NCM. } \\
d ' \\
\text { ORDINE }\end{array}$ & $\begin{array}{c}\text { NOME GENERICOO } \\
\text { E SPECIFICO }\end{array}$ & $\begin{array}{l}\text { SINONIMIA } \\
\text { dello } \\
\text { SPEC. INS, ULT. CAL. }\end{array}$ & $\begin{array}{c}\text { SINONIMIA } \\
\text { della } \\
\text { Fauna di ASPRomonte }\end{array}$ & L OCA L I T A \\
\hline $\begin{array}{l}207 \\
208 \\
209 \\
210 \\
211 \\
212 \\
213 \\
214 \\
215 \\
216 \\
217 \\
218 \\
219 \\
220 \\
221 \\
222 \\
223 \\
224 \\
225 \\
226 \\
227 \\
228 \\
229 \\
230 \\
231 \\
232 \\
233 \\
231 \\
235 \\
236 \\
237 \\
238 \\
239 \\
210 \\
211 \\
242 \\
243 \\
244 \\
245 \\
246 \\
247 \\
248 \\
249 \\
230 \\
251 \\
252 \\
253 \\
251 \\
255 \\
256 \\
257 \\
258 \\
259 \\
260 \\
261 \\
\end{array}$ & 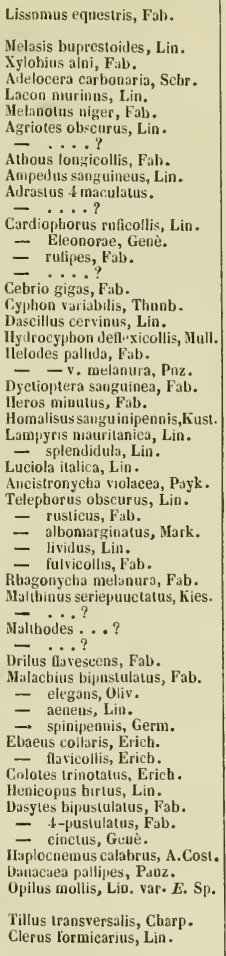 & Clerus formicarius. & $\begin{array}{l}\text { Mel. buprestoides. } \\
\text { Elat. carbonarius. } \\
\text { murinus. } \\
\text { " obscurus. } \\
\text { „ longicollis. }\end{array}$ & $\begin{array}{c}\text { Aspromoute. } \\
\text { Aspromonte. } \\
\text { Valli d'Aspromonte. } \\
\text { Ivi. } \\
\text { Ivi. } \\
\text { Aspromonte. } \\
\text { Ivi, rarissimo. } \\
\text { Ivi, id. } \\
\text { Aspromonte. }\end{array}$ \\
\hline
\end{tabular}


$-58-$

\begin{tabular}{|c|c|c|c|c|}
\hline $\begin{array}{c}\text { NLM. } \\
\text { d' } \\
\text { ORDISE }\end{array}$ & $\begin{array}{c}\text { NOME GENERICO } \\
\text { E SPECIFICO }\end{array}$ & $\begin{array}{l}\text { SINONIMIA } \\
\text { dello } \\
\text { SPEC. ISS. ELT. CAL. }\end{array}$ & $\begin{array}{c}\text { SINONIMIA } \\
\text { della } \\
\text { FAUNA DI ASPROMONTE }\end{array}$ & LOCALITA \\
\hline $\begin{array}{l}262 \\
263 \\
264 \\
265 \\
266 \\
267 \\
268 \\
269 \\
270 \\
271 \\
273 \\
273 \\
274 \\
273 \\
276 \\
277 \\
278 \\
279 \\
280 \\
281 \\
282 \\
283 \\
284 \\
285 \\
286 \\
287 \\
288 \\
289 \\
290 \\
291 \\
292 \\
293 \\
294 \\
245 \\
296 \\
297 \\
298 \\
249 \\
300 \\
301 \\
302 \\
303 \\
304 \\
305 \\
306 \\
307 \\
303 \\
309 \\
310 \\
311 \\
312 \\
313 \\
314 \\
315 \\
316 \\
317\end{array}$ & 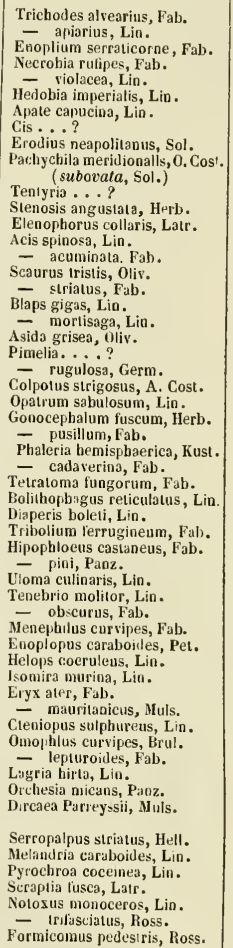 & $\begin{array}{l}\text { Clerus apiacius. } \\
\text { Plinus imperialis. }\end{array}$ & $\begin{array}{l}\text { Clerus apiarius. } \\
\text { Bostrichus capucinus. } \\
\text { Erodius gibbus. } \\
\text { Pimel. meridionalis." } \\
\text { Tagenia filiformis. }\end{array}$ & $\begin{array}{l}\text { Aspromonte: solto le cortecce } \\
\text { de'pini. } \\
\text { Aspromonte : solto le cortecce } \\
\text { de'laggi. }\end{array}$ \\
\hline
\end{tabular}




\begin{tabular}{|c|c|c|c|c|}
\hline $\begin{array}{c}\text { NUM. } \\
\text { d' } \\
\text { ORDINE }\end{array}$ & $\begin{array}{c}\text { NOME GENERICO } \\
\text { E SPECIFICO }\end{array}$ & $\begin{array}{c}\text { SINONIMIA } \\
\text { dello } \\
\text { SPEC, INS, ULT. CAL. }\end{array}$ & $\begin{array}{c}\text { SINONIMIA } \\
\text { della } \\
\text { FAUNA DI ASPROMONTE }\end{array}$ & L $0 \mathrm{CALITA}$ \\
\hline 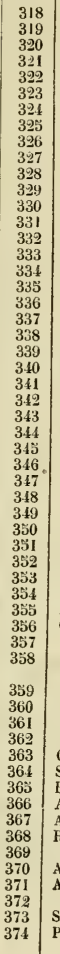 & 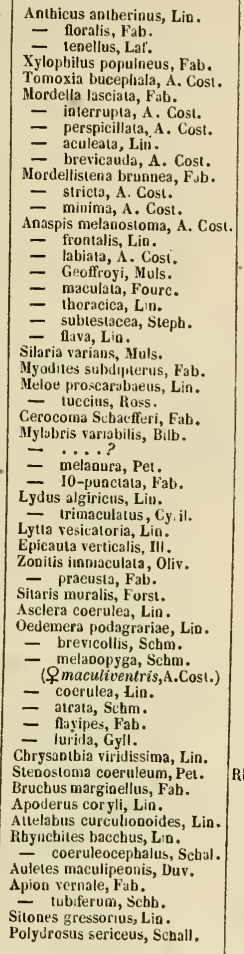 & |. & $\begin{array}{l}\text { Mel. proscarabacus. } \\
\text { Myl. cichorii. } \\
\text { y melanura. } \\
\text { 10-punctata. } \\
\text { Cantbaris trimaculata. } \\
\text { vesicatoria. } \\
\text { elongata. } \\
\text { Oed. podagrariae. }\end{array}$ & $\begin{array}{l}\text { Valle di B'uzzano: assai raro. } \\
\text { Adiacenze di Reggio. } \\
\text { Vetta di Montalto. } \\
\text { Valle di Popsis. } \\
\text { Aspromonte. }\end{array}$ \\
\hline
\end{tabular}


$-60-$

\begin{tabular}{|c|c|c|c|c|}
\hline $\begin{array}{c}\text { NUM. } \\
\text { d' } \\
\text { ORDINE }\end{array}$ & $\begin{array}{c}\text { NOME GENERICOO } \\
\text { E SPECIFICO }\end{array}$ & $\begin{array}{l}\text { SINONIIIIA } \\
\text { dello } \\
\text { SPEC, IAS, TLT. CAL. }\end{array}$ & $\begin{array}{c}\text { SINONIMIA } \\
\text { della } \\
\text { FAuNa di ASPromoxte }\end{array}$ & L OCA L I T A \\
\hline $\begin{array}{l}375 \\
376 \\
377 \\
378 \\
379 \\
380 \\
381 \\
382 \\
383 \\
384 \\
385 \\
386 \\
387 \\
388 \\
389 \\
390 \\
391 \\
392 \\
393 \\
394 \\
394 \\
396 \\
397 \\
\\
398 \\
349 \\
400 \\
401 \\
402 \\
403 \\
404 \\
405 \\
406 \\
407 \\
408 \\
409 \\
410 \\
411 \\
412 \\
413 \\
414 \\
415 \\
416 \\
417 \\
418 \\
419 \\
420 \\
421 \\
422 \\
423 \\
424 \\
495 \\
426 \\
427 \\
428 \\
429\end{array}$ & 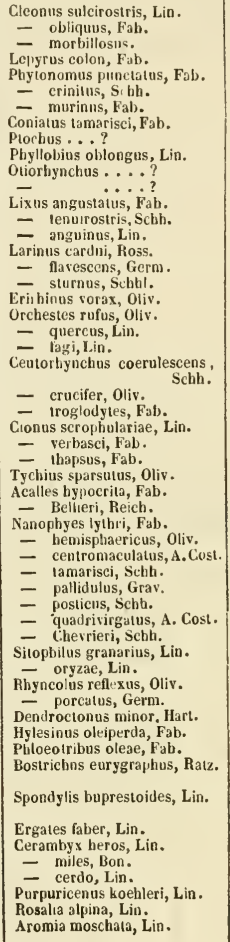 & $\begin{array}{l}\text { Cer, cerdo. } \\
\text { Lamia kahleri. }\end{array}$ & $\begin{array}{l}\text { Sp. buprestoides. } \\
\text { Prionus faber. } \\
\text { Cer. heros. } \\
\text { Cer. cerdo. } \\
\text { Lam. koebleri. } \\
\text { Cer. alpinus. }\end{array}$ & $\begin{array}{l}\begin{array}{l}\text { Aspromonte: raro. } \\
\text { Ivi: idl. }\end{array} \\
\text { Aspromonte: solto le cortecce } \\
\text { de' pini. } \\
\text { Aspromonte: solto le cortecce } \\
\text { de'pini. } \\
\text { Aspromonte, solto le cortecce } \\
\text { de'pini e de'falsi abeti. } \\
\text { Ivi: sotto le cortecce } \\
\text { de' pini. }\end{array}$ \\
\hline
\end{tabular}




\begin{tabular}{|c|c|c|c|c|}
\hline $\begin{array}{c}\text { NUM. } \\
\mathrm{d}^{\prime} \\
\text { ORDINE }\end{array}$ & $\begin{array}{c}\text { NOME GENERICO } \\
\text { E SPECIFICO }\end{array}$ & $\begin{array}{c}\text { SINONIMIA } \\
\text { dello } \\
\text { SPEC. INS. ELT, CAL. }\end{array}$ & $\begin{array}{c}\text { SINONIMIA } \\
\text { della } \\
\text { FAUNA DI ASPROMONTE }\end{array}$ & L 0 C A L I T A \\
\hline
\end{tabular}




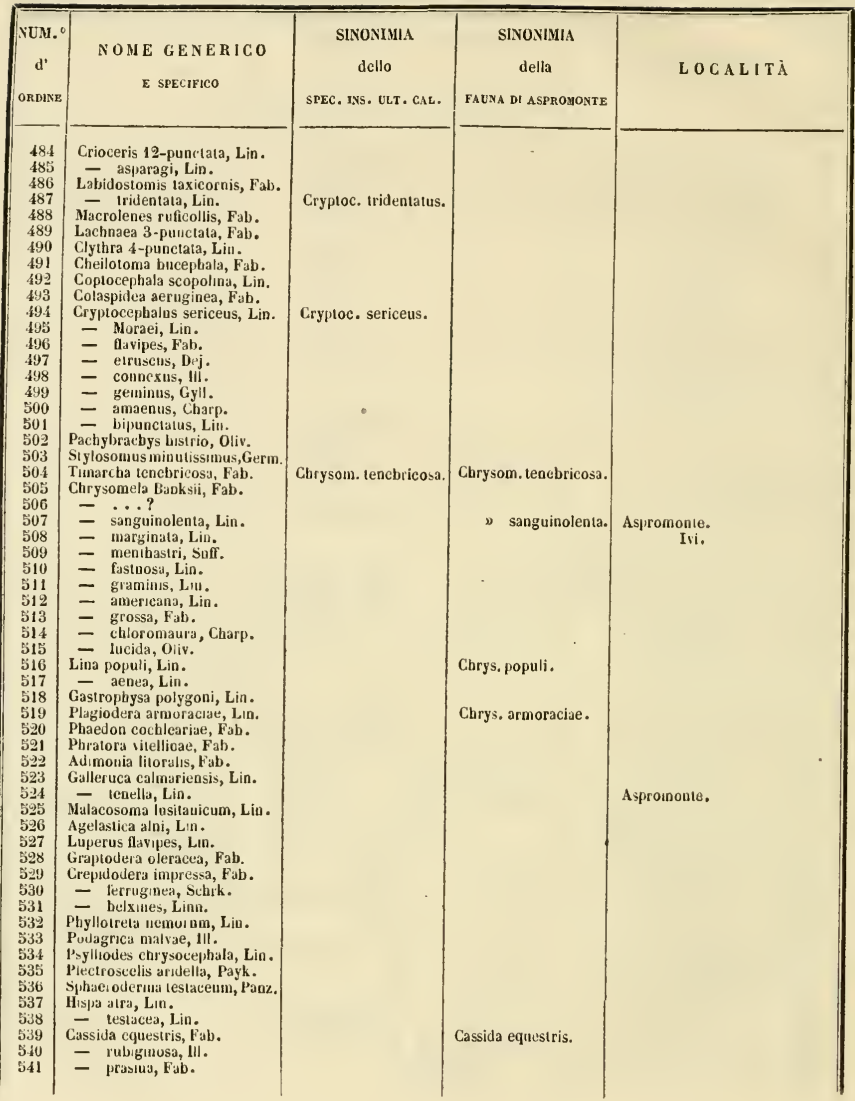




\begin{tabular}{|c|c|c|c|c|}
\hline $\begin{array}{c}\text { NUM. } \\
\text { d' } \\
\text { ORDINE }\end{array}$ & $\begin{array}{c}\text { NOME GENERICO } \\
\text { E SPECIFICO }\end{array}$ & $\begin{array}{c}\text { SINONIMIA } \\
\text { dello } \\
\text { SPEC. INS. ULT. CAL. }\end{array}$ & $\begin{array}{c}\text { SINONIMLA } \\
\text { della } \\
\text { FALNA DI ASrRonoNie }\end{array}$ & L OCA L I T A \\
\hline 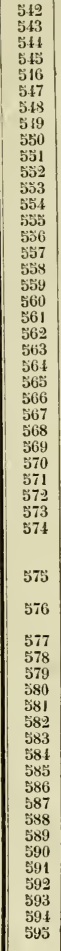 & 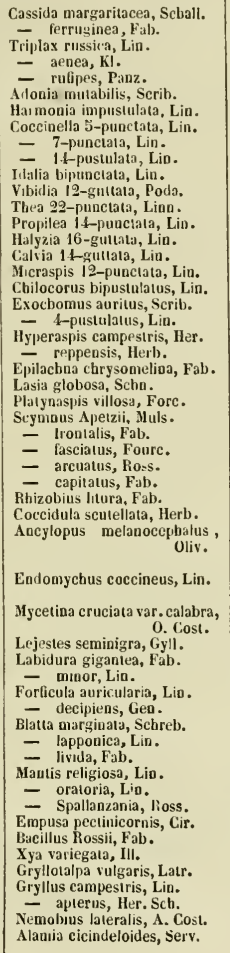 & $\begin{array}{c}\text { Cocc. 7-punctata. } \\
\text { Cocc. 1-1 -pustulata. } \\
\text { bipunctata. } \\
\text { 22-punctata. }\end{array}$ & 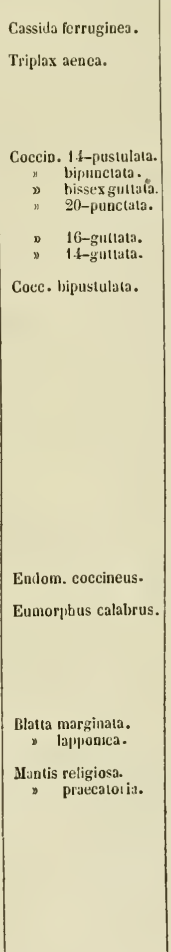 & $\begin{array}{l}\text { Ville di Bruzzano: ne'luoghi pa- } \\
\text { ludosi, alla radice delle } \\
\text { piante. } \\
\text { Aspromonte: sotto le cortecee } \\
\text { de'pini. } \\
\text { Col precedente. } \\
\text { Ivi, rara. }\end{array}$ \\
\hline
\end{tabular}




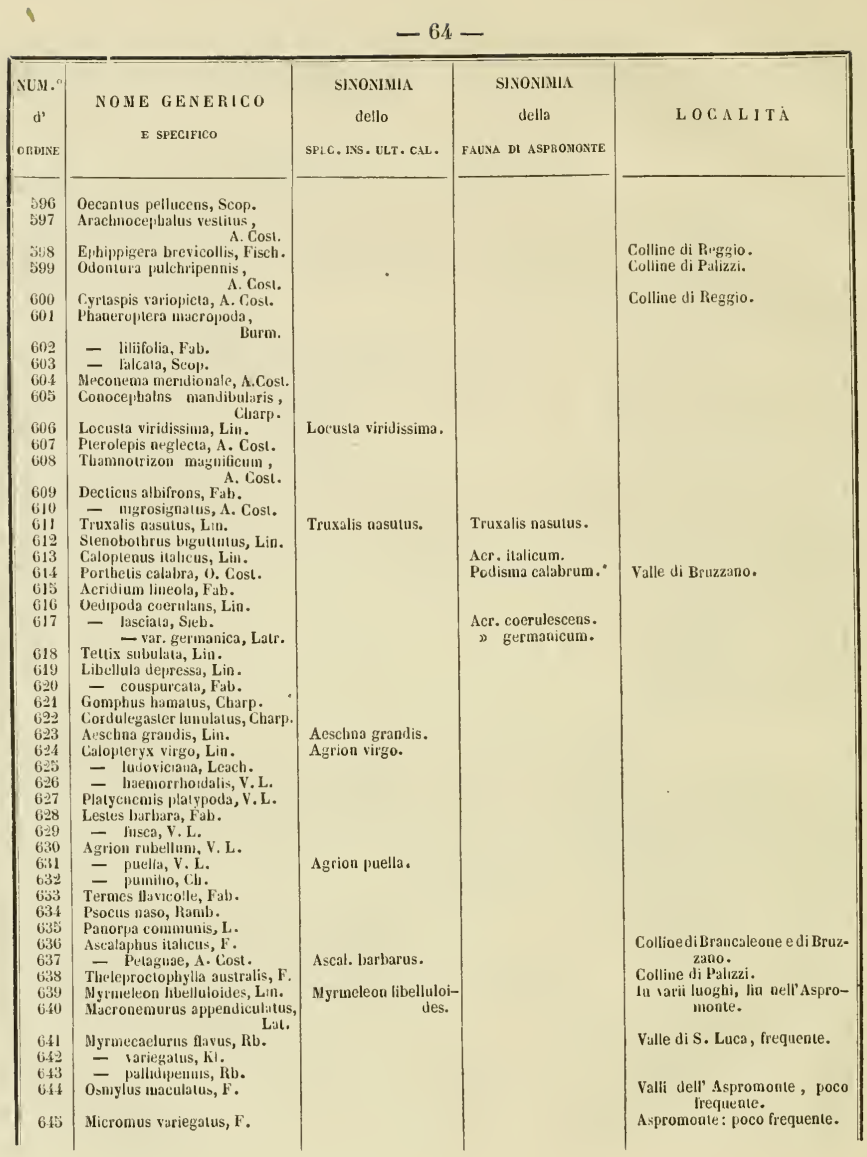




\begin{tabular}{|c|c|c|c|c|}
\hline$\left|\begin{array}{c}\text { NUM. } \\
d^{\prime} \\
\text { ORDINE }\end{array}\right|$ & $\begin{array}{c}\text { NOIIE GENERICO } \\
\text { E SPECIFICO }\end{array}$ & $\begin{array}{c}\text { SINONIMIA } \\
\text { dello } \\
\text { SPEC. INS. ULT . CAL. }\end{array}$ & $\begin{array}{c}\text { SINONIMIA } \\
\text { della } \\
\text { FAUNA DI ASrRomonte }\end{array}$ & L OC A L I T A \\
\hline $\begin{array}{l}616 \\
647 \\
648 \\
649 \\
650 \\
651 \\
652 \\
653 \\
651 \\
655 \\
656 \\
657 \\
658 \\
659 \\
660 \\
661 \\
662 \\
663 \\
664 \\
665 \\
666 \\
667 \\
668 \\
669 \\
670 \\
671 \\
672 \\
673 \\
674 \\
673 \\
676 \\
677 \\
678 \\
679 \\
680 \\
681 \\
682 \\
683 \\
685 \\
685 \\
686 \\
687 \\
688 \\
689 \\
690 \\
691 \\
692 \\
693\end{array}$ & 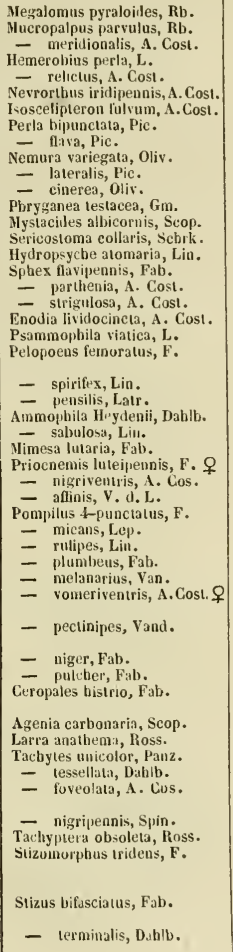 & & * & 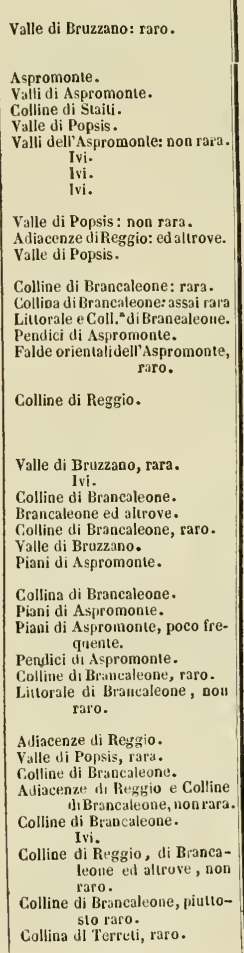 \\
\hline
\end{tabular}




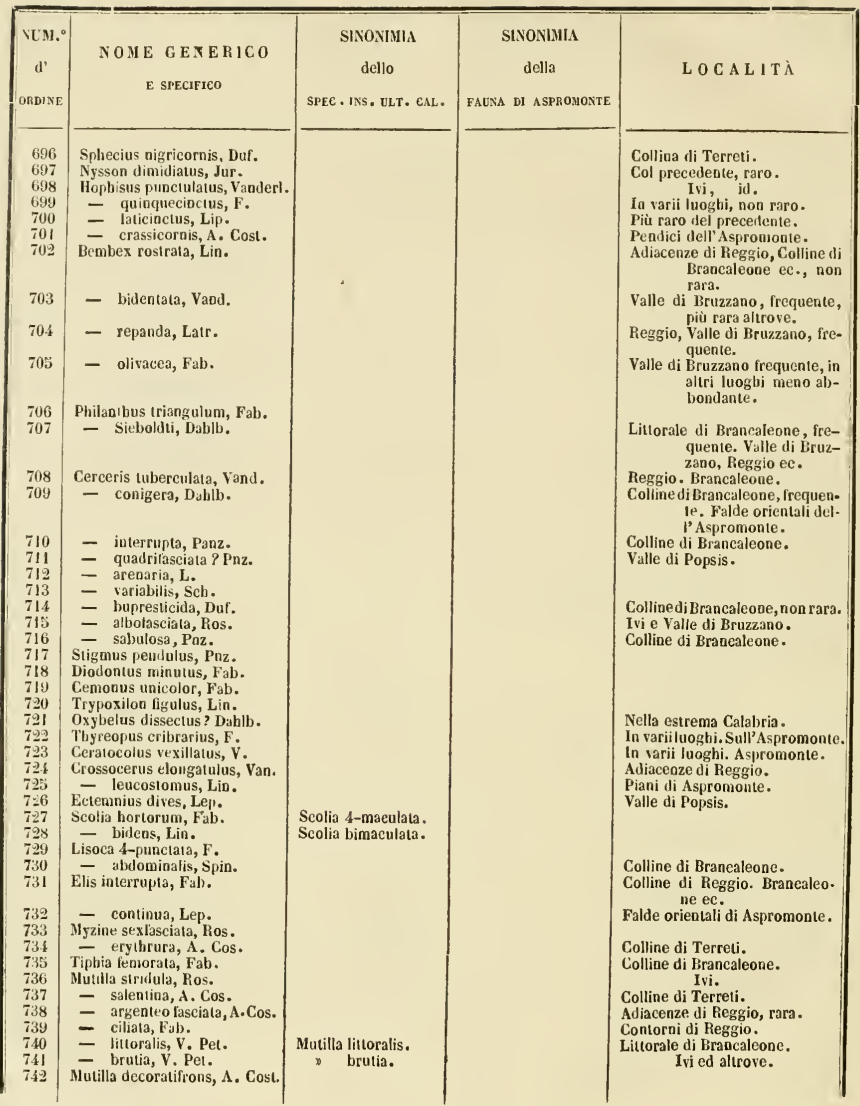


$-67-$

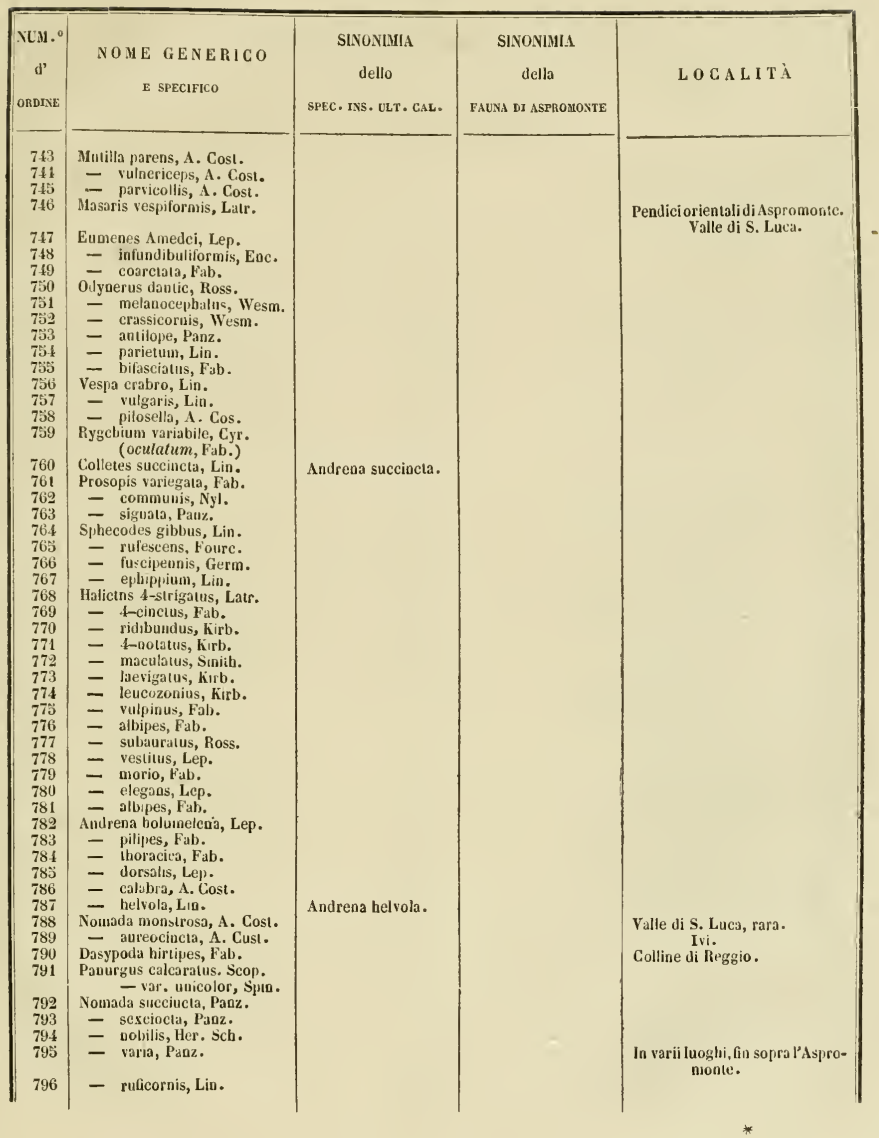




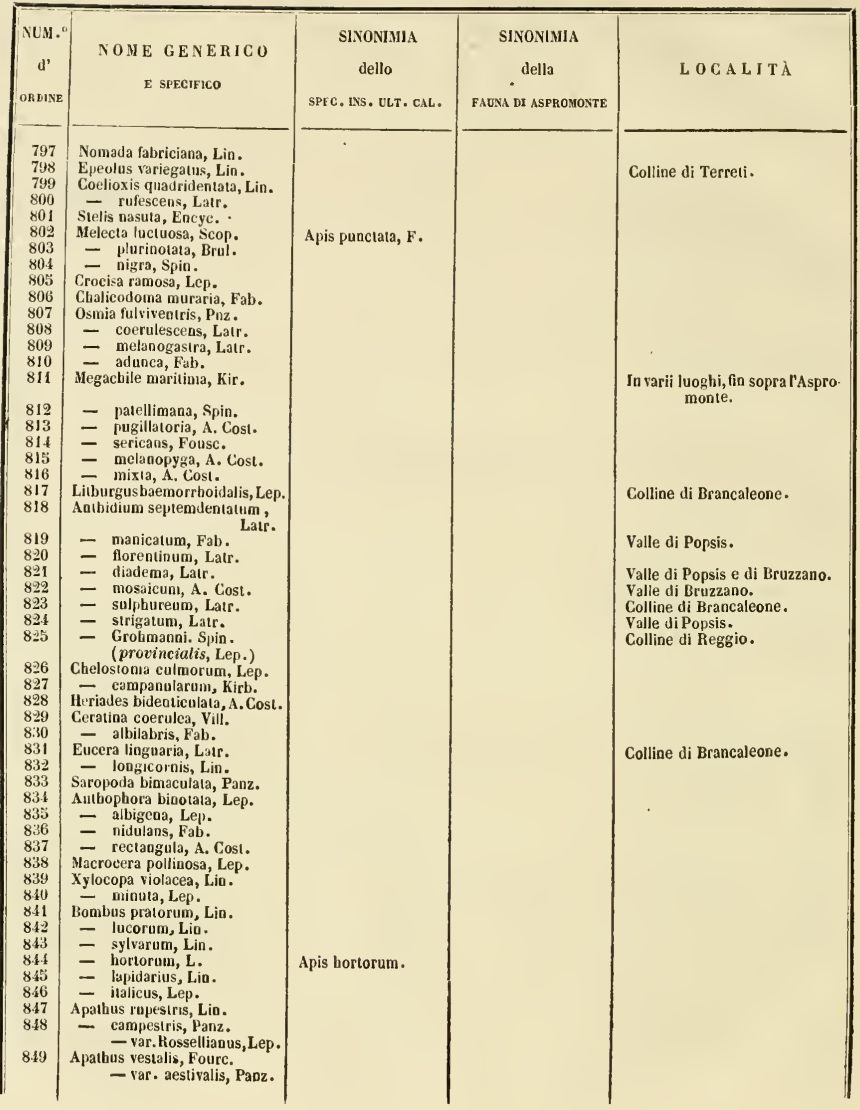


$-69-$

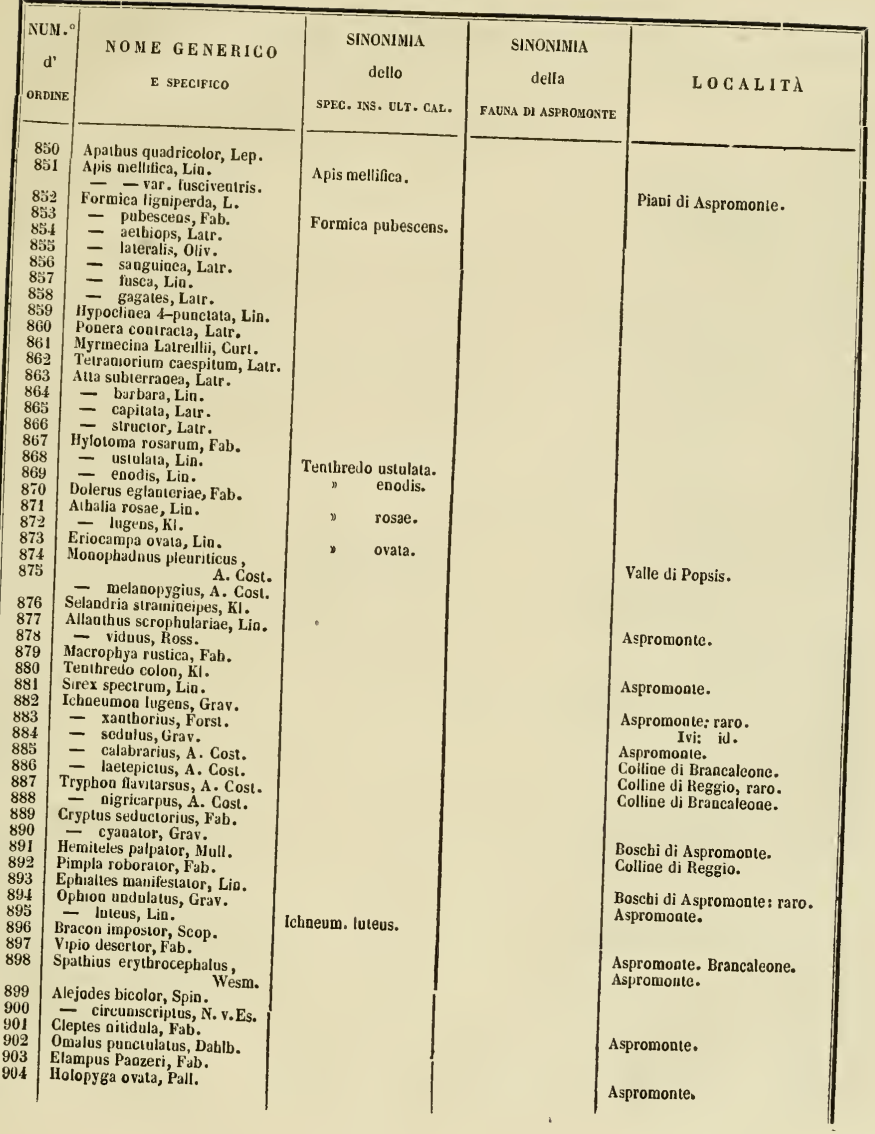


$-70-$

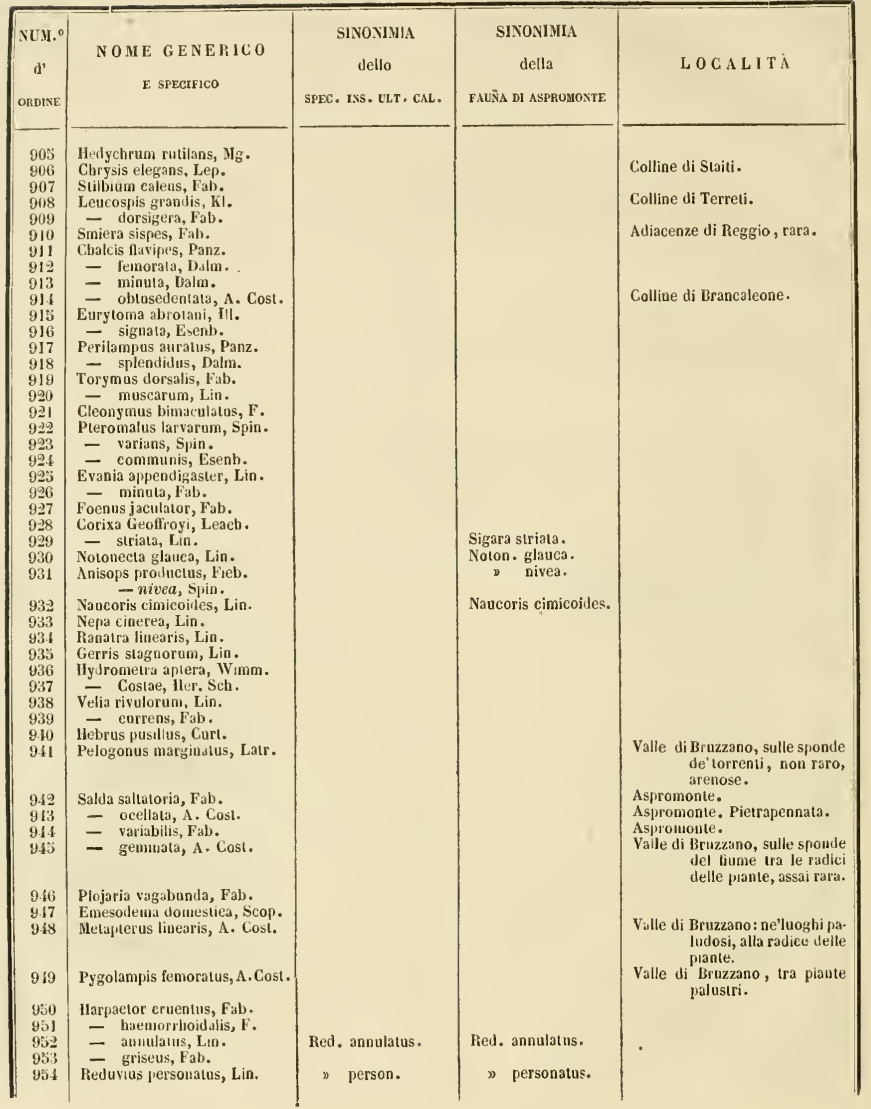


$-74-$

\begin{tabular}{|c|c|c|c|c|}
\hline $\begin{array}{c}\text { NUM. } \\
\text { d' } \\
\text { ORDINE }\end{array}$ & $\begin{array}{c}\text { NOME GENERICO } \\
\text { E SPECIFICO }\end{array}$ & $\begin{array}{c}\text { SINONIMIA } \\
\text { dello } \\
\text { SPEC. INS. ULT. CAL. }\end{array}$ & $\begin{array}{c}\text { SINONIMIA } \\
\text { della } \\
\text { FAuNA DI ASPROMONTE }\end{array}$ & L OCA L I T A \\
\hline $\begin{array}{r}955 \\
956 \\
937 \\
\\
958 \\
959 \\
960 \\
961 \\
962 \\
963 \\
961 \\
963 \\
966 \\
967 \\
968 \\
969 \\
970 \\
971 \\
972 \\
973 \\
974 \\
973 \\
976 \\
977 \\
978 \\
979 \\
980 \\
981 \\
982 \\
983 \\
981 \\
985 \\
986 \\
987 \\
988 \\
989 \\
990 \\
991 \\
992 \\
993 \\
994 \\
995 \\
996 \\
997 \\
998 \\
999 \\
1000 \\
1001 \\
1002 \\
1003 \\
1004 \\
1005 \\
1006 \\
1007\end{array}$ & 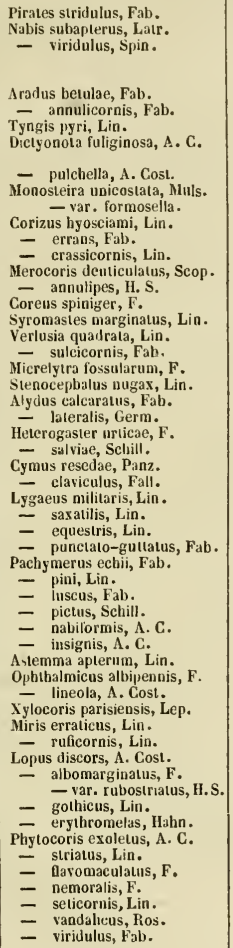 & $\begin{array}{l}\text { Cimex calcaratus. } \\
\text { Cin. saxatilis. } \\
\text { Cim. equestris. }\end{array}$ & $\begin{array}{l}\text { Coreus quadratus. } \\
\text { Lygaeus punctato-gut- } \\
\text { talus. } \\
\text { Lygaeus apterus. }\end{array}$ & $\begin{array}{l}\text { Adiacenze di Reggio ed alirove } \\
\text { sopra la Tamarixa alri- } \\
\text { cana, raro. } \\
\text { Pendici orientali dell' Aspro- } \\
\text { monte. } \\
\text { Adiacenze di Riggio. } \\
\text { A'liacenze di Reggio, rara. } \\
\text { Ivi. }\end{array}$ \\
\hline
\end{tabular}


$-72-$

\begin{tabular}{|c|c|c|c|c|}
\hline NUM. & $\begin{array}{c}\text { NOME GENERICO } \\
\text { E SPECTICO }\end{array}$ & $\begin{array}{l}\text { SINONIMIA } \\
\text { dello } \\
\text { SPEC. INS. ULT. CAL. }\end{array}$ & $\begin{array}{c}\text { SINONIMIA } \\
\text { della } \\
\text { FAUNA DI ASPRoyonte }\end{array}$ & L O C A L I T A \\
\hline \begin{tabular}{l|}
1008 \\
1009 \\
1010 \\
1011 \\
1012 \\
1013 \\
1014 \\
1015 \\
1016 \\
1017 \\
1018 \\
1019 \\
1020 \\
1021 \\
1022 \\
1023 \\
1024 \\
1023 \\
1026 \\
1027 \\
1028 \\
1029 \\
1030 \\
1031 \\
1032 \\
1033 \\
1034 \\
1035 \\
1036 \\
1037 \\
1038 \\
1039 \\
1040 \\
1041 \\
1042 \\
1043 \\
1044 \\
1045 \\
1016 \\
1047 \\
1048 \\
1049 \\
1050 \\
1051 \\
1052 \\
1053 \\
1051 \\
1055 \\
1056 \\
1057 \\
1058 \\
1059 \\
1060 \\
1061 \\
1062 \\
1063 \\
1064 \\
\end{tabular} & 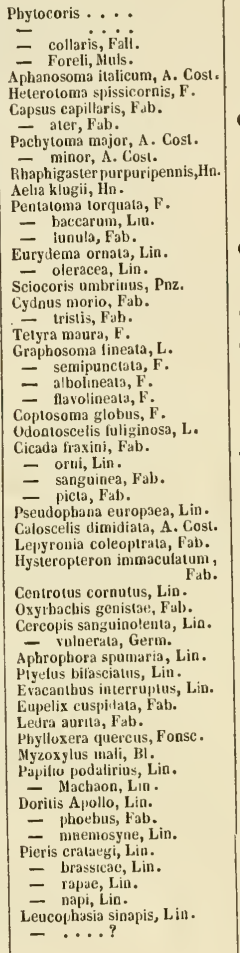 & $\begin{array}{l}\text { Cim. festivus. } \\
\text { Cim. tristis. } \\
\text { Cimeo manros. } \\
\text { Cim. vigrolineatus. } \\
\text { Cim. jancipunctatos. }\end{array}$ & 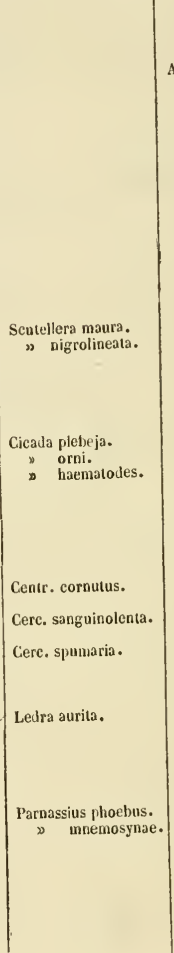 & Colline di Reggio. \\
\hline
\end{tabular}


$-73-$

\begin{tabular}{|c|c|c|c|c|}
\hline $\begin{array}{c}\text { VUM. } \\
\text { d' } \\
\text { ORDINE }\end{array}$ & $\begin{array}{c}\text { NOME GENERICO } \\
\text { E SPECIFICO }\end{array}$ & $\begin{array}{c}\text { SINONIMIA } \\
\text { dello } \\
\text { SPEC. INS. ULT. CAL. }\end{array}$ & $\begin{array}{c}\text { SINONIMIA } \\
\text { della } \\
\text { FAUNA DH ASPROMONTE }\end{array}$ & L O C A L I T A \\
\hline $\begin{array}{l}1063 \\
1066 \\
1067 \\
1068 \\
1069 \\
1070 \\
1071 \\
1072 \\
1073 \\
1074 \\
1075 \\
1076 \\
1077 \\
1078 \\
1079 \\
1080 \\
1081 \\
1082 \\
1083 \\
1084 \\
1085 \\
1086 \\
1087 \\
1088 \\
1089 \\
1090 \\
1091 \\
1092 \\
1093 \\
1094 \\
1093 \\
1096 \\
1097 \\
1098 \\
1099 \\
1100 \\
1101 \\
1102 \\
1103 \\
1104 \\
1103 \\
1106 \\
1107 \\
1108 \\
1109 \\
1110 \\
1111 \\
1112 \\
1113 \\
1114 \\
1115 \\
1116 \\
1117 \\
1118 \\
1119 \\
1120 \\
1121 \\
1132 \\
\\
\end{array}$ & 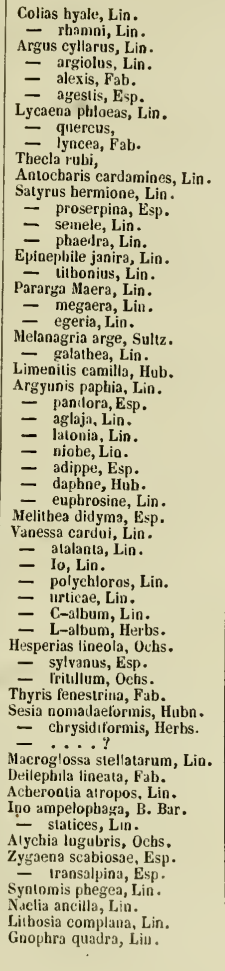 & $\begin{array}{l}\text { cardui. } \\
\text { „atalanta. } \\
\text { „10. } \\
\text { „ C-album. }\end{array}$ & 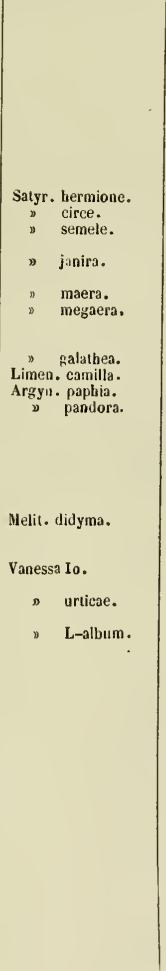 & 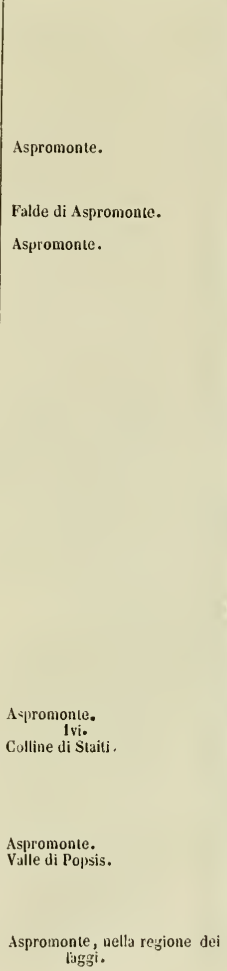 \\
\hline
\end{tabular}




\begin{tabular}{|c|c|c|c|c|}
\hline NUM. & $\begin{array}{c}\text { NOME GENERICO } \\
\text { E SPECIFICO }\end{array}$ & $\begin{array}{l}\text { SINONIMIA } \\
\text { dello } \\
\text { SPEC. INS. ULT. CAL. }\end{array}$ & $\begin{array}{c}\text { SINONIMIA } \\
\text { della } \\
\text { FatiNa di AspaUdoxte }\end{array}$ & LOCAL $\mid \mathrm{TA}$ \\
\hline 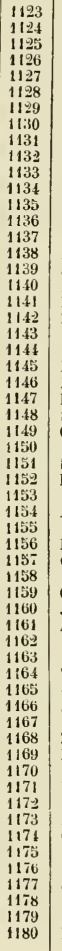 & 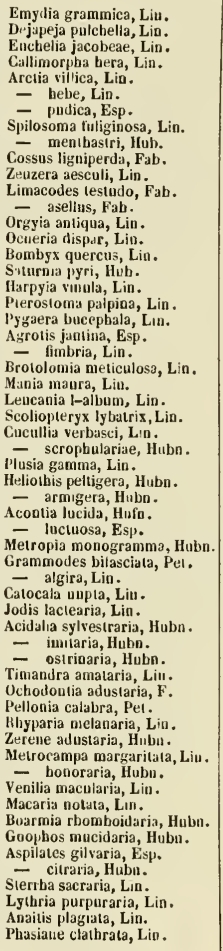 & & & $\begin{array}{l}\text { Aspromonte. } \\
\text { Adiacenze di Regrio. } \\
\text { Adiacenze di Reggio. }\end{array}$ \\
\hline
\end{tabular}




\begin{tabular}{|c|c|c|c|c|}
\hline $\begin{array}{c}\text { NUM. } \\
\text { d' } \\
\text { ORDINE }\end{array}$ & $\begin{array}{c}\text { NOME GENERICOO } \\
\text { E SPECIFICO }\end{array}$ & $\begin{array}{c}\text { SINONIMIA } \\
\text { dello } \\
\text { spec. iss. Uet, cal. }\end{array}$ & $\begin{array}{c}\text { SINUNIMII } \\
\text { della } \\
\text { FAUNA DI ASPROMOXTE }\end{array}$ & L OCA L J T A \\
\hline 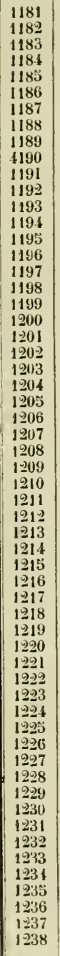 & 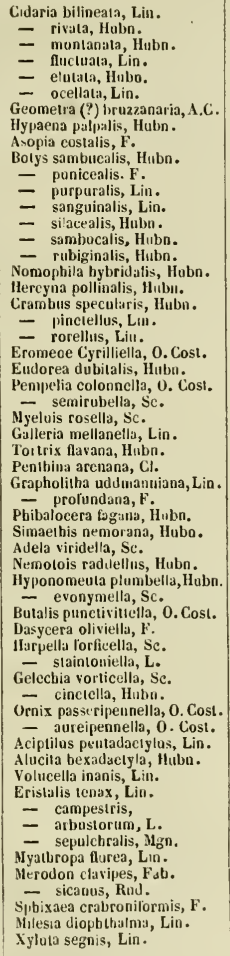 & $\mathrm{M} u s c a$ inanis. & & $\begin{array}{l}\text { Aspromonte, nella regione dei } \\
\text { laggi. } \\
\begin{array}{c}\text { Aspromonte, nella regione dei } \\
\text { faggi. }\end{array}\end{array}$ \\
\hline
\end{tabular}




\begin{tabular}{|c|c|c|c|c|}
\hline $\begin{array}{c}\text { NUM. } \\
\text { d' } \\
\text { ORDINE }\end{array}$ & $\begin{array}{c}\text { NOME GENERICO } \\
\text { E SPECHFICO }\end{array}$ & $\begin{array}{c}\text { SINONIMIA } \\
\text { dello } \\
\text { SPEC , INS. ULT. CAL. }\end{array}$ & $\begin{array}{c}\text { SIXONIMIA } \\
\text { della } \\
\text { FAUNA DI ASPROMONTE }\end{array}$ & L O C A L I TA \\
\hline 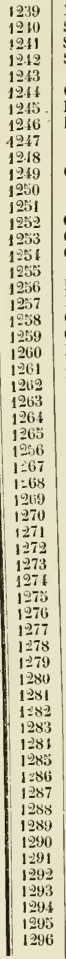 & 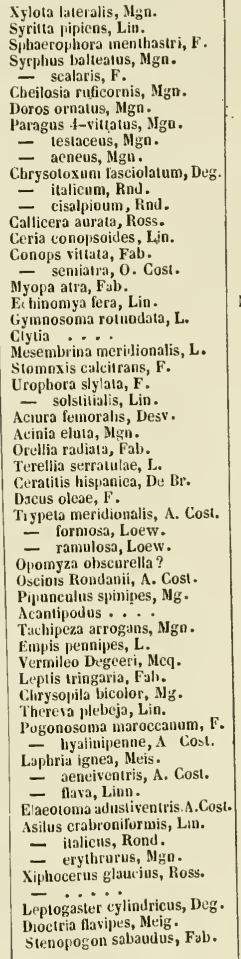 & • & . & $\begin{array}{l}\text { Adiacenze di Reggio. } \\
\text { Adiacenze di Reggio. } \\
\text { Adiacenze di Ringgio. } \\
\text { Aspromonte, vallate. } \\
\text { Adiacenze di Reggio. } \\
\text { Colline di Staiti. } \\
\text { Adiacenze di lieggio. } \\
\text { Aspromonte. } \\
\text { Aspromonte. } \\
\text { Colline di B anealeone. } \\
\text { Pendici orientali dell' Aspro- } \\
\text { nonte, raro. } \\
\text { Piani di Aspromonte, e sue pen- } \\
\text { dici: abbondante. }\end{array}$ \\
\hline
\end{tabular}




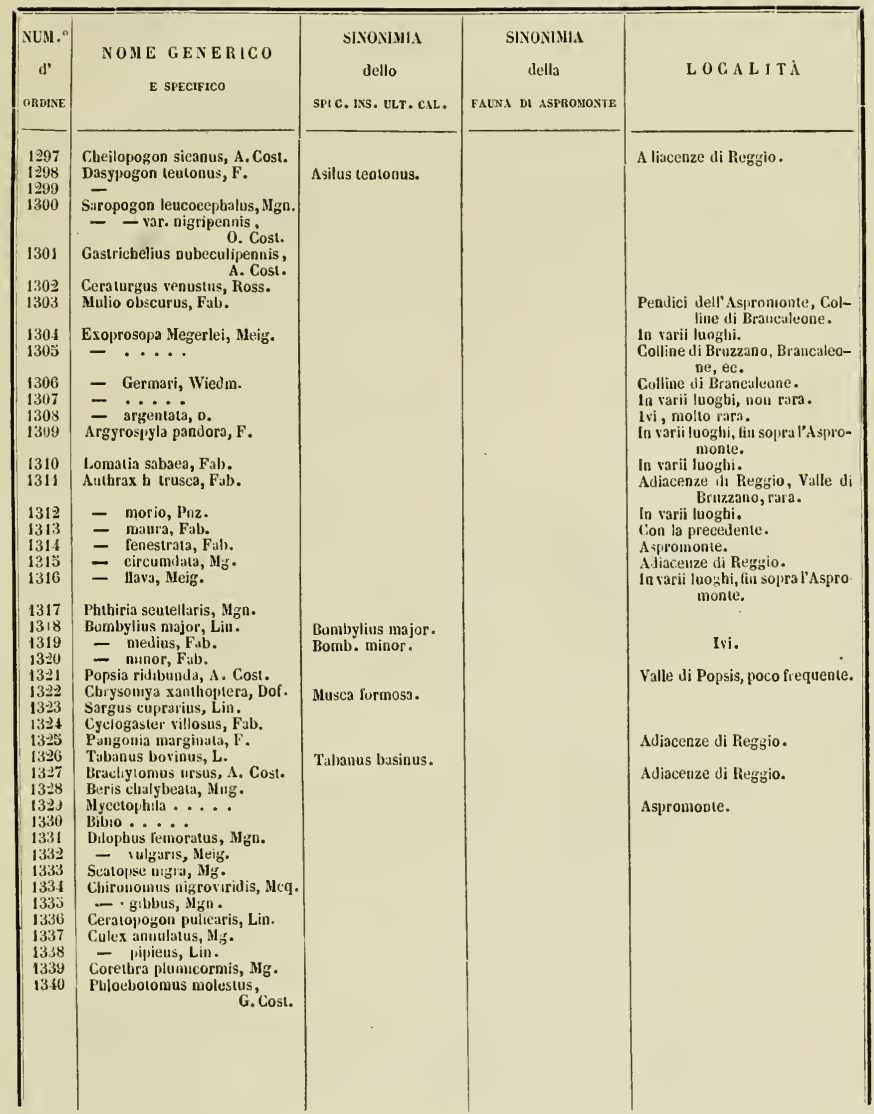




\section{SPIEGAZIOAE DELLE TIVOLE}

\section{TAVOLA I.}

Fïg. 1. Dasytes cinctus, Gené, varietas.-A. antenna.

2. Aulctes maculipcnnis, Duv.

3. Nanophyes centromaculatus, A. Cost.

4. Nanophyes quadrivirgatus, A. Cost.

5. Leptura excelsa, A. Cost. - A. maschio, B. femmina.

6. Odontura pulchripennis, A. Cost. maschio. - A. le due elitre; B. appendici anali vedute dalla faccia ventrale - C. le stesse vedute dalla faccia dorsale.

7. Odontura pulchripennis, femmina.

8. Cyrtaspis variopicta, A. Cost. Fauna Napol. Locustidei, p. 17)A. le appendici anali vedute dal dorso - B. le stesse vedute dalla faccia ventrale.

9. Meconema meridionale, A. Cost. (Fauna Napol. Locust. pag. 14 Maschio - A. capo e torace veduti di lato - B le appendici anali dorsali.

10. Meconema meridionale, femmina - A il capo veduto di lato B la estremitå della trivella.

11. Pterolepis neglecta, A. Cust. maschio.-A. estremità anale superiore, B. valvola sottoanale.

12. La trivella della femmina della stessa Plerolepis. 
TAYOLA II.

Fig. 1. Andrena calabra, $\Lambda$. Cost.

2. Nomia monstrosa, A. Cost. (Fauna Napol. Andrenid. pag. 4).

3. Nomia aureocincta, A. Cost. (Fauna 1. c. pag. 8).

4. Megachile pugillatoria, A. Cost. Maschio.

5. Megachile pugillatoria, femmina.

6. Anthidium mosaicum, A. Cost. Maschio-A. gli ultimi due anelli addominali dorsali.

7. Heriades bidenticulata, A. Cost. $-A$. antenna, $B$. l'addome veduto di profilo.

8. Anthophora rectangula, A. Cost. femmina.

9. Ichneumon calabrarius, A. Cost. - A. aja metatorica.

10. Ichneumon laetepictus, A. Cost.

11. Tryphon favitarsus, A. Cost.

12. Tryphon nigricarpus, A. Cost.

TAVOLA III.

Fig. 1. Mutilla decoratifrons, A. Cost. femmina (Fauna Napol. Mutillidei pag. 31).

2. Mutilla parens, A. Cost. femmina (loc. cit. pag. 32 ).

3. Mutilla vulnericeps, A. Cost. femmina (loc. cit. pag. 33 ).

4. Mutilla parvicollis, A. Cost. femmina (loc. cit. pag. 35 ).

5. Chalcis obtusedentata, A. Cost.

6. Metapterus linearis, A. Cost. (Additamenta ad Centurias Cimicum Regni Neapolitani, pag. 10)-a. primi articoli delle antenne; $b$ piede anteriore; $c$ elitra; $d$ estremità anale del maschio veduta da sopra; $e$ la stessa veduta da sotto; $f$ estremità anale dorsale della femmina; $g$ estremità anale ventrale della stessa; $h$ anelli toracici.

7. Dictyonota pulchella, A. Cost. (Additam. pag. 9).

8. Caloscelis dimidiata, A.Cost. mas. (Faun. Napol. Caloscelidei, p. 5).

9. Psylla lactea, A. Cost.

10. Geometra Bruzzanaria, A. Cost.

11. Elaeotoma adustiventris, A. Cost.

12. Gastricheilus nubeculipennis, A. Cost.

13. Popsia ridibunda, A. Cost. 


\section{TAYOLA IV.}

Fig. 1. Thamnotrizon magnificum, A. Cost. Maschio-A. estremità anale dorsale; B. estremità anale ventrale.

2. Trivella della femmina della predetta specie.

3. Decticus nigrosignatus, A. Cost. maschio veduto dal dorso e di lato - C estremità codale dorsale.

4. Trivella della femmina della predetta specie.

5. Isoscelipteron fulvum, A. Cost.-A. l'ala anteriore.

6. Mucropalpus meridionalis, A. Cost.

7. Nevrorthus iridipennis, A. Cost.

8. Sphex strigulosa, A. Cost. (Fauna Napol. Sfecid. p. 29).

9. Enodia lividocincta, A. Cost. (loc. cit. pag. 30).

10. Pompilus vomeriventris, A. Cost. Femmina.

11. Pompilus orbitalis, A. Cost.

12. Scolia abdominalis, Spin.

13. Andrena calabra, var.

ALCUNI ERTORI DA CORIRGGERE

$\mathrm{Pag} .17$ verso 10 affinis

» 26 minuta

1814 Dyctionota

„ „ formosella

„ 31 Vereli

„3 Tamarin leggi aureocincta

mixta

Dictyonota

pulchella

Foreli

Tamarix. 


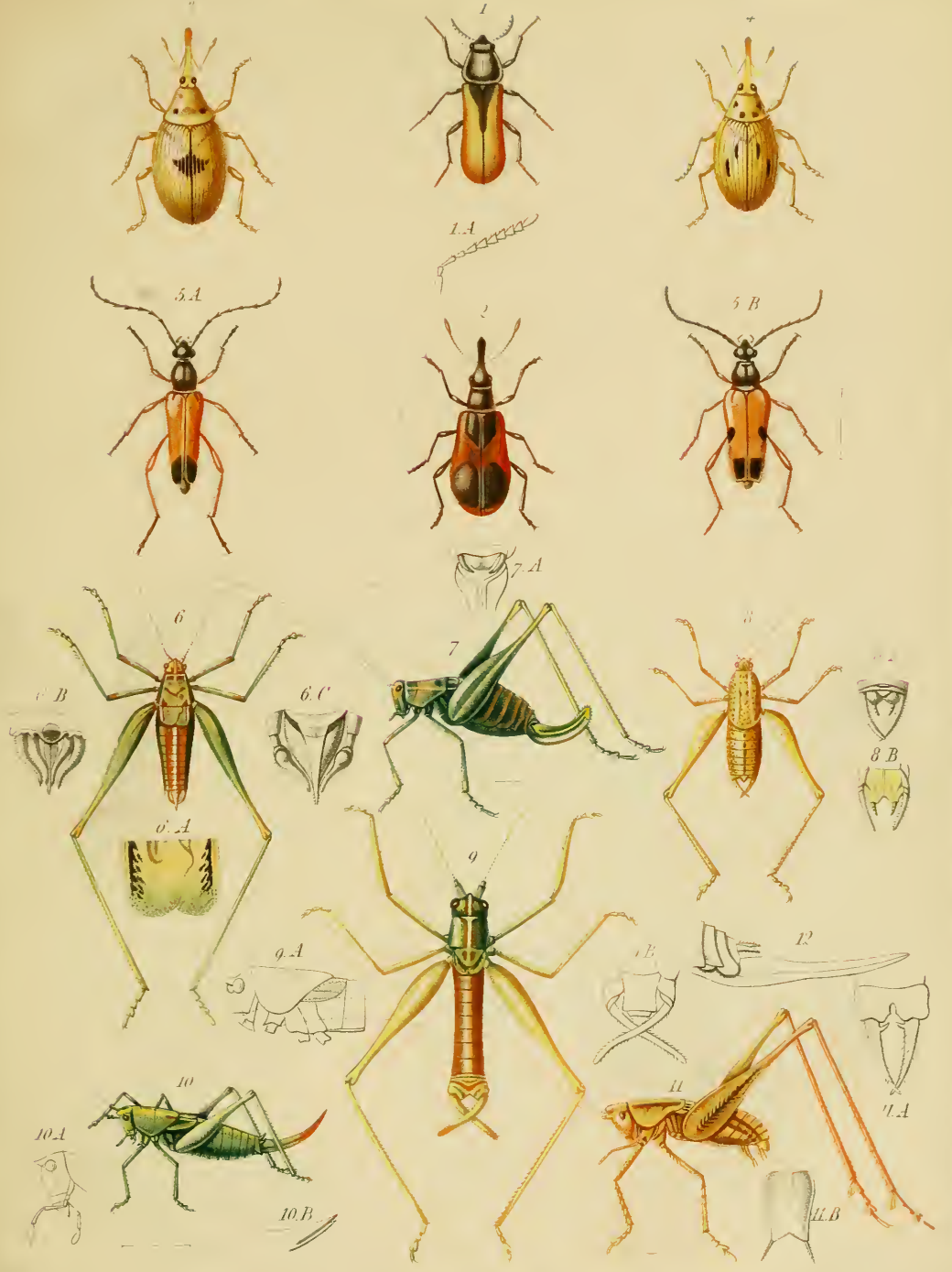




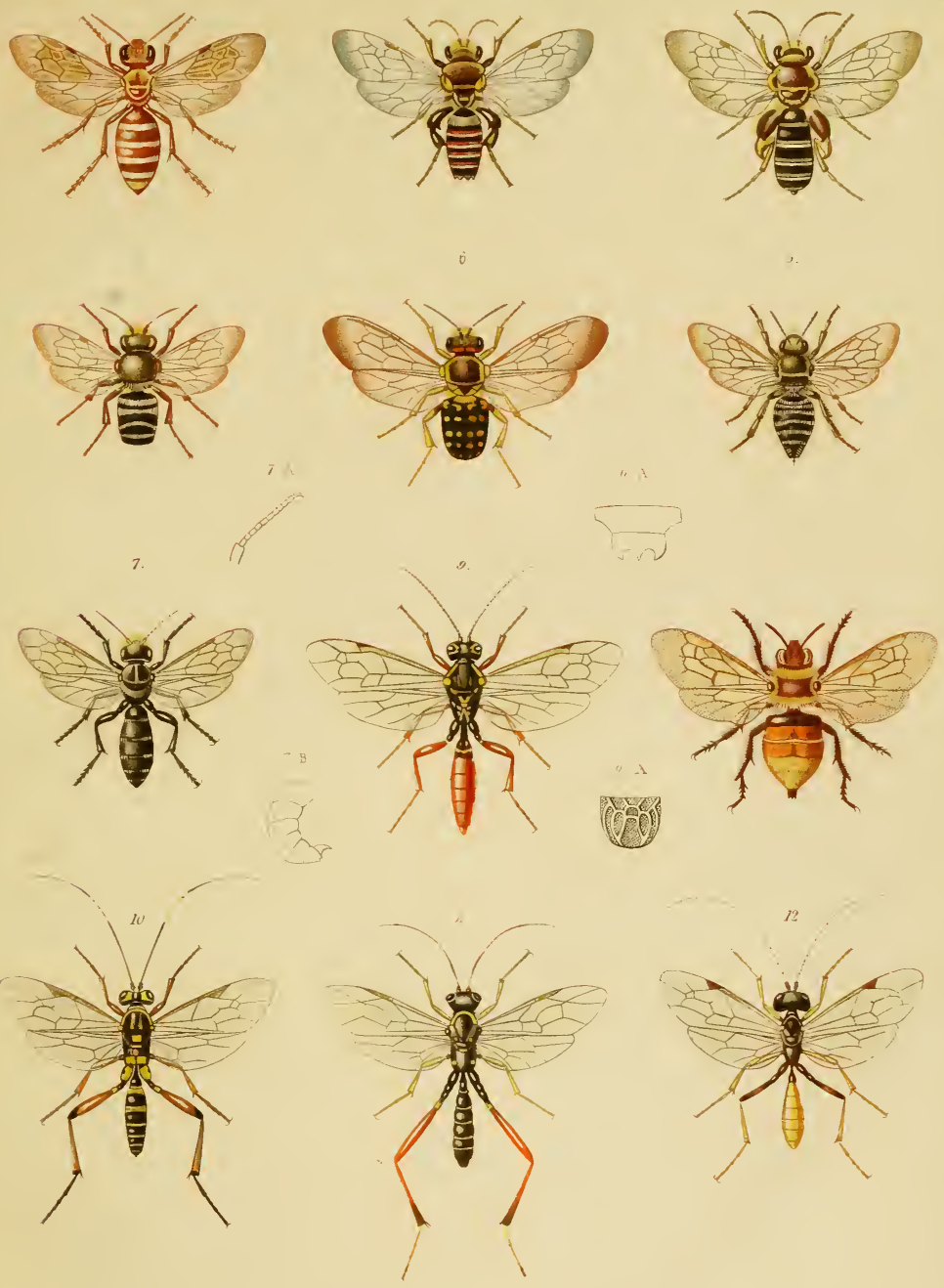


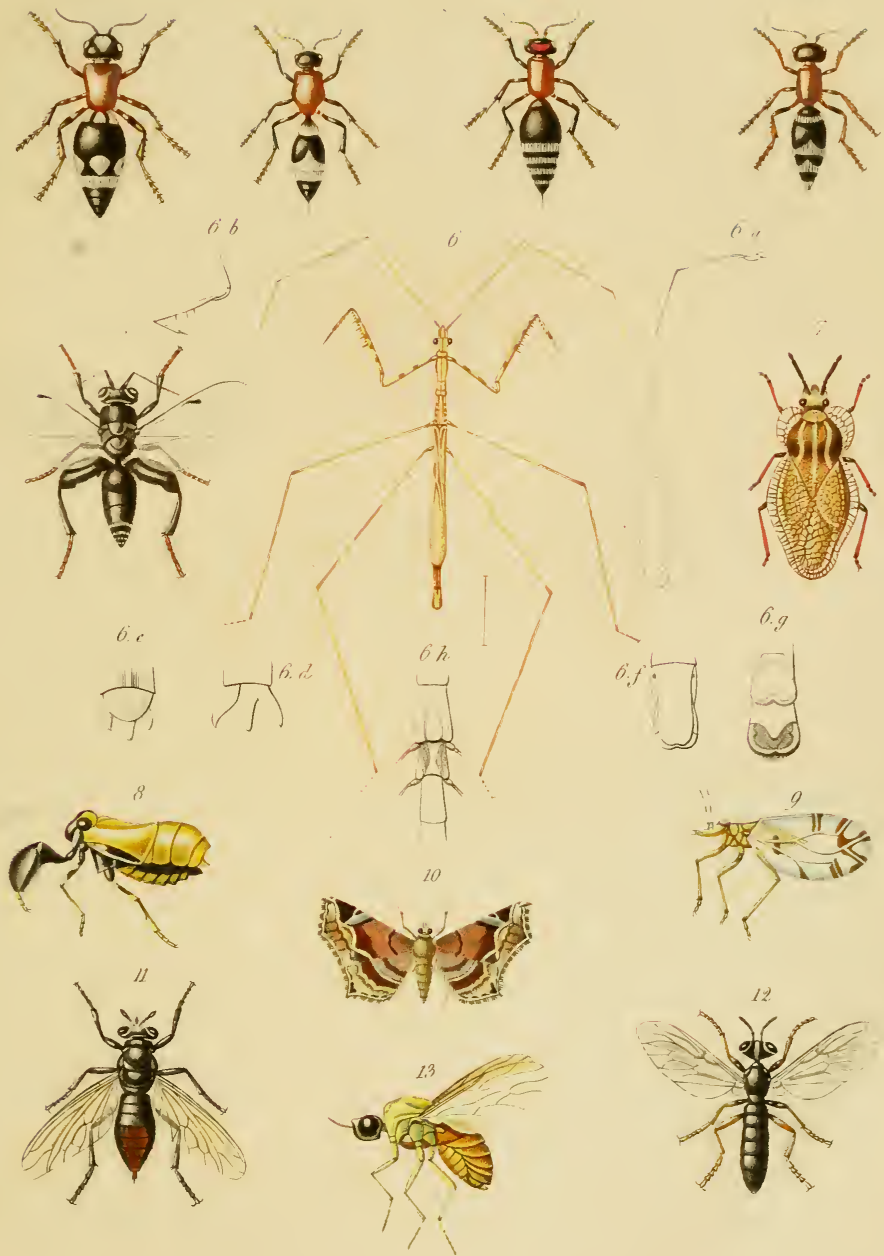


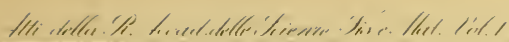

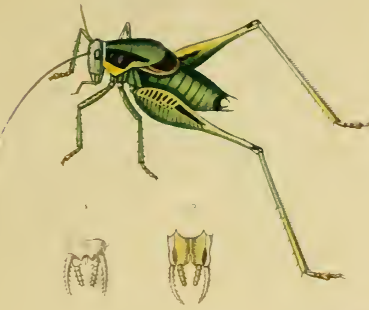

鉴
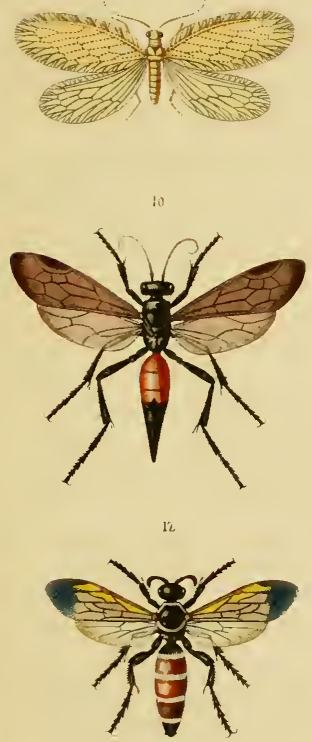

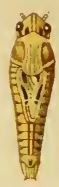

0
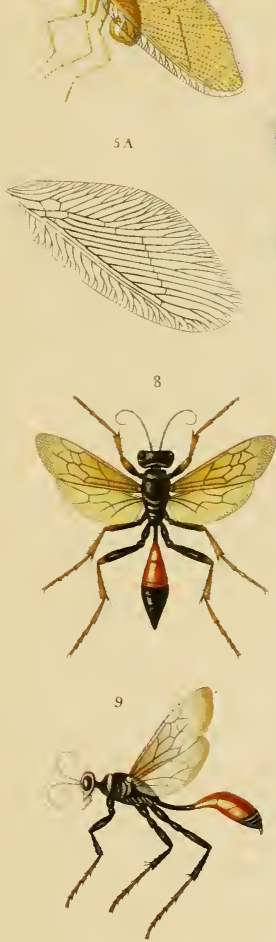
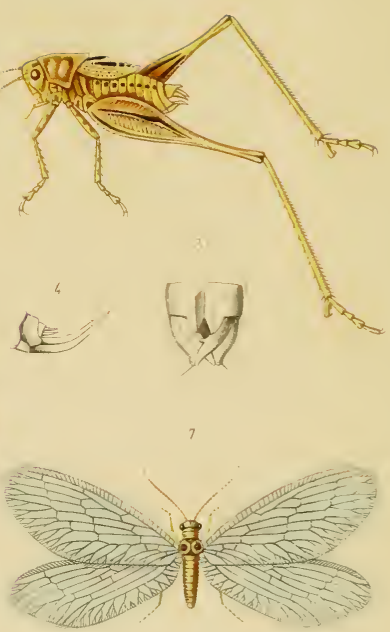

11
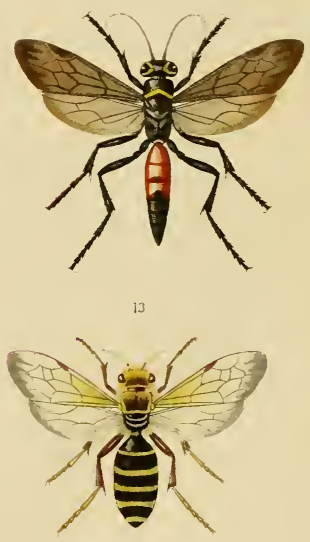


$$
\text { i. }
$$




PROPERTY OF

Z. P. METCALF 


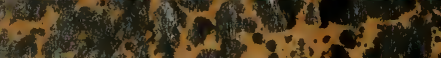

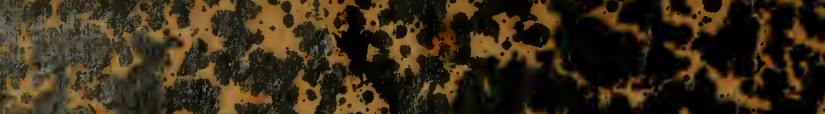

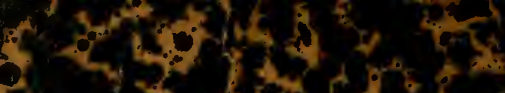

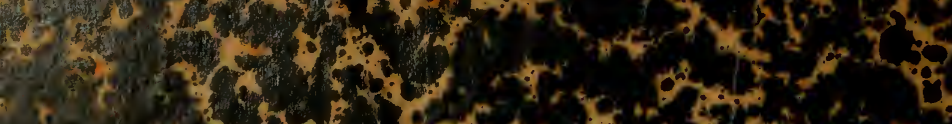

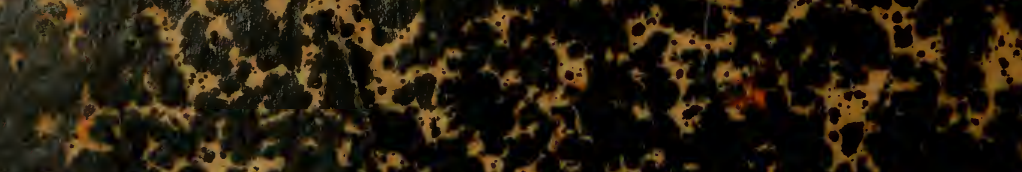

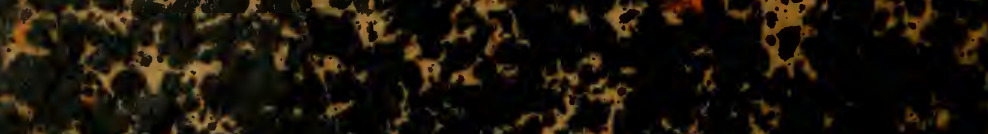

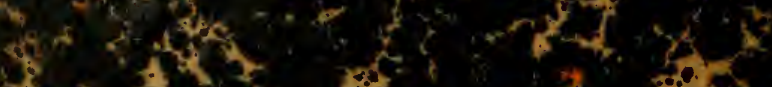

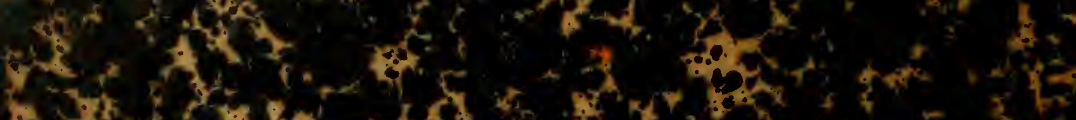

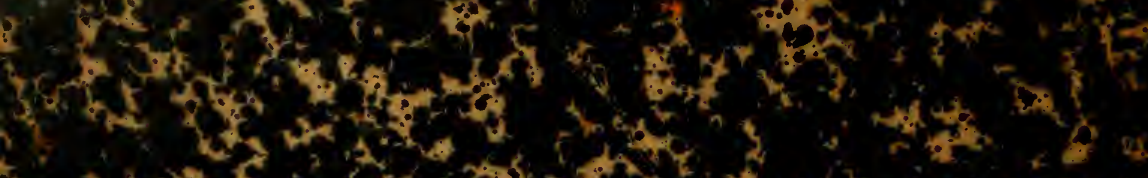

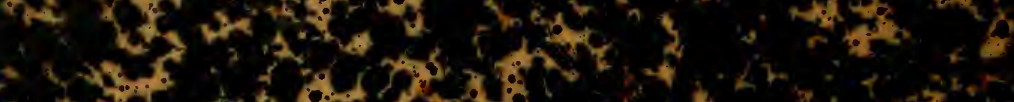

Cor

The

36

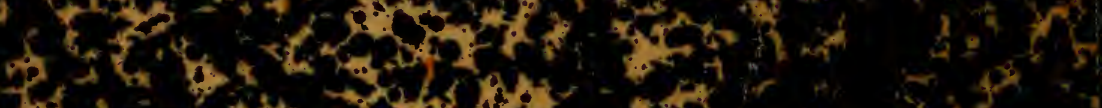

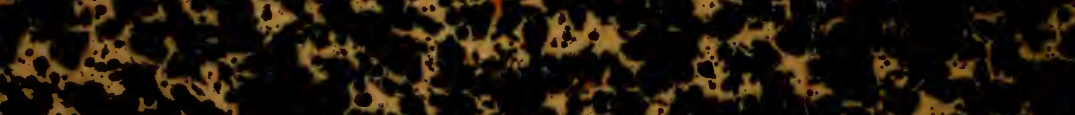

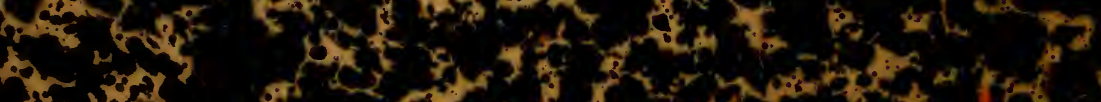

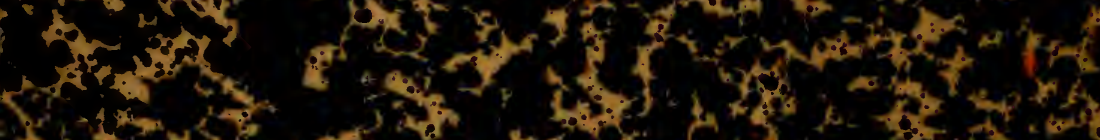

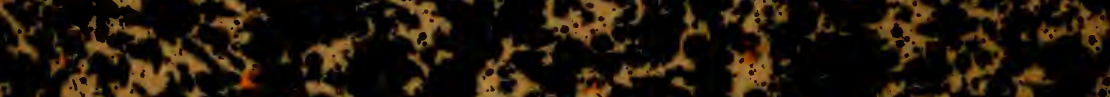

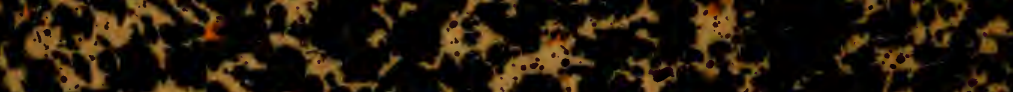

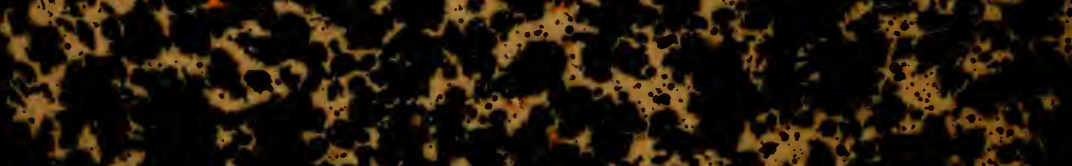

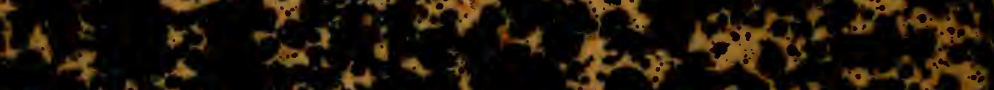

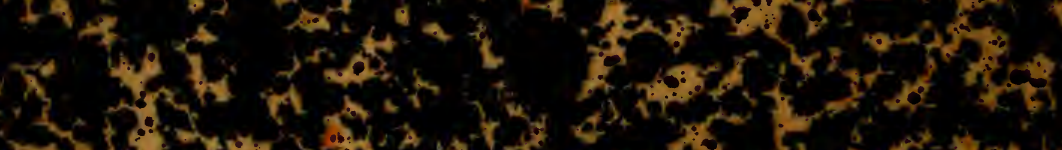

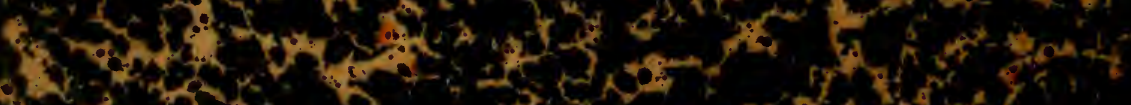
Q
4. a t
(t) (3) T.

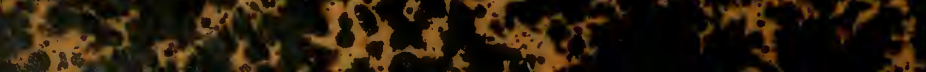
a 4 क

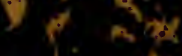

